\title{
Hakarongo Mai!
}

\section{Rapanui women and decolonisation for development}

\section{Karly Gempp Christ}

2012

A thesis submitted to Victoria University of Wellington in partial fulfilment of the requirements for the degree of Master in Development Studies

School of Geography, Environment and Earth Sciences Victoria University of Wellington

Supervisors: Teresia Teaiwa and Warwick Murray 



This thesis is dedicated to women in the world who struggle against oppression in their lives and work towards a more just and equitable future for their families and their communities

And to my mother, Annie Barnes, who is still the strongest woman that I know 


\section{Acknowledgements}

My sincere thanks to the women in Makenu for sharing your time, stories and lives with me. The passion, dedication and commitment you have to your families, your community and your island is motivating and inspiring, and I am forever humbled by this experience. To other members of the Rapa Nui community who also participated in this project, helping me to understand and appreciate life on the island and the struggles of the Rapanui people.

To Teresia Teaiwa for keeping me sharp, thoughtful and reflective throughout this process, and for the many chats that went beyond this work. To Warwick Murray for providing support throughout my three years of this degree, and always having faith in my ability and my potential to succeed. To John Overton, Warwick Murray and the Marsden project, White Poppy Peace Scholarship, Katherine Stewart Postgraduate Scholarship, DF McKenzie Award, Lady Stout Bursary, and Katherine Pattison Memorial Award, for the financial support that made this project possible.

To Riet for so many things, but especially for taking me in, sharing your knowledge, and becoming a special friend. To Moira for your amazing generosity and friendship - I cannot begin to express my gratitude. To Poncho and Lili for looking after me and always making sure I was happy. To Nano and Juan for the asados, music and inclusion into your family life. And to the numerous others in Chile, on the island and at home for supporting my work and providing your friendship especially Rodrigo, Mauricio, Marcela and Sandra. Thank you.

To Marto, for always showing interest in my work and helping me to overcome barriers throughout the writing process. To Marianne for being my sounding board. To Annette for the welcomed distractions, the loyal friendship, and for helping me to format this monstrous piece of work. To Gemma for feeding me delicious food and always providing an ear. To Emily and George for your essential editing skills. To Amy for being there when I needed you most, and the massages that kept me balanced. To Hannah for the much needed "Newtown holidays", the unforgettable laughter and for editing this thesis. To Anna and Helen for being great thesis buddies. To all the DEVE girls - you guys rock! To my family for their love and unwavering support. And finally to Jan, for being my "rock", encouraging my dreams and always inspiring me to be a better person. 


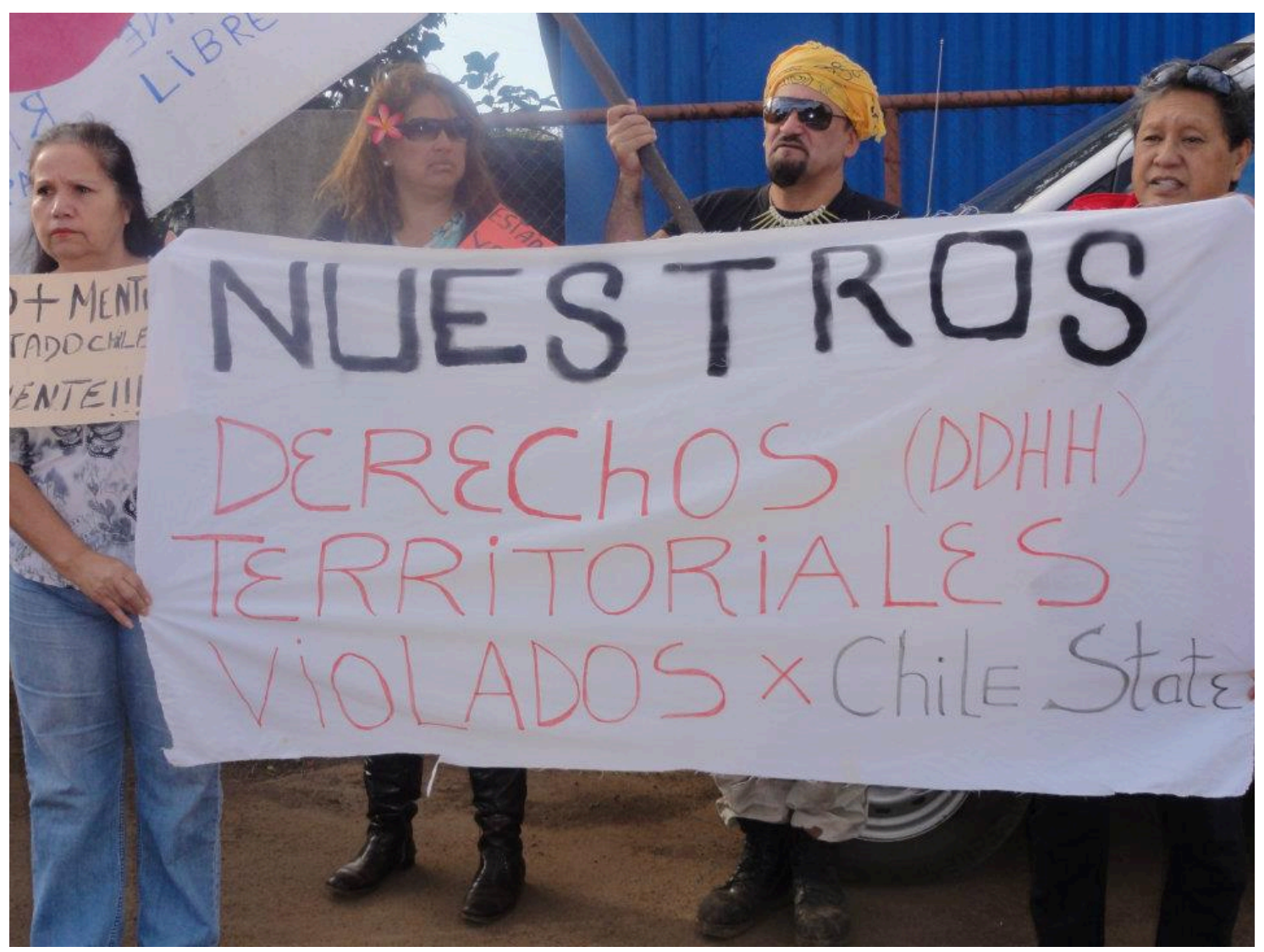

Figure 1: Protest, $23^{\text {rd }}$ July 2011

(Karly Christ, 2011)

\section{Abstract}

On the Pacific island of Rapa Nui, there are growing calls from the indigenous population for political and cultural decolonisation. This research explores and documents how some women in Rapa Nui are engaging in these struggles. It investigates their aspirations for decolonisation and the strategies they are employing to have their voices heard. It also identifies and describes some of the challenges these women have faced as well as the successes they have had in the context of these struggles to date. Sharing the stories of women who are active participants in these efforts, this research seeks to provide space for their perspectives and their experiences, acknowledging the presence and significance of women within decolonisation efforts on Rapa Nui. 
In framing and carrying out this research I draw on feminist and indigenous epistemologies, as well as Participatory Action Research (Kindon, Pain, \& Kesby, 2007) and Appreciative Inquiry (Cooperrider, Whitney, \& Stavros, 2003). My methods include a series of unstructured and semi-structured interviews, Talanoa (Otsuka, 2006; Vaioleti, 2006) as well as participant observation.

By considering the critical issues women identify within their struggles, this study illustrates how their aspirations for decolonisation are intrinsically focused on development goals, strongly linked to and framed by their colonial resistance. Additionally, centring women in this analysis, the important role they play within these processes is highlighted. This affords a fuller understanding of the range of possibilities that exist for Rapa Nui's decolonisation and future development, pushing Development Studies to pay better attention to the voices coming from the Fourth World, as people within these contexts strive for positive development within their communities. 


\section{Table of contents}

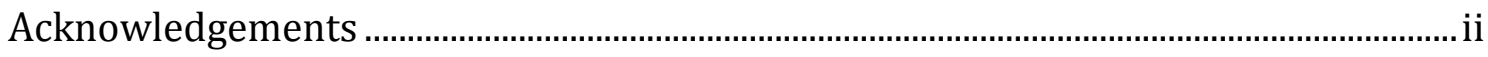

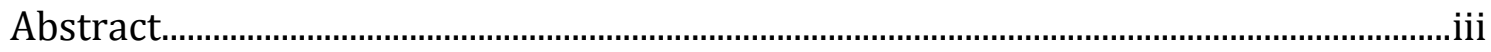

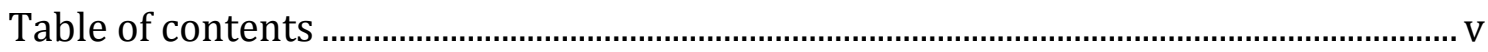

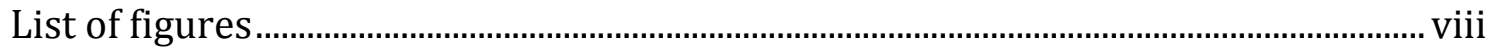

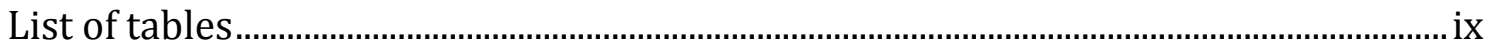

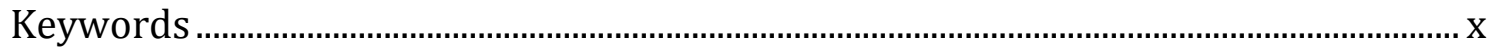

Glossary of Rapanui words...............................................................................................

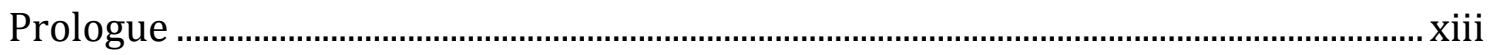

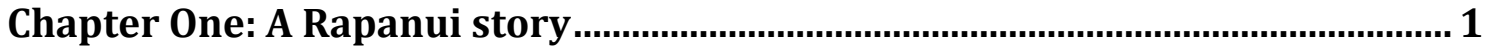

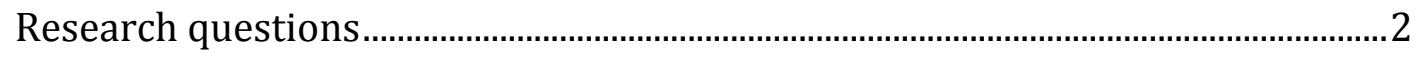

The beginnings of a research journey ........................................................................

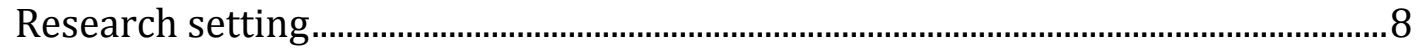

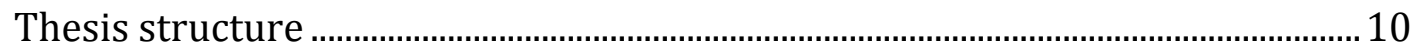

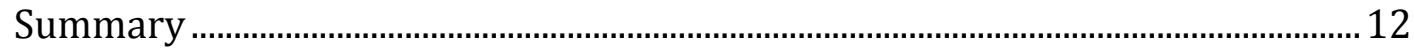

PART I: FRAMING THE RESEARCH 13

Chapter Two: Development, decolonisation and women...................................14

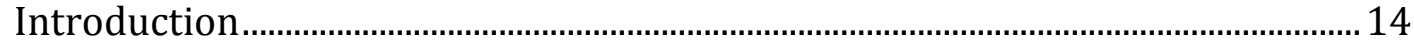

Section One: Towards a decolonising development framework ........................... 14

Section Two: Women and decolonisation .................................................................. 22

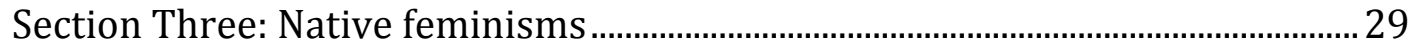

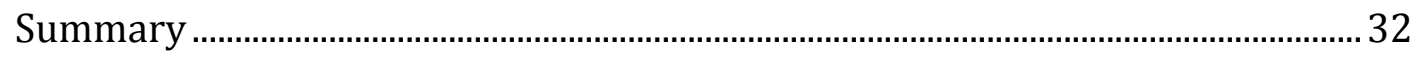

Chapter Three: Approach and methodology .........................................................34

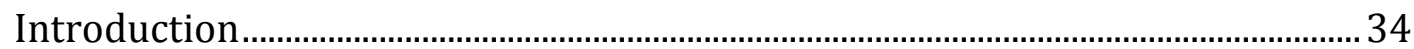

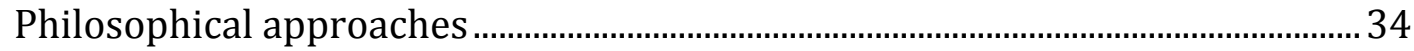

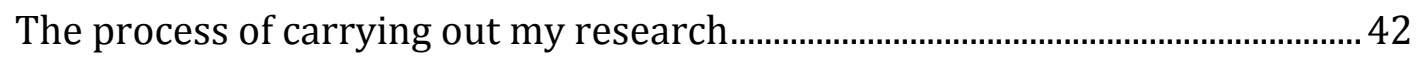

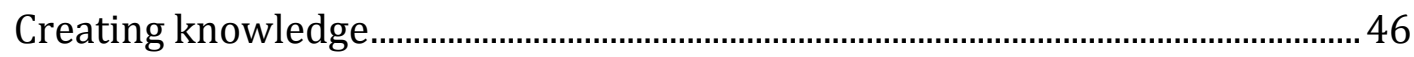


Chapter Four: Rapa Nui - A history of resistance ........................................... 54

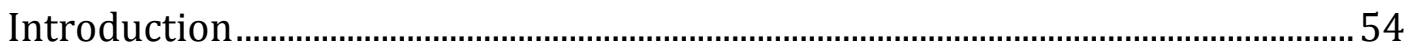

Section One: Pre-contact and early contact period ................................................5 54

Section Two: Chile's more recent engagement...........................................................63

Section Three: Rapanui women's acts of resistance ……........................................... 73

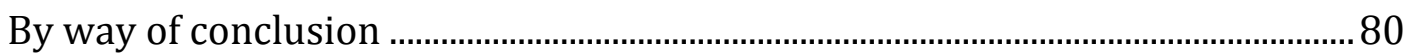

PART II: MAKENU'S STORIES OF STRUGGLE 82

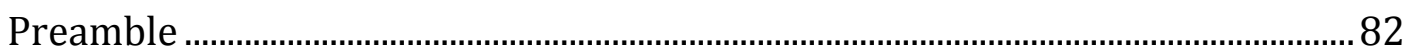

Chapter Five: Makenu Re'o Rapa Nui - "the Voice of the People"......................... 84

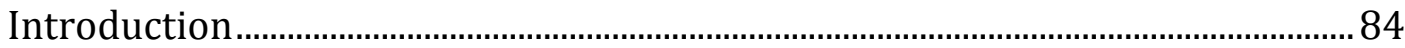

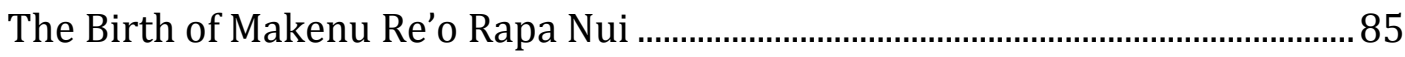

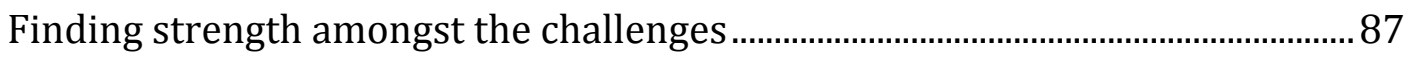

Working together and working apart......................................................................... 90

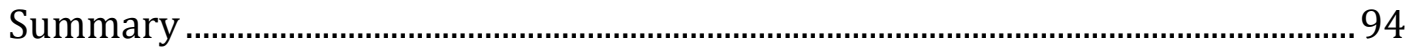

Chapter Six: Decolonising Kaina - experiences of local development ............ 95

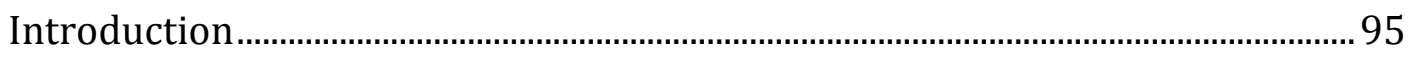

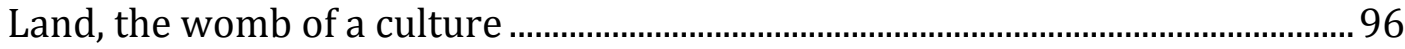

Holistic economic development?........................................................................ 98

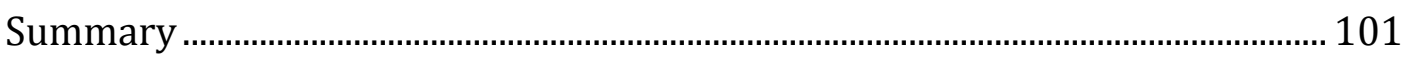

Chapter Seven: Unfettered immigration ........................................................103

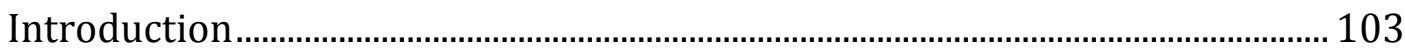

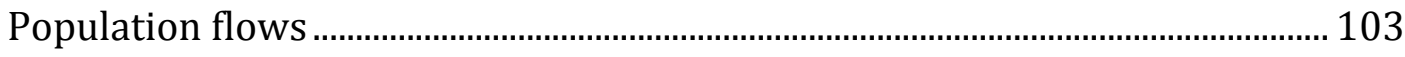

Immigration and Rapanui Kaina .......................................................................... 109

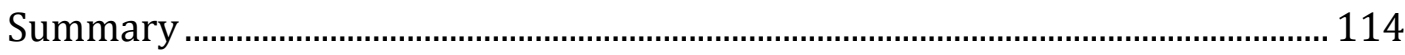


Chapter Eight: Decolonisation for development - Makenu's approach and critiques

Introduction

Rapa Nui's modernisation 116

Makenu's two prong approach - a political and cultural battle. 128

Native feminisms and Makenu, native feminisms and me 132

Chapter Nine: Final reflections. 135

Summary of my findings 135

Further research 141

Final reflections on my time with Makenu. 142

Contributions of this thesis 143

References 146

Appendix One: Spanish quotes 169

Appendix Two: Participant information sheet (Spanish) .177

Appendix Three: Participant information sheet (English)..........................................179

Appendix Four: Agreement of confidentiality ……...........................................................181

Appendix Five: Makenu’s Migration Law Proposal ...............................................................182

Appendix Six: Women in the public sphere ....................................................................190

Appendix Seven: Informe Technico - Aplicacion instrumento de consulta al Pueblo Rapanui. 


\section{List of figures}

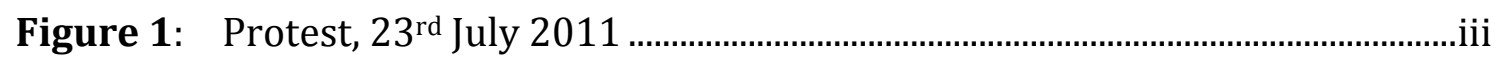

Figure 2: "So the international community knows: Rapa Nui never ceded sovereignty to Chile" sign near the Parlamento Rapanui ............................. 4

Figure 3: Protest sign calling for rights to the Rapanui territory ................................ 6

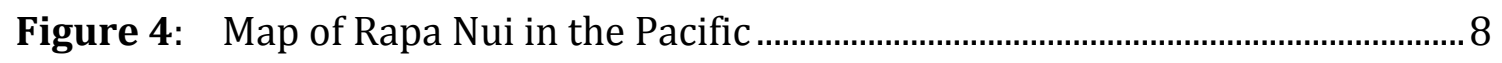

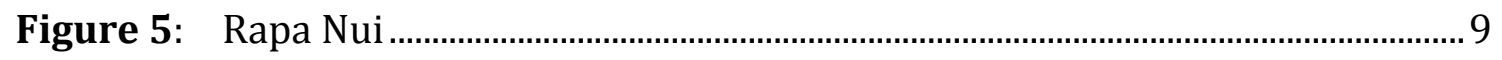

Figure 6: Parlamento Rapanui calls for self-determination, decolonisation

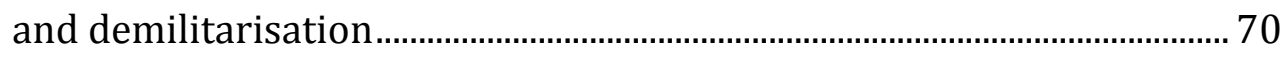

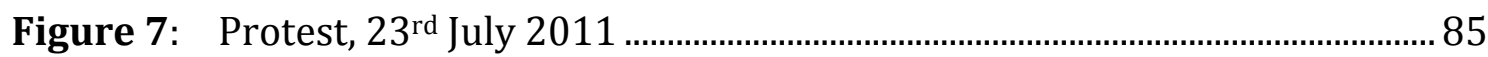

Figure 8: A Makenu presentation to the Rapanui community, international lawyers and international observers about immigration. Seminario, Hangaroa, 1 August 2011 ........................................................................... 90

Figure 9: Ministry of Housing and Urban Development - population increase .104

Figure 10: Preparing for the $23^{\text {rd }}$ July protest 109

Figure 11: Four women from Makenu in San Andrés, Colombia 112

Figure 12: Makenu's invitation to the community to protest their "objection to the abuse and militarisation of the Rapa Nui territory" on the part of Chile.

Figure 13: Women in Makenu working . 137

Figure 14: "Cable TV kills my culture". 140 


\section{List of tables}

Table 1: Ministry of Housing and Urban Development - population estimates....103 


\section{Keywords}

Rapa Nui, women, decolonisation, development, feminisms 


\section{Glossary of Rapanui words}

Ahu:

Aku aku:

Ariki:

Ariki mau:

Henua:

Henua poreko ranga: the land where the ancestor was born

Hotu Matu'a:

Iva-atua:

Kaina:

Makenu Re'o Rapa Nui: Voice of the People

Mana:

Mata:

Matato'a:

Moai:

Pipi horeko:

Royoroyo:

Tayata manu:

Tapu:

Te Pito o Te Henua:

Ure:

Vanaya Rapanui: ceremonial platforms

spirits

chief

king

land/placenta

the Great Parent, the original coloniser of the island, the ariki mau

priests

land/territory, the umbilical connection to mother earth someone who holds power, moral authority and prestige clan

Rapanui warriors

carved stone statutes built to venerate Rapanui ancestors stone cairns used to indicate boundaries

Rapanui script which consists of glyphs

the birdman cult

can mean sacred or forbidden

the navel of the earth

lineages (pertaining to mata)

the Rapanui language 
"As colonized people, we are colonized to the extent that we are unaware of our oppression. When awareness begins, then so too does de-colonization".

(Trask, 2000, p. 1)

“...beginning to create and record our Pacific women's world through research, encouraging women's artistic and creative endeavours in all forms and using this record to show our women's world and women's contributions in our communities and the region. Researching, writing and publicising the lives and achievements of our Pacific women heroines, past and present..."

(Griffen, 2006, p. 131) 


\section{Prologue}

Acknowledging genealogy and the importance it has in Pacific Island cultures, I would like to begin this thesis by greeting you, the reader, with my family origins. To know one's genealogy or whakapapa is to know one's identity. As my mihi ${ }^{1}$ below illustrates, I am still exploring who I am and where I come from as many gaps remain in my family narrative and memory, but it is this journey of selfdiscovery that helps me grow as I continue to plant roots in the communities to which I choose to contribute.

Both of my parents trace their ancestry to Europe. My mother, Ann Marie Ouellette, is of French and French-Canadian descent. My father, Kurt Christ, is of Swiss German heritage. My grandfather, Romeo Ouellette, on my maternal side, is First Nations, hailing from the Trois Rivières region of Quebec, Canada. We aren't sure which nation we belong to as time and colonisation have erased that part of our ancestral past. All we are left with from that period in our family history is a rough idea of the region and lands where our people may have once dwelled.

My maternal grandmother's family also came from Quebec, Canada. My grandparents, Loretta Richard and Romeo Ouellette, met each other in the United States in Fall River, Massachusetts, spending their lives and raising their eight children there, as well as in various parts of central Florida. My mother calls Massachusetts her home but holds a piece of Florida in her heart.

My father's side, including both my maternal and paternal family, immigrated to the United States around the turn of the $20^{\text {th }}$ century, coming originally from Switzerland but setting down roots in various parts of Germany, such as Wiesbaden and Baden-Baden. My grandmother, Katherine Luster, grew up in New York and my grandfather, George Christ, in Massachusetts. They raised their two children in Swansea and Massachusetts is where my father calls home.

1 Mihi or mihimihi is a Te Reo Māori word for introductory speech. I use Māori language here because it is in Aotearoa, New Zealand that I learnt about the importance of genealogy in Pacific peoples' lives. 
Both of my parents were born in the United States and I was raised American, but never allowed to forget where my ancestors came from as this connection with our heritage was always fostered, defining how we construct our family identity.

As for me, Karly Gempp Christ, I grew up in rural Massachusetts, a farming and fishing community with beautiful beaches and a lazy river that cuts through the rolling hills of the countryside. My village Acoaxet, the Wampanoag or Narragansett name meaning "at the fishing promontory" or "place of small pines" is situated on a peninsula, surrounded by the Westport River and Atlantic Ocean, with ponds and creeks scattered across the land. Our lands are rich for farming and the sea is abundant with fish. When I go back to the land where I was born and where my family still resides, Elephant Rock, Richmond Pond, and the Point of Rocks, the smell of lobster, quahogs, scallops, and cod remind me of who I am, and where I come from; they tell me I am home.

For the last five years, I have lived in Aotearoa, New Zealand and have come to greatly appreciate this place I now call home. I am grateful for the opportunity to live in these Māori lands, to be treated as part of a wider community, and to be accepted in a place where I was not born but have truly come to love. 


\section{Chapter One: A Rapanui story}

This research explores and documents how women in the Makenu Re'o Rapa Nui ${ }^{2}$ group are engaging in decolonisation struggles on Rapa Nui (Easter Island). ${ }^{3}$ It investigates what their aspirations for decolonisation are and the strategies they are employing to have their voices heard. It identifies and describes some of the challenges these women have faced as well as the successes they have had within these struggles.

The Rapanui territory and its people are under the sovereign control of Chile. Development Studies rarely takes into account the Fourth World, as mainstream development theory and practice tends to centre its analysis on peoples within the Third World context (Laurie \& Calla, 2004; Radcliffe, 2007; Radcliffe \& Laurie, 2006). ${ }^{4}$ The term Fourth World refers to peoples, or nations, that are forcefully incorporated into states. Manuel and Posluns in The Fourth World: an Indian reality, (1974, p. 40) describe people of the Fourth World as:

Indigenous peoples [who have] descended from a country's aboriginal population and who today are completely or partly deprived of the right to their own territories and its riches.

Similarly, Griggs (1992, p. 1) notes:

These are the 5,000 to 6,000 nations representing a third of the world's population whose descendants maintain a distinct political culture within the states which claim their territories. In all cases the Fourth World nation is engaged in a struggle to maintain or gain some degree of sovereignty over their national homeland.

2 From here on Makenu Re'o Rapa Nui is referred to as Makenu.

3 Isla de Pascua is the Spanish name for Easter Island and Rapanui is the Polynesian name. The spelling of Rapanui or Rapa Nui has been a source of discussion amongst scholars (see Fischer, 1993). As Rapanui is the Polynesian way of spelling, I have chosen to use that throughout this thesis. However for clarity, I have opted to call the island Rapa Nui and the people and language Rapanui.

4 When Fourth World appears within key works in development, such as (Desai \& Potter, 2002; Potter, Binns, Elliott, \& Smith, 2008) the mention is brief. It also often pertains to the poorest of countries not indigenous peoples who make up the 'Fourth World' within the states that claim sovereignty in their territories. 
Western concepts of development emerged in the wake of World War Two, and the era of decolonisation, whereby bringing 'development' to those less privileged in the newly independent 'underdeveloped' states was the central focus of the western world. Therefore, the preoccupation with development of the Third World is not surprising. With the era of decolonisation having come and gone, colonialism ought to be a concern of the past. However, it is alive and well. Indigenous peoples continue to struggle for their right to political self-determination in which social, cultural, and economic development can be pursued. While decolonisation is in many ways the root of Development Studies, in the context of the Fourth World and the focus of this thesis - Rapa Nui - what we have is a co-temporal arrangement where development and decolonisation are taking place in the same time and space. In various localities around the world, indigenous peoples strive towards development within a decolonising context, or stated differently, pursue a 'decolonisation for development' agenda. With this in mind, I arrived at the following questions.

\section{Research questions}

1) What aspirations for 'decolonisation for development' have women articulated in Rapa Nui?

2) What strategies are women employing to have their voices heard in the decolonisation struggle?

3) What have been some of the challenges and successes women have experienced within decolonising efforts?

In connection to these questions, this study's key objectives are:

1) To identify and describe how a key women's group such as Makenu Re'o Rapa Nui is engaged within local decolonisation struggles.

2) To document and highlight the concerns and aspirations of women actively engaged in the 'decolonisation for development' of Rapa Nui.

3) To provide a case study that adds to the literature on the role of women in decolonisation, thereby accentuating how paying attention to women helps us to better understand decolonisation processes.

4) To illustrate how the articulated aspirations and concerns of decolonisation struggles are intricately linked to development. 
In considering the processes occurring in Rapa Nui, I coined the term: 'Decolonisation for development' as I felt it spoke to Makenu's engagement within decolonisation struggles. Decolonisation involves the 'undoing' of colonialism. It is the unravelling of introduced cultural, political and economic systems that are not of benefit to indigenous peoples. While decolonisation involves deconstructing and pulling apart colonial oppressions, it is also a process of creating and inventing, wherein lies an opportunity to construct a new vision for the future and a new pathway for indigenous development.

This research demonstrates how these women's aspirations are intrinsically focused on development goals, strongly linked to and framed by their colonial resistance. Decolonisation cannot be seen as only a process that seeks to acquire the instruments of government but is an ongoing and multilayered process involving the psychological divesting of colonial constraints (Tuhiwai Smith, 1999). The social dimensions of decolonisation processes are essential for Rapanui peoples' survival, as they attempt to prevent destruction by external forces of their values, cultural identity and ways of being. Issues such as immigration, land, natural resources, education and language are fundamental to these struggles and central to positive Rapanui development. By paying attention to women's perspectives and experiences and centring them within the analysis, it becomes clear that they have an acute awareness for the breadth and scope of what these struggles must entail, highlighting their demands for political autonomy alongside the reconstruction of a positive Rapanui identity. 


\section{The beginnings of a research journey}

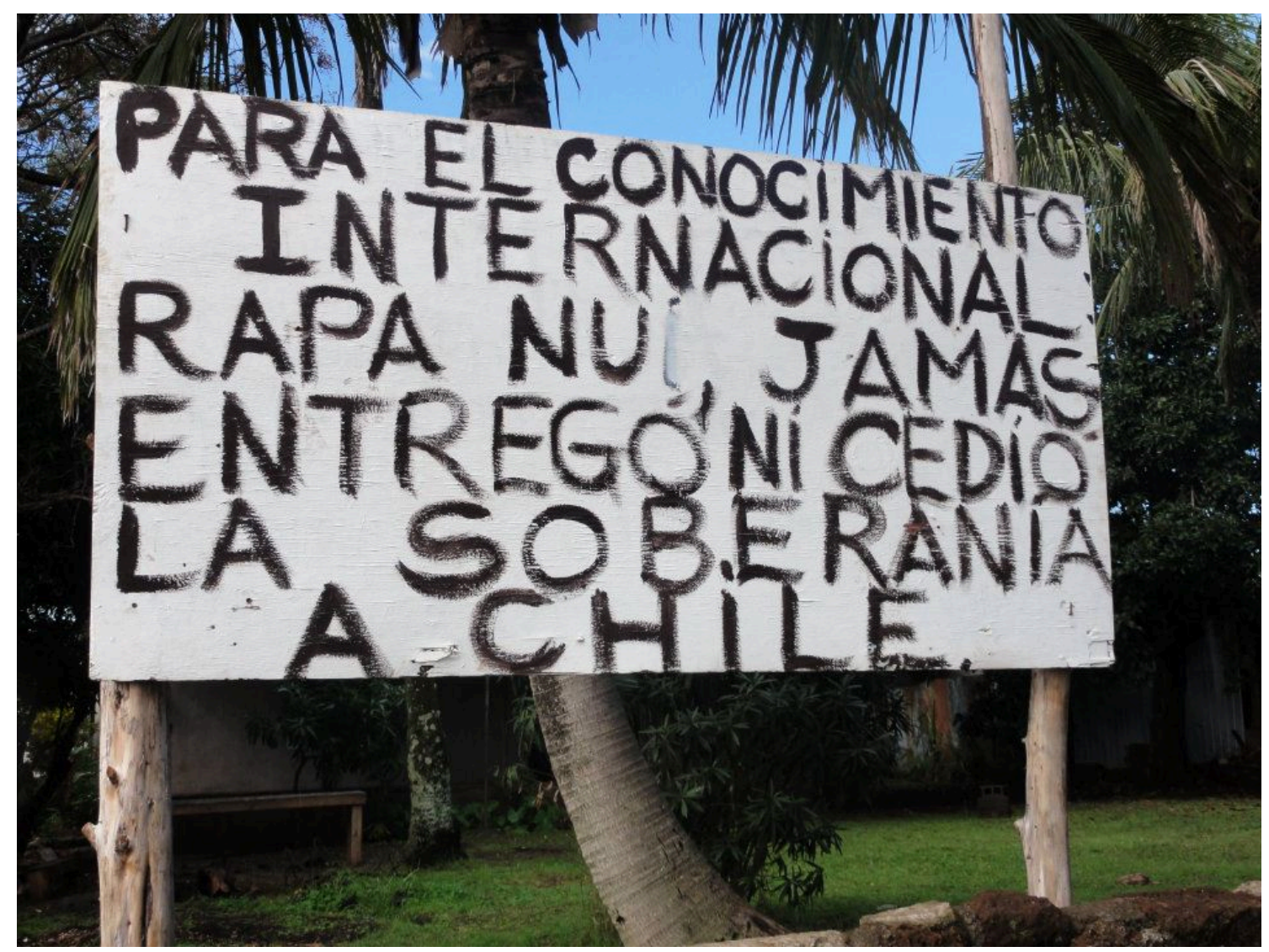

Figure 2: "So the international community knows: Rapa Nui never ceded sovereignty to Chile" sign near the Parlamento Rapanui

(Karly Christ, 2011)

In order to make clear how this thesis materialised and the motivations that underpin it, I will tell a little story about how I found my topic concerning Rapanui women and decolonisation, and how it found me. Understanding this background helps make clearer my assumptions and positionality within this research.

The original catalyst for conducting this study emerged from my interest regarding land and indigenous issues, particularly in the Pacific. Having attended a seminar given by a Samoan academic (Dr. Iati Iati) in 2010 about the effects of land reform in Samoa, ${ }^{5}$ I began to more fully understand and appreciate the importance of land in Pacific peoples' lives, alongside the current debates occurring within development policies in the Pacific. While Iati did not offer a gendered analysis of these land reforms, I immediately started to think about how these reforms were

\footnotetext{
5 To see the research paper this talk was premised upon see (lati lati, 2010).
} 
affecting women in Samoa and other places, as women have been frequently marginalised, and often do not enjoy many of the benefits that development policies and land reform projects have promised to deliver (see for example, Agarwal, 1994; Deere, 1985; Deere \& Leon, 1998; Razavi, 2003, 2007).

It was also at this time that I was invited to participate in a Marsden funded research project investigating the impacts of the changing aid modalities on development policy sovereignty in the Pacific, led by Professor John Overton and Professor Warwick Murray at Victoria University of Wellington. This broader sovereignty research was what brought about the initial thoughts on Rapa Nui, as it was on the table as a potential case study for the project. While most of the case studies in the project are independent states, the research looks across the region and at the various dependency levels that exist including dependent islands ( such as New Caledonia and Rapa Nui) and semi-dependent islands (such as the Cook Islands and American Samoa), for example. The research is progressive in its approach, and it was exciting to be offered a place within the team. While at this time it was not clear which islands would be a part of the research's central focus, and still maintaining my interest in land issues and the desire to conduct research in this area for my Master's research, I accepted the offer to be a research associate for this research project. 6

It was only a few months after this talk by Iati and the Marsden research proposal that the island of Rapa Nui appeared in the spotlight, as land conflicts erupted on the island and both Chilean and international media latched onto the events. Images $^{7}$ and stories of Rapanui women and men fighting for their ancestral land were captured, highlighting their protests, land occupations, and the illegal Chilean violence they endured in response to their peaceful actions (for some media coverage see: "Chilean government mum on Rapa Nui conflict," 2010; Lee, 2010;

6 Rapa Nui, it was later decided, is not a central case study for the work being done within this group. My time on Rapa Nui and my research, while beneficial to the Marsden project, was not focused on set goals of the project, nor was it structured to fit the research project. However, with the research I have done, I am able to contribute to the project, and will do so as a broadening of basis for the comparative analysis being undertaken.

7 There are a number of YouTube videos that show the violence that occurred during this time period. Two examples can be found: 
Shikina, 2010). While the people of Rapanui have been struggling against the Chilean state for a long time, 2010 demonstrated a tipping point in their resistance. My thoughts again went to a gendered analysis of women and land. Some of the questions I considered were: How are women participating in land struggles and what aspirations do they embrace for their land? What does land tenure on Rapa Nui look like and what are the gender roles concerning land? What do women's rights to land look like? As I later realised, my framing and thinking regarding land issues on Rapa Nui proved to be problematic as it articulated a host of assumptions that I tried to push through a white feminist lens. However, this initial idea, thought process and line of questioning was what brought me to conduct this study in Rapa Nui.

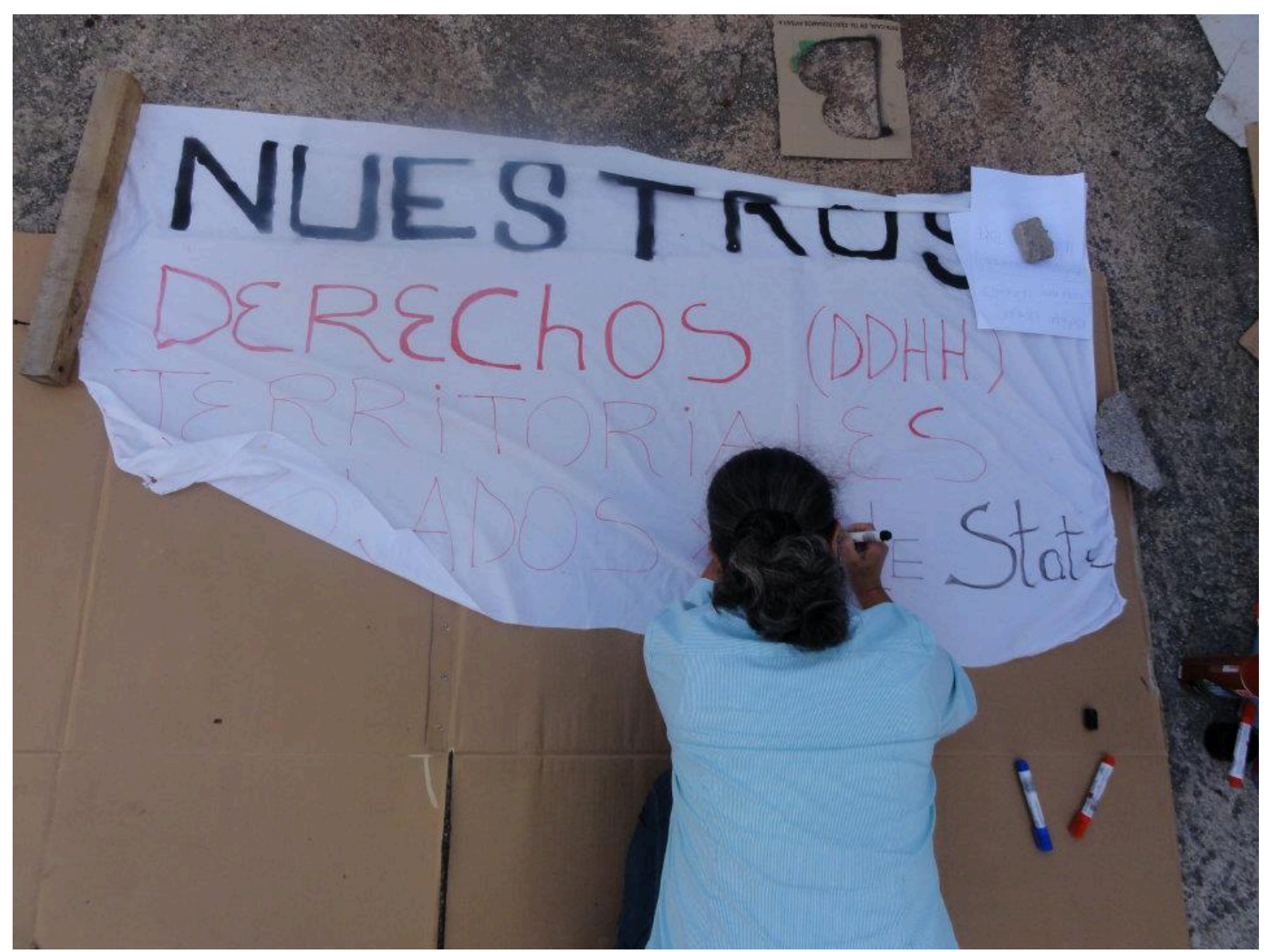

Figure 3: Protest sign calling for rights to the Rapanui territory

(Karly Christ, 2011)

While my research began as an investigation into women's participation in 'land struggles', the story that is this thesis does not address the questions I articulated in the previous paragraph. 'Land' for the Rapanui is henua or kaina. Kaina is not 
'land', 'tierra' or 'terreno"8 but rather refers to territory, and even territory is insufficient in describing the deeper significance that kaina holds in Rapanui lives. ${ }^{9}$ The concept of kaina is embedded in Rapanui cultural understandings, indigenous language and the ontological and epistemological beliefs that foster them. Kaija roots Rapanui peoples' place in the world and it is from this foundation that identities are formed, and knowledge is created, maintained, and understood. While kaina proved to be an essential part of women's decolonisation agenda and integral to their future development, the process of conducting this research made me realise that 'land' was only one of many issues that these women identified as important for them, their community and their future.

With all of this in mind, I realised that not only would I be doing the participants in this study an injustice if I only talked about land in this thesis, but I also realised that looking at land and the emerging land conflicts in this framework, as an independent 'land issue' was problematic. It became clear that land struggles are part of a much bigger conflict that Rapanui have with the Chilean state, and are critically entrenched within Rapanui struggles for decolonisation and selfdetermination. These struggles of course include land, but are not limited only to land. Approaching this study as a politically motivated researcher, aspiring to listen to voices less heard and providing a space for alternative stories to be articulated, it was important to represent the participants in this study as best I could. This meant that I needed to not only talk about the land struggles on the island, I needed to talk about women's struggles for decolonisation.

Most literature has ignored women's participation within anti-colonial struggles, leaving them out of the histories of decolonisation (Levine, 2010a), focusing on male perspectives and experiences when constructing knowledge of colonial and postcolonial eras (Spivak, 1988), and upholding decolonisation as a purely masculine achievement (Teaiwa, 1992). As Chapter Two explores further, this is indeed counterproductive to the decolonisation agenda. As such, I have kept women and their stories as central within this study. I have listened to their

8 Tierra means earth or land in Spanish. Terreno means a plot of land. Both are used to describe land on Rapa Nui and are used as translations of kaina.

9 Hito (2004, p. 1) describes kaina as the "umbilical connection to mother earth". He also notes how kaina in other Polynesian languages translates to mean the "motherland". 
experiences in order to gain a greater understanding of the complexities and nuances of the Rapanui peoples' struggle for decolonisation and the challenges to development that they face. It is also within this line of thinking that the title of this dissertation becomes most poignant. Hakarongo Mai! means "listen!" in the Rapanui language (vanaya Rapanui). This "listen" is directed at Development Studies, demanding that attention be paid to these women and to the context from which they speak. It is also directed at decolonisation scholars who must incorporate women's voices within their analysis. And finally, this "listen" is for me, the researcher. Reminding me to listen deeply, to think carefully and to represent these women's stories the best I can.

\section{Research setting}

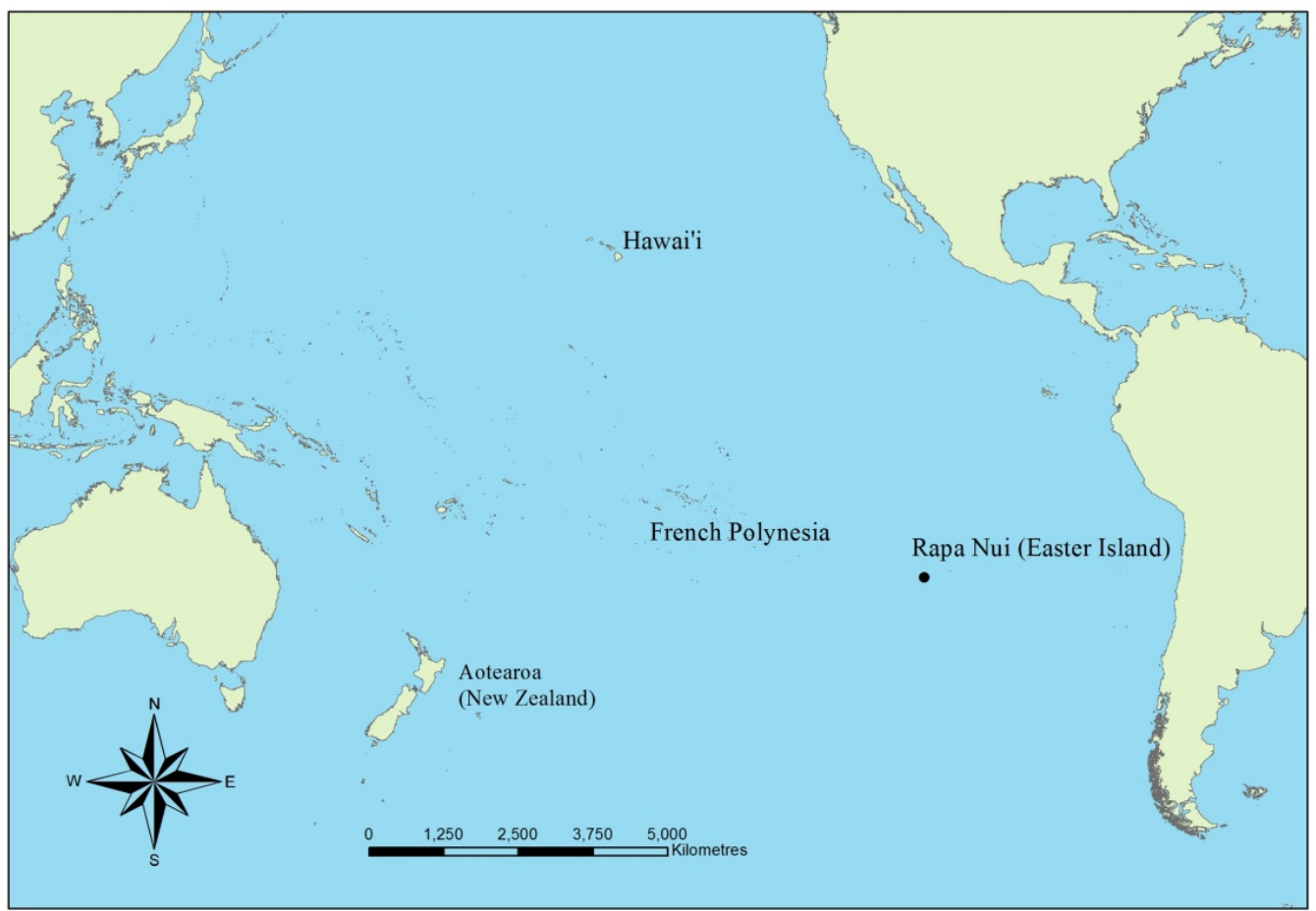

Figure 4: Map of Rapa Nui in the Pacific

(National Geophysical Data Center., 2012) 
Map of Rapa Nui: the three volcanoes, Hangaroa and international airport

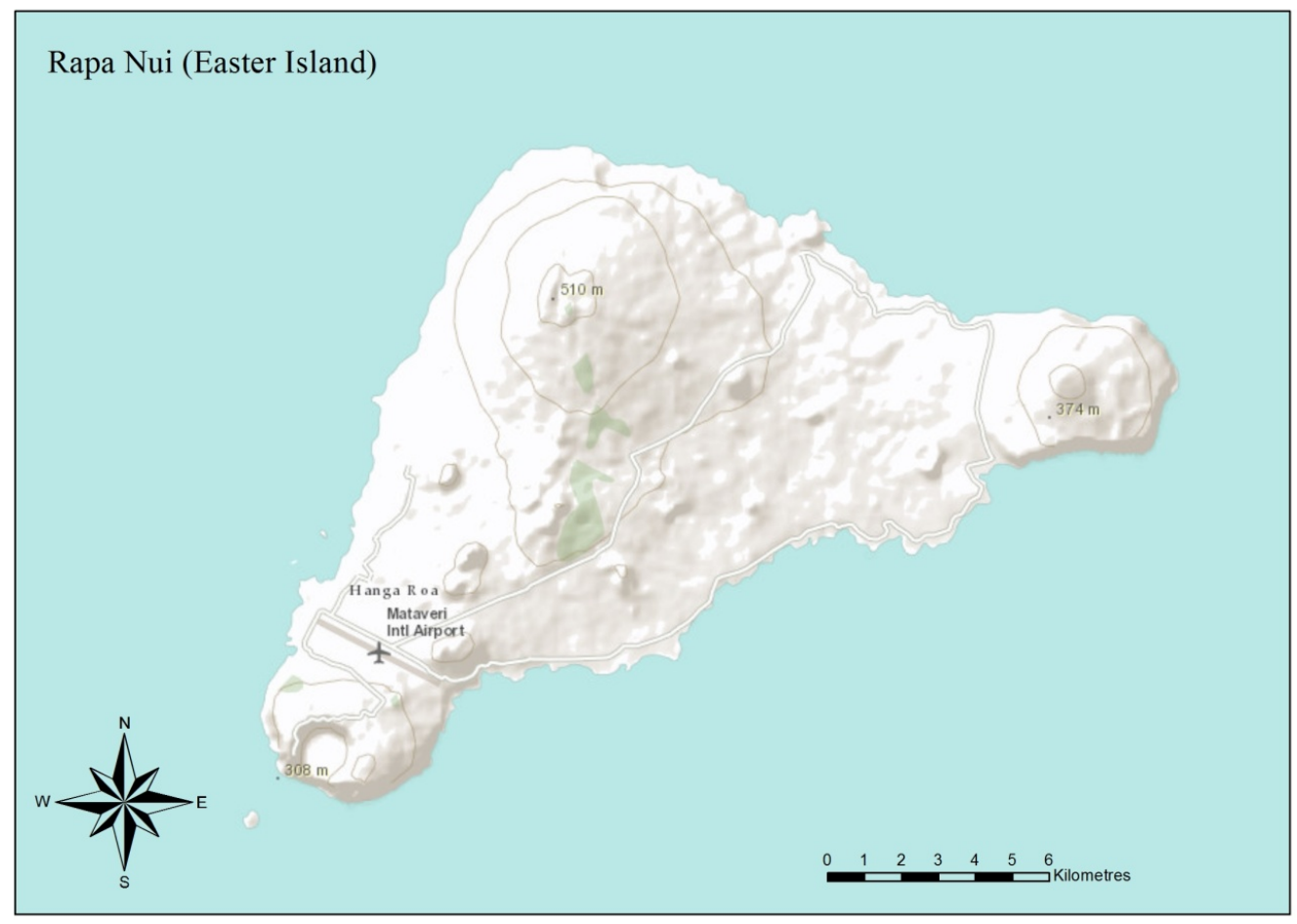

Figure 5: Rapa Nui

(ArcGISOnline, 2012)

Rapa Nui is a remote island situated at the most eastern point of the Polynesian triangle approximately $1800 \mathrm{~km}$ from the Pitcairn islands, $3700 \mathrm{~km}$ from the coastline of South America, and some $4000 \mathrm{~km}$ from the shores of Tahiti. Just 166 square kilometres, this small volcanic island is one of the most remote, inhabited places on earth. The island is sparsely populated with most of the population living in and around the only township of Hangaroa. The last census in 2002 placed the inhabitant number at approximately 3700. However more recent estimates place this number closer to 5000 ("Estimaciones de poblacion," 2007). The island is in the shape of a triangle with rolling, barren hills and consists of three extinct volcanoes: Poike in the east, Rano Kau in the southwest, and Maunga Terevaka in the northwest. The island and the people are known as Rapanui, and they are best known for their monolithic stone statues they call moai. ${ }^{10}$

Contested explanations of Rapa Nui's historical background, particularly as it relates to how the moai were constructed and how and why the island experienced

\footnotetext{
${ }^{10}$ These carvings, which Rapanui is most well-known for, are venerations of their ancestors and are erected on ceremonial platforms called $a h u$.
} 
the intensive environmental problems that it did, and simultaneous or subsequent loss of social equilibrium, have come to dominate modern day discussions about Rapa Nui (see Bahn and Flenley, 1992; Diamond, 2005; Fischer, 2005; Flenley \& Bahn, 2003; Hunt \& Lipo, 2009; Van Tilburg, 1994). Contemporary issues on the island are rarely the focus of academic research. ${ }^{11}$ Called a mysterious land where there are innumerable problems and puzzle pieces that have yet to be solved or put together, what has been often neglected is the living, breathing and evolving culture of people on the island today and their lived realities and experiences. This was frequently made clear to me on the not-so-rare occasion that I was asked about my research and would get the response of "there are people who live on Easter Island?" The disconnection between the people who inhabit the island and their ancestors who built the magnificent statutes, creates a detachment between contemporary Rapanui and their patrimony. Here, I consider the ways in which Rapanui people, particularly women, have been (un)represented within Rapa Nui's evolving history, hoping to carve a bit more space for their voices, perspectives and experiences.

\section{Thesis structure}

This thesis is structured in two parts. The first part explores the literature which helps frame the research and the methodological approaches employed. It also provides an historic background for understanding the ways in which women in Rapa Nui engage in decolonisation struggles on the island. The second part of the thesis presents the findings of this study, articulating the stories and voices of the women in Makenu with whom I had the opportunity to spend time. It discusses themes that emerged and finally draws some conclusions.

Chapter Two provides a framework for this thesis, reviewing literature relevant to my research questions. It is divided into three sections which deal with decolonisation, development and women. It introduces development concepts, focusing in on literature pertinent to working with women in development. It highlights the gaps within development literature pertaining to indigenous development, particularly as it relates to gender. It then examines colonialism and

11 See (Chapman, 2007) for a breakdown of research topics on the island, highlighting where academia is pouring most of its thoughts. 
the effects it has had on indigenous peoples, and the gendered processes involved in both colonisation and decolonisation processes. Lastly, it explores literature pertaining to women's involvement in decolonisation struggles within the Fourth World and the debates occurring within these contexts.

Chapter Three discusses the theoretical and methodological lenses and approaches that informed this study. These draw mainly from feminist and indigenous methodologies. This chapter describes and details the methods and techniques used in this research while discussing the reflexivity and positionality of the researcher. Guided by these epistemological underpinnings, I was pushed to conduct this research as ethically as possible in order to engage in research that is not colonising or imperialist, but is respectful of peoples' lives, while invoking what Enloe (2004) has described as a "feminist curiosity", compelling me to pay attention to women and to listen deeply to their stories.

Chapter Four provides a background for the study, and offers a platform from which my research can explore women's roles in decolonising struggles in the subsequent chapters. This chapter is divided into three parts. The first and second sections explore the colonial history of Rapa Nui up until the present day. Using this background, the final section centres women's roles in resistance efforts on the island, looking back as early as 1914 through until 2010. It brings women's contributions to the foreground, recognising women's historic agency, and helps contextualise the efforts of women in Makenu whose voices are privileged in the final chapters.

The second part of this thesis includes Chapters Five, Six, and Seven and is where I present the primary information generated from the research. These chapters seek to centre women's voices within the analysis and explore what concerns women have, aspirations they articulate and challenges they face. Chapter Five describes the important role women in Makenu play within their community and within decolonisation struggles. It highlights the different ways they engage on the island in order to achieve their goals. Chapter Six illustrates the importance of land in Rapanui lives, and the centrality it has within their struggles for decolonisation as well as the critical role it plays in Rapa Nui development. Chapter Seven illustrates why immigration is an important issue for women in Makenu, identifying critical issues of sustainability that the island faces. All three of 
these chapters, through women's articulations of their aspirations, demonstrate how development and decolonisation are inextricably intertwined, while illustrating the key issues of concern that make up Makenu's 'decolonisation for development' agenda.

Chapter Eight begins tying the thesis together by exploring further the key findings that emerged from Chapters Five, Six and Seven in relation to the literature in Chapter Two. This involves the critiques offered by the women in Makenu as they relate to development, while discussing and describing how a positive development looks in Rapa Nui. It also considers the cultural and political approaches Makenu uses to engage in decolonisation struggles and lastly presents some further reflections on the research process.

Chapter Nine summarises the research findings in relation to my research questions. It draws attention to future areas of research and shows the contribution of this thesis to Development Studies. It also offers some further reflections on my experience of being a researcher in Rapa Nui.

\section{Summary}

In this introductory chapter, I have located my research personally and geographically while beginning to position the work within the relevant literature bases. In the following chapter I explore the debates in related research, and in doing so, frame the particular areas in which this study aims to speak. 


\section{PART I: \\ FRAMING THE RESEARCH}

There are also common histories of resistance. I think resistance is terribly important because in no place did people just give up and say: Okay, you can have the land, we are leaving. They always stood and fought. And with that resistance came a culture of resistance, a history of opposition. There was a notion of the indigenous peoples uniting to fight outsiders so as to preserve their identity ... there is a similar stress on the need to hold onto the indigenous languages ... We have to concentrate on learning our own languages and the construction of a history, a narrative. These are part of what I call opposition and resistances.

(Edward Said cited in, Māhina \& Nabobo-Baba, 2004)

The first part of this thesis provides the necessary framework for understanding how Makenu women engage in decolonisation struggles in Rapa Nui, and their articulations for positive development on the island. It introduces the context from which they launch their resistance, and describes the methods employed for gathering information and creating the knowledge represented in this thesis. This helps to shape the chapters in Part Two of this dissertation, which presents women's voices and stories as told to me, before providing discussion on the emerging themes and drawing some conclusions in the final chapters. 


\section{Chapter Two: \\ Development, decolonisation and women}

\section{Introduction}

In this chapter I discuss the theoretical frameworks that help situate this research, seeking to contextualise the questions I have posed. The overall aim of this research is to explore the role of women in decolonisation struggles on Rapa Nui. The findings presented in this chapter correspond to three key elements: development, decolonisation and women. As I contend that women's decolonisation aspirations in Rapa Nui are in fact intimately linked to their development goals, the first section of this review offers some definitions of development, seeking to identify relevant issues that resonate with the stories of the research participants before turning my attention to how women have been included in development approaches and discourse. Section Two contextualises women's involvement in decolonisation struggles, in order to help better understand and reflect on the Rapa Nui situation. The final section on native feminisms presents current debates within Fourth World contexts regarding women and decolonisation struggles in order to appreciate the complexity of ways in which women engage with decolonisation processes.

\section{Section One: Towards a decolonising development framework}

Development as a concept in the West has its foundational roots planted in the post World War Two era, or decolonisation era. As Escobar (1995, p. 9) notes with regard to the post-war period and development discourse:

[It] inevitably contained a geopolitical imagination that has shaped the meaning of development for more than four decades. For some, this will to spatial power is one of the essential features of development (Slater, 1993). It is implicit in expressions such as First and Third World, North and South, centre and periphery. The social production of space implicit in these terms is bound with the production of differences, subjectivities and social orders. 
This time period produced a metanarrative, alleging that economic growth based on western models of development was the way 'progress' could be achieved. 'Progress', underpinned by Rostowean linear development theory, is encapsulated by the term 'modernisation' (Rostow, 1956). It was assumed that in order to transform 'underdeveloped' areas into 'developed' ones, countries needed to strip themselves of their traditional cultures, embrace western knowledge, and through western capital and technological capability, 'development' would inevitably occur (Dodds, 2002). Colonial representations of the 'Third World women' as exotic, oppressed victims, sex objects, and the most ignorant of these 'backward' societies, led women to be ignored within the first two decades of the development project (Marchand \& Parpart, 1995). This particular worldview, which was embedded in enlightenment thought, legitimated and perpetuated a type of modern development project that focused on bringing material prosperity to the 'underdeveloped' world. This was done without taking heed of context specificity, culture or indigenous epistemological ways of knowing and doing, as the very notion was contrary to the foundation and underlying beliefs of what development is and ought to be - an emulation of and catch up to the West.

Criticisms of this approach to development have been prolific throughout the last 60 years from theoretical schools competing, yet in dialogue with each other, all concerned with development in the 'Third World' (Hettne, 2002). The failure of the modernisation model to tackle inequalities and to incorporate all areas of society into development has been forcing other theories to be considered (Mosse, 1993). The questioning of development is not new - earlier Marxist and feminist critiques challenged the status quo nature of development (Desai \& Potter, 2002). However, a growing list of scholars have offered a spectrum of positions in relation to development, which can be seen to join these earlier critiques. From Dependency and World Systems theorists in the late 1960s and early 1970s (Amin, Arrighi, Frank, \& Wallerstein, 1982; Frank, 1967a, 1967b, 1969; Prebisch, 1950; Wallerstein, 1976) through to 'postist-stances' such as post-development, antidevelopment and beyond development in the 1990s (Crush, 1995; Escobar, 1995; Esteva \& Prakash, 1998; Rahnema \& Bawtree, 1997; Rist, 2002; Sachs, 1992), and in conjunction with the emergence of participatory and alternative development (Chambers, 1983, 1997; Cornwall, 2003; Guijt \& Shah, 1999; Hickey \& Mohan, 
2004; Kindon, 1998), development approaches, as well as the very notion of 'development' have been constantly questioned.

There is no universal definition of development and bearing these critiques and alternatives in mind, it becomes clear that the spectrum of what constitutes development is complex and varied, theoretically as well as politically. Ife (2010) notes how the concept of development is almost universally valued even though the ways in which development has been implemented has frequently been critiqued. Similarly, Thomas (2004, p. 1) argues development is "contested...complex and ambiguous". Cowen and Shenton (1996) note how development can be defined in a multiplicity of ways, notably because there is a multiplicity of 'developers'. And Corbridge (1998, p. 139) purports, "development does not come in one size or shape, or with an overbearing capital d", emphasising that development need not be conceived only in terms of 'progress' modelled after the West. Chambers (1997) definition of development is "good change" insinuating that development means betterment or improvement. While this is an ambiguous definition (Cowen \& Shenton, 2003), it allows for alternatives to the ways in which we conceive of development, what development can mean, and who defines it.

By recognising the situatedness of these interpretations of development alternative value systems can be realised allowing for cultural and spiritual assets to be recognised (Hickey \& Mohan, 2004). The roots of the development project grew from the concept of westernisation where poor Third World nations needed only to follow in the footsteps of the First World to achieve 'development'. However how we define it is dependent, or should be dependent, on those who are the intended beneficiaries of development making room for their knowledges, perspectives and aspirations as to what constitutes "good change", and opening up the creative possibilities for human development.

\section{Indigenous development in the Fourth World}

'Indigenous' is not an easily defined term. There are significant differences in the circumstances of indigenous peoples all over the world, "manifest by varying degrees of dispossession, different health and education experiences, and diverse political relationships" (Durie, 2005, p. 301). However, Durie also suggests that there are many shared aspirations amongst indigenous peoples, including their 
aim to regain indigenous values and language and to exercise a degree of autonomy within their territories. Achieving such autonomy is 'good change', and therefore decolonisation and development are linked inextricably. Centring their identity and culture, and working to have greater control over their lives in order to live with dignity and respect within their territories, involves decolonising processes that are embedded in and focused on development aspirations.

Radcliffe and Pequeño (2010, pp. 987-988) note how in Latin America, "development discourse and practice at the national level have largely attempted to modernize indigenous populations who, from a western-oriented nationhood perspective, are viewed as anachronistic and even as impeding development". Concepts of modernisation, which still often dominate development discourse, emphasis that economic progress is not possible without painful adjustments, which include the shedding of ancient philosophies and cultures, thereby threatening the survival of indigenous values, languages and ways of being. However development has normatively been focused on the Third World (Hettne, 2002), and while there is a growing amount of literature documenting the problems for indigenous peoples in development (Andolina, Laurie, \& Radcliffe, 2009; Laurie \& Calla, 2004; Radcliffe, 2007; Radcliffe \& Laurie, 2006), and indigenous peoples have received some consideration in international and national development policies, they still remain largely invisible. The ways in which development has paid attention to indigenous peoples has mostly been through the context of indigenous and ethnic rights claims and international legal instruments in which indigenous groups are recognised to have rights pertaining to decision-making processes. For example, the International Labour Organisation Convention 169 of 1989 asserts that indigenous peoples have rights to participation, consultation and decision-making concerning their own priorities, goals and control over development (Radcliffe \& Pequeño, 2010).12

However, while indigenous development literature is on the rise, one axis of exclusion in relation to indigenous development is gender (Radcliffe \& Pequeño, 2010). This is troublesome considering that across a number of indicators indigenous women experience less access to resources and services as compared

12 See (Andolina, et al., 2009) for a survey of indigenous development policy. Also note, the ILO Convention 169 does not make any concession for gender within its mandate. 
to indigenous men and non-indigenous men and women (Peredo Betrán, 2004). Indigenous women occupy a space in which constructs of tradition, racism, and context-specific influences of colonialism all contribute to the marginalised position that they occupy. As Radcliffe and Pequeño (2010) note, this intersection between gender, ethnicity, class and race is important for understanding indigenous women's perspectives on development, as they offer a distinctive view compared to that found in current development policy and practice.

\section{The place of women in development}

Recent decades have produced an abundance of literature focusing on gender. It was initially focused on women in 'developed' countries as liberal feminist movements pushed discussions concerning women. It later began to address the situations of women in other parts of the world, challenging western feminist discourse and theory and recognising the diversity and multiplicity of identities and relationships, based on factors of class, race, sexuality, ethnicity, etc., that women experience in their daily lives (Amos \& Parmar, 1984; hooks, 1989; Mohanty, 1993). There has been considerable discussion about women and gender dynamics in the 'Third World' within the field of Development Studies (see for example Bhavnani, Foran, \& Kurian, 2003; Kabeer, 1994; Mosse, 1993; Parpart, Connelly, \& Barriteau, 2000; Riley, 2004; K. Saunders, 2002; Sen \& Grown, 1987; Tinker, 1990; Visvanathan, Duggan, \& Wiegersma, 1997). However, the relationship between women and development has primarily been considered through western feminist approaches to development: Women in Development (WID), Women and Development (WAD) and Gender and Development (GAD) (Beneria \& Sen, 1981; Boserup, 1970; Moser, 1993; Rathgeber, 1990; Razavi \& Miller, 1995; Reeves \& Baden, 2000) and has rarely taken into account the experiences of women in the Fourth World.

As modernisation policies were implanted in societies where hierarchical structures were already established, rather than fostering equality, they exacerbated inequalities that already existed, affecting men and women differently within the process (Mosse, 1993). Women were first integrated into the development agenda in the 1970s (Parpart, et al., 2000) as the gap between those benefiting from modernisation policies of economic development and 'trickle down' approaches was widening and becoming increasingly obvious (Bhavnani, et 
al., 2003; Braidotti, Charkiewicz, Häusler, \& Wieringa, 1994; Mosse, 1993). Within the mainstream development model that emerged from the post-war era, women were identified as mothers and wives, not as contributors to development, and policies for women were restricted to social concerns such as home economics and nutritional education, referred to as the "welfare approach" (Razavi \& Miller, 1995).

Danish economist Ester Boserup was one of the pioneers of Women in Development (WID) and in her influential book, Women's Role in Economic Development, she challenged the assumptions of the "welfare approach" to development, pointing out women's invisibility and exclusion from development (Beetham \& Demetriades, 2007; Bhavnani, et al., 2003; Boserup, 1970; Moser, 1993; K. Young, 2002). Coined by a Washington-based network of female development professionals who had experience on overseas missions, ${ }^{13}$ WID emerged as an alternative development approach in which women's productive role was emphasised and strategies developed, seeking to integrate women into economic systems (Razavi \& Miller, 1995; Tinker, 1990).

WID approaches were essential for making women visible within development theory and practice. However, they did not question women's subordination and oppression, or challenge the existing social structures (Rathgeber, 1990). By the second half of the 1970s, the WID paradigm drew substantial criticism, initially from Marxist feminists (WAD proponents) (see Beneria \& Sen, 1981; Sen \& Grown, 1987). Drawing from dependency theories of development, and critiquing modernisation theory, WAD theorists emphasised that the question was not how to integrate women, but rather to question why women were excluded from development, since their contributions have always been central to development processes (Bhavnani, et al., 2003). However prescriptions from proponents of WAD were criticised for making very little real difference in women's lives and sharing the same shortcomings as WID (Kabeer, 1994). Following WAD came Gender and Development (GAD) which is the discourse most used by scholars and

13 These women were part of the Women's Committee of the Washington, DC, chapter of the Society for International Development (Rathgeber, 1990). 
development planners ${ }^{14}$ up until today regarding the relationship between development processes and women's inequality.

GAD theorists were highly critical of the economic growth model underpinning development policies. Advocates argued that the reproductive roles of bearing and caring should be given economic value, as women provide unwaged labour to the family (K. Young, 2002). They also argued that women would not accept a model of development in which self-interest was the focal point, nor would they privilege profit-making over meeting the needs of the majority (ibid 2002). GAD proponents asserted that development should be "not only [about] integrat[ing] women into development but [should] look for the potential in development initiatives to transform unequal social/gender relations to empower women" (Canadian Council for International Co-Operation 1991 cited in Bhavnani, et al., 2003, p. 5). While GAD theorists asserted that women were absent from the "corridors of power" referring to lack of women's involvement in politics, religion and finance (K. Young, 2002, p. 322), it also upheld that women are not without agency. Notions such as 'emancipation', 'organisation' and 'empowerment' became central to this approach.

While advocates of WID, WAD, and GAD have differences in their theoretical perspectives, at a fundamental level they share a belief that women are important to development processes. They condemn assumptions that development polices and projects can be carried out without the participation of women (K. Young, 2002) and they highlight the necessity to implement gender-sensitive agendas, programmes and policies to ensure women are not left out of the development process (Beetham \& Demetriades, 2007).

Feminist studies have asserted that critical and analytical work and policy is impoverished if adequate attention is not paid to women (Bhavnani, et al., 2003; Enloe, 1989, 2004). The "labour, cultures and histories of women are rarely taken into account" (Bhavnani, et al., 2003, p. 7), and the work that informs development policy and practice through gender and development discourses has largely been developed and advocated for by western feminists focused on women in the Third World. This western-centric gaze in gender and development research and

14 Including organisations such as the World Bank and the International Monetary Fund (Bhavnani, et al., 2003). 
promotion of cartographies of the category of 'Third World women' has been heavily critiqued (Laurie \& Calla, 2004; Mohanty, 1993), in parallel with the ethnocentric assumptions it makes about men and women in different societies (Bhavnani, et al., 2003). Mohanty (1993) asserts that 'women' as a category of analysis is problematic, referring to the critical assumption that because of the same gender, regardless of cultures and classes, women are a socially constituted homogenous group which is produced not on the basis of biological essentials, but "rather on the basis of secondary sociological and anthropological universals", characterised on the basis of shared oppression (p. 337). ${ }^{15}$ Failure to disaggregate the category Third World women, by not engaging with complex constructions of multiple gender identities, has been a failure of feminist research (Laurie \& Calla, 2004). These shortcomings, in part, have been reflected in how gender and ethnicity have largely been conceptualised separately within Development Studies (ibid 2004).

Just as mainstream development has tended to centre firmly on the Third World, the perspectives and experiences of Fourth World women, such as the women who participated in this study, are deeply in shadow as they are rarely considered within these gendered frameworks. With regard to indigenous women, Radcliffe and Pequeño (2010) argue that indigenous women are positioned at the intersection of gender and ethnicity within a Fourth World context. Also, the GAD paradigm, emerging from a liberal western feminist perspective, is nominally concerned only with gender to the detriment of understanding women's positionality and the disadvantaged position women occupy as a result of multiple oppressions in their life, not only gender. Similarly, Laurie and Calla (2004) note how in Development Studies, identities have been discussed in terms of gender or ethnicity, but not an intersecting analysis of the two which is required to understand indigenous women's position within their given context and society.

As such, it is contended that different approaches are required when dealing with indigenous women and development, as indigenous women hold perspectives that differ from GAD paradigms (see Andolina, et al., 2009; Prieto, Cuminao, Flores, Maldonado, \& Pequeno, 2005). Women of the Fourth World need to be central to

15 Mohanty notes five specific ways that 'women' as a category of analysis is used by western feminists discourse on 'Third World women'. See (Mohanty, 1993) for further analysis. 
indigenous development programmes and projects. However, they cannot just be slotted into the GAD approaches to development. Development must recognise the multiple factors, including gender, class, and ethnicity and the local specificities of colonialism that influence women's positionality, in order to contextualise how women are affected by development and what development means to them. And as Radcliffe and Pequeno (2010, p. 987) note, by paying attention to indigenous women in development, acknowledging their unique perspectives and experiences, we see that women's critiques are not centred around gender, going beyond this western-centric account, to work towards the decolonisation of their territories, cultures and societies. ${ }^{16}$ As such, to understand how women conceive of development and the perspectives they have, it is important to acknowledge how colonialism is impacting their lives and framing their aspirations for change.

\section{Section Two: Women and decolonisation}

Some have compared colonisation to a holocaust. Certainly if measured against the decimation that took place in the holocaust, as well as the extensive alienation of land, deculturation and the loss of power and autonomy, it had some of these characteristics. It was at least cataclysmic (Durie, 2003, p. 184).

\section{Processes of colonisation}

Context and location is important for understanding the breadth and scope of the effects of colonialism on indigenous peoples. While recognising that there are historic accounts that offer insights into colonialism as a two way process with less clear cut binaries of power, and more nuanced understandings of the interactions between coloniser and native (for work in the Pacific see, Diaz, 2010; Howe, 1977; also see, Parry, 1995), within the context of this thesis colonialism was extreme and largely defined by domination and oppression. As such, the account of colonial processes presented in the following pages more closely aligns with what Durie (2003) has called catacylysmic.

Indigenous peoples worldwide have experienced profound and deliberate oppression at the hands of colonial powers. While these processes have varied

16 Also see (Lugones, 2007). 
depending on historic contexts and the ways in which race, class, gender and sexuality have intersected, colonialism has affected indigenous peoples in political, cultural, religious, and social ways with clear patterns across space and time. ${ }^{17}$ On all accounts, the colonial project has been one of cooptation; power exuded by colonisers on the colonised in both physical and psychological terms. Losses of generational knowledge through the subjugation of indigenous ways of being, seeing and knowing, and the relegating of indigenous peoples to an inferior status within their own territories has affected the ways in which indigenous peoples construct their identities and define their place in the world.

Colonisation, in the context of this thesis, is seen as a structural relation that is defined by domination and oppression (Mohanty, 1993), and refers to the varying degrees of control and power a metropolitan territory has over another territory, whereby this control touches not only the political, military and economic areas, but also implies cultural domination (Said, 1978 as cited in Kennedy, 2000). The process of creating essentially or ontologically the 'other', through representations constructed by the articulation of difference in racial and sexual terms, served to fix the realities and 'truths' about the 'other' (Bhabha, 1983; Fanon, 1961; Memmi, 1974; Said, 1978, 1993; Spivak, 1984, 1988), and allowed the imperialist tentacles to be spread by explorers, traders, and missionaries - clearing the path for the colonial establishment. By establishing the 'native' through planned "epistemic violence" (Spivak, 1988)18 and creating a "regime of truth" (Foucault, 1980) colonisers gained and maintained, through repetition and what Bhabha (1994) calls "fixity", power and control over the colonised, allowing the colonisers to pursue their aspirations for economic profit at the expense of indigenous populations.

Feminists have taken different approaches when dealing with women and the colonisation process. Saunders (2006) discusses feminists who contend that

17 This has been widely discussed within many theoretical frameworks. For a fuller discussion, see postcolonial authors: (Ashcroft, Griffiths, \& Tiffin, 2006; Bhabha, 1983; Fanon, 1961; Freire, 1970; Loomba, 1998; McClintock, 1995; McClintock, Mufti, \& Shohat, 1997; Memmi, 1974; Said, 1978; Spivak, 1984, 1988). For scholars who reflect this point, and are writing from decolonising contexts, within formal colonial political structures, see (Battiste, 2000; Mihesuah, 2003; Trask, 1993; Tuhiwai Smith, 1999).

18 Spivak (1988) analyses three different examples of 'othering' in order to show what she has called the epistemic violence of the imperial project. Involved in this planned violence is 'establishing the "native" as the self -consolidating Other' (p. 130) of Europe, through the operation of the systems of law, ideology and the human sciences (cited in Kennedy, 2000). 
patriarchy oppresses women as a coloniser oppresses the colonised, those that demonstrate the ways in which local patriarchies have been engaged in the colonial process leading women to a "double colonisation" and those that have highlighted the silencing of women both in postcolonial studies and in western feminism. Regardless of the approach, all have argued that the processes involved in the colonial project have been profoundly gendered. ${ }^{19}$ The invention of 'race' as a replacement for relationships of superiority and inferiority established through domination (Lugones, 2008) fortified a patriarchal hierarchy within colonial contexts. However, while racial categories/hierarchies were used as tools to achieve the goals of colonisation, in which both men and women were affected, the colonial experiences and realities of indigenous men and women were different. Not only were females marginalised based on their ethnicity, as were their male counterparts, but also on their gendered identity as women. Where indigenous peoples, in the eyes of the coloniser, had not yet been 'properly gendered' or 'civilised', colonisers were afforded ultimate control with colonised females accorded the inferior status of gendering as women (Butler, 1990; Lugones, 2008). Under Christian patriarchal structures of white male superiority, which underpinned coloniser's worldviews and motivations, the role and place of women was deemed inferior, alongside their degraded status as indigenous creating two spaces in which the colonial project was able to launch its oppression.

The power relations between the colonised and coloniser, and the violence (both physical and symbolic), had widespread effects on indigenous ways of life, their understandings of the world and their place within it. The racist and classist domination that subjugated many for economic gain, alongside missions of 'civilising', involved a highly gendered provocation in which gender was central to obtaining and maintaining power and authority. Within colonial contexts, the disruption of 'native' gender relations and sexual identities through the promulgating of colonial notions of gender subjectivity and sexism enabled the coloniser to subordinate colonial subjects, particularly women (Butalia, 2004;

19 For some works addressing colonialism and gender, see (Alexander \& Mohanty, 1997; Barker, 2008; Ladner, 2009; Lugones, 2008; Mohanty, 1993; Schiwy, 2007; Spivak, 1988). For some scholars discussing gender and colonialism in the Pacific, see (Aspin \& Hutchings, 2007; Hutchings, 2002; Kahaleole Hall, 2008; Linnekin, 1990; Merry, 2000; Smith, 2003; Smith \& Kauanui, 2008; Teaiwa, 1992, 1994; Trask, 1984, 1993; Tuhiwai Smith, 1999). 
Maese-Cohen, 2010; McClintock, 1995; Oyewumi, 1997; Schiwy, 2007). As Levine (2010a, p. 1) asserts, the maintenance of the power dynamics established between coloniser and colonised were contingent on "carefully calibrated (albeit ultimately unstable) gender roles".

While the 'divide and rule' strategy is a well-known ruse of the colonial enterprise, this was profoundly distinguished amongst men and women (Butler, 1990; Teaiwa, 1992) thereby naturalising social hierarchy and leading to the shifting (and depreciating) status of women in various colonial contexts (Clea Hoskins, 2000; Hutchings, 2002; Smith \& Kauanui, 2008; Trask, 1984; Turpel, 1993). Maese-Cohen (2010) and others (Kauanui, 2008; Merry, 2000) suggest that the systems put in place not only diminished the status of women, as the cultural systems which encompassed gender roles were destroyed, but it altered and weakened men's place and power within society as well. The language of gender and colonisation, Saunders (2006) purports, is grounded in a process of natural development whereby the 'pregendered' as with the 'pre-colonial' are naturally assigned to that of the status of a child. The likening of the indigenous man to that of a child or a woman emasculates the indigenous man by making him ignorant and submissive feminising him - (Butler, 1990) while denigrating and marginalising indigenous woman in the same breath.

Oyewumi (1997, pp. 124-125) discussing the colonial legacy of gendering, asserts:

The very process by which females were categorized and reduced to "women" made them ineligible for leadership roles... The emergence of women as an identifiable category, defined by their anatomy and subordinated to men in all situations, resulted, in part, from the imposition of a patriarchal colonial state. For females, colonization was a twofold process of racial inferiorization and gender subordination. The creation of "women" as a category was one the very first accomplishments of the colonial state...

While the effects of colonisation on indigenous populations varies across contexts in its degree and scope, most indigenous peoples around the world have been subjected to some aspects of socialisation that include conversions to Christianity and education based on colonial notions, through to their incorporation into an unequal and exploitative capitalist economic system making them vulnerable to 
these gender identities and patriarchal relationships (St Denis, 2007). "These institutions play a significant role in producing and reproducing ideologies about what it means to be a man or a woman or a family, not through force but through common-sense ideas that are enacted in everyday practices like going to school, courting, getting married and giving birth" (St Denis, 2007, pp. 41-42). As Kahaleole Hall (2008, p. 278) has also suggested:

Whatever the disagreements about the nature of the precolonial status of women within various indigenous societies, there is no ambiguity about the negative consequences of the views and actions brought by European missionaries, soldiers, and settlers. The deliberate destruction of non-heteronormative and monogamous social relationships, the indigenous language that could conceptualize these relationships, and the cultural practices that celebrated them has been inextricable from the simultaneous colonial expropriation of land and natural resources.

Colonialism did not only affect the colonised territory through resource expropriations, but had profound effects on indigenous ways of seeing the world, their place within it, and the knowledge and meanings they created to understand it.

Still, colonialism did not alter all aspects of gender roles nor did it completely succeed in destroying indigenous identities. Haussman, Sawer and Vickers note how "...individuals and communities simultaneously manifest competing cultural identities and understandings of gender...while the breadth and depth of the internalising of colonialism is debatable, the existence of competing ideas is critical to understanding the contemporary visions, strategies and pursuits of indigenous women" (2010, p. 74). This acknowledgment is also important when considering how women engage in decolonisation struggles, as they work within the multiple worlds in which they are a part.

\section{Processes of decolonisation}

Fanon (1961) has referred to decolonisation as a violent process - bloody and ruthless - as was the case in his home of Algeria under French occupation. Feminist historians have written about India's partition and decolonisation process in a similar light, describing the atrocities endured by the colonised population and accentuating their experiences within these struggles - particularly 
those of women (see Butalia, 2000; Butalia, 2004; Levine, 2010a, 2010b; Menon \& Bhasin, 1998). Anti-colonial struggles and resistance are as old as colonisation itself. Decolonisation continues to occur in various localities and colonial contexts around the world, ${ }^{20}$ and depending on coloniser and colonised, space and time, it is unfolding in a multitude of ways in which political as well as cultural resistance strategies are undertaken.

The era of decolonisation came at the end of World War Two, when war-torn Europe was confronted by staunch resistance from indigenous populations in their colonies. Scrambling to rebuild their shattered continent, the European powers were unable to maintain control over their overseas territories in the face of so much adversity. Political decolonisation brought a new entity onto the world stage, and within the context of Cold War politics, the 'Third World' was born. National sovereignty, the right to self-determination and human rights acquired normative status as the basis of international law and practice (Darwin, 2011). New hopes developed as young nations tried to create fresh starts - developing governments and laws in their own image, reflecting their optimism and dreams for their new societies. However as Said (1989) has asserted, colonisation did not end when the last policeman left and when the last European flag came down. Colonialism is alive - politically, economically and culturally. While not all decolonisation struggles have been bloody and ruthless, the 'undoing' of colonialism presents immense challenges for indigenous peoples, as they try to assert their rights to their land and territory, to self-governance, to education, health, language and culture - to a life free from oppression and subordination.

Decolonisation, or the 'rebirth' of nations, has been portrayed as a largely masculine achievement (Teaiwa, 1992), occurring in a masculine space (Green, 2007; Lazreg, 1994; Levine, 2010a), where colonised men confront colonising men. Mhalinia Sinha (2004, p. 194) has observed, "political rights for men have flown directly from their eligibility to shed blood for the nation". Levine (2010a) discusses how in British India, French Africa, and elsewhere, women's rights were

\footnotetext{
20 In the 10 years following the adoption of the Declaration on the Ending of Colonialism (1960 to 1970), 27 territories (with a total population of over 53 million) attained independence. Some 44 territories (with a population of approximately 28 million) remained under foreign rule or control ("Independence of Colonized Peoples: Progress of Decolonization," 2007-2012).
} 
considered secondary to the task of rebuilding economies and infrastructures of the newly forming nation-states. Rather than seeing women's rights and the project of nation-building as mutually constituted necessities, she asserts, women's claims were denied. Promises were left unfulfilled and hopes dashed as male-led governments took power and began to reconstruct war-torn societies, excluding women in the process. This is noted further by Levine (2010a) when she describes how, while women have agency, they are limited by patriarchy and this patriarchy, shared across colonial and postcolonial societies, creates betrayal when the newly formed states does not produce liberation for both men and women.

Patriarchy has been described as "the structural and ideological system that perpetrates the privileging of masculinity" (Enloe, 2004, p. 4). This system of domination, which activists within decolonisation struggles sought to eradicate, ends up being replicated in the new nation, looking strikingly similar to that of their colonial masters as it is constructed by what Jaimes (1998) called a "trickledown patriarchy". Chatherjee (1993), describing the situation in India, observes that it was important to pull women into the decolonisation movement, having them fight against the colonisers, as they constituted half of the population. However he also notes that their involvement did not result in women's emancipation, but rather they now "had a new form of patriarchy, and one that was made increasingly more legitimate" (Chatterjee, 1993, p. 16), as it was no longer the colonisers who were responsible for their oppression, but was now their own men. Vanuatu scholar and poet Grace Mera Molisa describes the decolonisation process, and the dichotomy between thought and action, as the "bitter-sweet/fruit/of sovereignty struggle," as the sweet fruit of her country's independence has been 'for men only' (cited in Jones, Herda, \& Suaalii, 2000, p. 11).

Gayatri Spivak in her important work "Can the Subaltern Speak", ${ }^{21}$ challenges postcolonial scholars to acknowledge the limits and possibilities for recognising women's historic agency, as archival sources of coloniser and colonised alike have been patriarchally constructed and articulated. It is therefore through male

21 The term subaltern, which was first employed by Marxist political activist, Gramsci (Louai, 2012), is contentiously debated with regards to how it should be defined. Spivak, influenced by Gramsci, replaces his definition with a more nuanced and flexible understanding of the term, informed by deconstruction, in which women's lives and histories are taken into account (Morton, 2004, p. 48). At a basic level for understanding the term, it is used to describe marginalised groups. 
perspectives and experiences that knowledge has been constructed in the colonial and postcolonial era. Equally, she contends that women have engaged in anticolonial struggles, yet their participation is continuously excluded in historic accounts, and patriarchal hierarchies are reconstructed, framed as ideals for national sovereignty.

The question is not of female participation in insurgency, or the ground rules of the sexual division of labor, for both of which there is 'evidence' rather, both were used as objects of colonialist historiography and as a subject of insurgency, though the ideological construction of gender keeps the male dominant. If in the context of colonial production, the subaltern has no history and cannot speak, the subaltern as female is ever more deeply in shadow (cited in Louai, 2012, p. 7).

Spivak's work has brought into focus women as subjects of colonisation's enterprise. She highlights women as active participants within anti-colonial resistance, revealing the silent condition in which they have been positioned. However while portraying them as unable to speak she importantly emphasises that while they have been silenced, they are not without knowledge (Maese-Cohen, 2010).

This speaks to the archival sources on offer in Rapa Nui, as accounts have largely been constructed by male explorers, entrepreneurs and missionaries, leaving women out of their realm of analysis, or when included, constructing them through western patriarchal discourses. It is therefore important to consider how women have been silenced within historical accounts in Rapa Nui, while acknowledging that women have historic agency, and have always been a part of struggles, if even their voices and contributions remain largely unaccounted for.

\section{Section Three: Native feminisms}

While appreciating Rapa Nui as a place within the Pacific, with Polynesian customs and traditions, the literature I assess in this section is mainly the work of Native scholars in Canada and the United States, including Hawai'i. These women's writings, theories and struggles are launched from within a Fourth World context, making their experiences and discussions most appropriate within this study. As 
very little work has been done in Rapa Nui by Rapanui women addressing contemporary issues, I try to garner some understanding of the issues confronting indigenous women in other parts of the world who are also engaged in anticolonial struggles.

\section{Native women's struggles}

Many indigenous female scholars currently involved in decolonisation processes argue that feminist politics are in conflict with the politics of sovereignty and selfdetermination, and in some cases are viewed as extremely divisive to their struggles (for some works dealing with this conflict see: M. A. Jaimes, 1992; M.A. Jaimes \& Halsey, 1992; Monture - Angus \& Turpel, 1995; Trask, 1996; Turpel, 1989). ${ }^{22}$ It is important to note, however, that few have written on the topic of feminism, and reiterate that women's experiences and participation within decolonisation struggles has often been left out of historic accounts, and their aspirations ignored (Butalia, 2000, 2004; Levine, 2010a).

Describing the renunciation of feminism by some, Kahaleole Hall (2008) identifies two schools of thought that help root their criticisms. The first is a critique of western feminism ${ }^{23}$ stressing that it is about white women's struggles to gain equal status with white western men, which continues to uphold the unequal (superior) status that white women have vis-à-vis everyone else. In the second school of thought, feminism is believed to create an artificial division between indigenous men and women and is divisive to the strength of the 'people', as some of the scholars mentioned above contend. Some argue that gender cannot be separated out from race or class, as women experience oppression not just as women but as indigenous women (Ladner, 2009). Lorelei DeCora Means (cited in Smith, 2005, p. 117) argues:

We are American Indian women, in that order. We are oppressed, first and foremost, as American Indians, as peoples colonized by the United States of America, not as women. As Indians, we can never forget that. Our survival, the survival of every one of us - man, woman, and child -

22 For an inventory of why many Native women reject feminism, see (St Denis, 2007).

23 For some scholars who critique western feminism see: (Amos \& Parmar, 1984; Andzaldúa, 1987; hooks, 1989; Mohanty, 1993; Trask, 1996). 
as Indians depends on it. Decolonization is the agenda, the whole agenda, and until it is accomplished, it is the only agenda that counts for American Indians (emphasis in original).

Expressing similar sentiment, Trask, states:

At this stage in our collective lives, Hawaiians are determined to make our own history, with or without white feminist support. We will do so as Hawaiian people, not only as Hawaiian women. Feminists, as other white people, must understand that our sovereignty struggle requires working with our own people, including our own men. This is preferable to working with white people including feminists. Struggle with our men, occurs laterally across and within our movement. It does not occur vertically between white women and indigenous women on one side and white men and Hawaiian men on the opposing side...culture is a larger reality than women's rights (1996, p. 914).

Decolonisation is articulated as a national movement in which choices must be made and strategies employed - reflecting indigenous men and women's decisions to silence differences in order to secure collective recognition (Ladner, 2009).

However some scholars suggest that it is the constructed division itself between gender and sovereignty that is problematic. They argue that this competition depicts the sexism that exists within indigenous social relationships (Barker, 2006, 2008; Sunseri, 2000) as it asserts that indigenous women should defend a nation that ignores sexism as part of the liberation from colonisation (Ramirez, 2007). This division forces women to make a choice between indigenous sovereignty and women's empowerment. Likewise, Kahaleole Hall (2008), Smith (2005), and Ramirez (2007) note the sexual and gendered nature of patriarchal colonialism alongside the contemporary rates of sexual abuse and domestic violence experienced by indigenous women, emphasising that sovereignty can no longer mean "independence and separation but must also incorporate a sense of respect embedded within social relationships" (Ramirez, 2007, pp. 34-35). Gender must be linked to discussions of sovereignty and nationalism, as well as masculinity, as these dominant notions all contribute to violence against women, and therefore need to be reconceptualised (Ramirez, 2007). 
These scholars maintain that decolonisation agendas must involve a native feminist consciousness. This can help indigenous men and women understand some of the social problems that exist within their communities and help build stronger senses of well-being. Others, while recognising the sexism and violence that exists in indigenous communities, argue that with the successful decolonisation of indigenous nations these social ills would be remedied with the reclamation of their traditional culture, in which women held status in communities and were not subjugated by indigenous men (see M. A. Jaimes, 1992; Monture-Angus \& Turpel, 1995; Turpel, 1989). As gender relations within contemporary indigenous communities have been heavily influenced and shaped by colonial practices, reasserting indigenous cultural traditions would strengthen indigenous sovereignty and nationhood while improving women's issues - without creating any community divisions in order to achieve that goal.

Like Jaimes (1992) and Monture-Angus and Turpel (1995), Ramirez (2007) and Kahaleole Hall (2008) believe that remembering and incorporating pre-colonial traditions and culture, including gender systems and roles, is important not only for constructing native feminisms, but for indigenous survival. Reclaiming tradition "can open new/old ways of being" (Kahaleole Hall, 2008, p. 279) as it brings together past and present in forms both inherited and innovative. However, like Smith (2005), Kahaleole Hall and Ramirez do not believe that with successful decolonisation problems of sexism are automatically eliminated. For these scholars, women's concerns, aspirations and well-being must also be included in their agenda. It must include specifically how indigenous people, both women as well as men, experience oppressions. It must also include a redefinition of nationalism, sovereignty and gender from a Native feminist lens, turning to indigenous frameworks of gender relations to "develop an inclusive nationalism [which] ultimately work(s) to decolonize Native nations" (Ramirez, 2007, p. 34). 


\section{Summary}

Through colonial processes, patriarchal notions of gender have constructed native sexualities and prescribed gender roles, naturalising a social hierarchy, and creating divisions amongst its subjects. As colonisation is a ubiquitously gendered process, so too is decolonisation. Women have played significant roles within decolonising processes, yet their contributions are rarely accounted for, constructing the decolonising space as a masculine one in which women's aspirations and experiences are continuously left out.

Indigenous women struggle against the oppression of their people, and they work on behalf of their kin. They are not always fighting for 'women's rights' but for indigenous rights, in order for their community to develop in ways that address local needs and are born from indigenous knowledges and ways of being, including the reinvigoration of their culture, language, customs and norms. Women's concerns are fundamentally development issues - prioritised and mobilised by the push and pull of decolonisation. There are tensions and constant negotiations that occur within decolonisation, and the decolonising space is not easily negotiated or clearly defined. Understanding these tensions gives an appreciation for the deeprooted difficulties of achieving meaningful social change that has positive outcomes for all, while highlighting the importance of including women, allowing for a broader and more holistic understanding of development processes. 


\section{Chapter Three: Approach and methodology}

When we enter a field we make footprints in the land, and are likely to disturb the environment. When we leave we may have mud on our shoes, pollen on our clothes (Letherby, 2003, p. 6).

\section{Introduction}

As a non-indigenous researcher working with indigenous peoples and contemplating voices that are often excluded, my approach and methods were an essential part of this work. I employ a variety of qualitative research methods for knowledge generating with women in Makenu. These methods have led me to identify particular themes which are presented in Chapters Six, Seven and Eight, and from which I draw conclusions in an effort to address the research questions posed.

This chapter discusses how I came to talk to the women whose voices are privileged in this work, how I generated information, and how I transcribed and translated the information I gathered. It explores some of the issues that arose while conducting this research and discusses the ethical and practical constraints of this process.

\section{Philosophical approaches}

The process of carrying out research is as important as the findings, particularly when conducting research with indigenous peoples who have been systematically and continually oppressed by research (see Crazy Bull, 1997; Tuhiwai Smith, 1999). To engage in decolonising research, the researcher must be explicit about not only what the research seeks to explore, but also how it endeavours to do so. 'Regimes of truth' have the function to create power, and so a critical eye must be engaged to ensure the research does not do more harm than good (Sunseri, 2007). The presumption that the social world can be accurately known and truthfully and objectively represented is questioned as knowledge-making is seen to be political in nature (Cameron \& Gibson, 2005). As such, this work recognises multiple 
perspectives, worldviews and knowledges, and in doing so challenges positivist approaches which claim objectivity and universal 'truth'.

Qualitative methodologies have been used in carrying out this research and these have allowed me to explore multiple viewpoints through a multimethod approach. According to Denzin and Lincoln, qualitative researchers emphasise the "socially constructed nature of reality, the intimate relationship between the researcher and what is studied and the situational constraints that shape inquiry" while also "locat[ing] the observer in the world" (1994, p. 5). The methods I have chosen in this research have allowed me to explore how participants have made sense of their own lives, and through our interactions, exchanges, and relationships, produced the knowledge I present in this thesis.

\section{Indigenous methodologies}

We have been pathologised by Western research methods that have found us deficient either as genetically inferior or culturally deviant for generations. We have been dismembered, objectified and problematised via Western scientific rationality and reason. We have been politically, socially, and economically dominated by colonial forces and marginalised through armed struggle, biased legislation, and educational initiatives and policies that promote Western knowledge systems at the expense of our own. We know better now (Louis, 2007, p. 131).

Rapanui people have experienced a long history of oppression and marginalisation, and have engaged in multiple strategies of resistance in an effort to increase their autonomy and strengthen their culture and territorial control. Drawing on their ancestral knowledge and traditions, their engagement has been both creative and political. In this research, I aim to expand whose knowledge is listened to and taken into account as valid knowledge within these struggles.

For indigenous peoples research is inextricably linked to the processes of colonisation and imperialism (Battiste, 2000; Bishop, 1997; Bishop \& Glynn, 2003; Crazy Bull, 1997; Gegeo \& Watson-Gegeo, 2001; Louis, 2007; Trask, 1993; Tuhiwai Smith, 1999). As was discussed in Chapter Two, colonisation has subordinated indigenous ways of being and knowing, disconnecting indigenous peoples from fundamental aspects of their lives, such as spirituality, land, family, and community. 
It has also isolated and silenced women's voices. Research, to use Linda Tuhiwai Smith's assertion, is "probably one of the dirtiest words in the indigenous world's vocabulary" (1999, p. 1). It, like colonialism, has codified racism, marginalised indigenous knowledges and closed off spaces for alternative perspectives and understandings of the world. It is through objective, scientific, and rational research that indigenous peoples have been repeatedly, as Louis (2007) states above, represented as genetically or culturally deficient and problematised by western researchers. As a result, research has become a site of protest, struggle and resistance for many indigenous peoples. Indigenous scholars have begun to confront ideologies embedded in these processes that continue to oppress, setting out a research agenda that works towards "decolonising minds" as essential to the politics of indigenous peoples' movements and their pursuit of the right to selfdetermination (Louis, 2007; Tuhiwai Smith, 1999).

Decolonising research has been carried out by indigenous scholars seeking to validate indigenous epistemologies, developing methodologies that are firmly placed within indigenous worldviews (N. Denzin, Lincoln, \& Tuhiwai Smith, 2008; Gegeo \& Watson-Gegeo, 2001; Tuhiwai Smith, 1999), while questioning the positivist approach that underpins much of the research still carried out today. Part of a broader "reflexive" process which is continually questioning the position of "researcher as observer" (Hodge \& Lester, 2006, p. 41), decolonising research, through the use of indigenous methodologies, presents alternative ways of thinking about research processes (Louis, 2007). It shifts focus to centre on indigenous concerns and worldviews, in which cultural protocols, values and behaviour are fundamental to how research is approached (Tuhiwai Smith, 1999). It aims to ensure that research is done ethically, respectfully, sympathetically, and from an indigenous perspective (Louis, 2007; Tuhiwai Smith, 1999).

Indigenous methodologies push western researchers to approach research untied to western epistemological frameworks and reference points (Gegeo, 1998; Hereniko, 2000). Using an indigenous lens and engaging with indigenous peoples' knowledge and worldviews is paramount for undertaking decolonising research. However this is a complex task. I have grown up in the West, raised in the western tradition. This will always affect the way I see the world and the ways in which I create meaning. Crook (2007) discusses his experience and the difficulties he 
encountered when doing field work in Papua New Guinea, referring to knowledge sharing as an "exchange of skin" and illustrating how to understand the Min people was to do it from "within their skin". This, however, is not a matter of just picking up another set of lenses and switching between worlds with ease, but is a complicated process that requires constant reflection and awareness of self and surroundings. Unlike Crook, who engaged in long-term field work in Papua New Guinea, my research had to be done within particular timeframes, and was subject to the structural constraints that exist within academic institutions. For one, living in Rapa Nui for years was not an option within the frameworks of obtaining a Master's degree. And secondly, the research is always operating from inside a western institution in which western cultural frameworks are favoured (Settee, 2007). However, I think it is important for us as researchers to at least try, if even imperfectly, to take these steps to further decolonise our research practice. By engaging as intimately as we can with our research participants, by being reflexive, ethical, and following the protocols and methodological approaches put forth by indigenous scholars, we are engaging in research that is not colonising or imperialist, but is respectful of peoples' lives, experiences and perspectives.

\section{Feminist approaches}

In line with indigenous approaches to research, I also drew from feminist epistemologies. At the heart of this research, I invoke what Enloe (2004) has described as a "feminist curiosity", where I am compelled to take women's lives seriously, to ask them what concerns them and to listen deeply to what they share with me. Feminist approaches maintain similar principles to indigenous methodologies in that they both urge the researcher to question concepts of truth, consider issues of voice, representation and ethics (Cannella \& Manuelito, 2008), to be sensitive and thoughtful in our approaches and conduct, and to strive for social justice.

Historically, women's concerns have not been given much attention within mainstream research. Approached through a positivist lens, men and women's experiences were seen as equivalent, and history has largely been written based on the experiences of men. However, what has been termed the 'postmodern turn,' emerged from Marxist and feminist critiques of positivist and neopositivist empiricism, in which serious challenges to these methodological approaches were 
launched (England, 1994; Haraway, 1988; Sharp, 2004; Tuhiwai Smith, 2008). Western feminism provided more radical challenges than Marxism, as feminists attacked not only the body of knowledge, but also the science of the way in which knowledge is understood (Letherby, 2003; Tuhiwai Smith, 1999).

However, as was discussed in Chapter Two, western feminists have been critiqued, in particular by women of colour, for conforming to the same value systems and attitudes and contributing to or perpetuating systems of knowledge and worldviews that continue to subjugate and oppress (Hill Collins, 2000; hooks, 1989) while also adding to the academic tradition of speaking for 'others' (Letherby, 2003). The representation of 'women', in which a homogenous category is assumed, renders invisible the various experiences that exist between women of different race, ethnicity, age, sexuality, etc. However, hooks (1986) suggests that feminism is possible, not because all women are the same and share the same experiences but rather because there exists a possibility of engaging in common resistance against oppression (cited in Letherby, 2003).

In my research I talk about 'women in Makenu'. I would like to note here that I recognise the various perspectives and subjectivities amongst Rapanui women as well as those within the Makenu group, and am aware of the risks posed by aligning all women in Makenu. Like Canella and Manuelito (2008) note, regarding their aims to form an alliance of feminist, native, and womanist worldviews, I risk privileging some voices and perspectives over others, while potentially essentialising, marginalising or even erasing all together other viewpoints. By using the term 'women in Makenu' I do not wish to assume homogeneity within the group and in fact am acutely aware of many of the differences and complexities that shape their experiences and identities. However, to understand how some women in Rapa Nui are engaging, and focusing not on a 'random sample' of women in the community, but specifically asking for them to come forward and speak to me not only as women, but as Makenu members, had influence on what they told me about their struggles and about their lives. Additionally, it is largely under the 'Makenu' banner from which they engage in their 'decolonisation for development' struggles.

While there are no specific methods for conducting feminist research, feminist researcher's in their tool kits are mostly equipped with qualitative methods, which they wield in pro-feminist ways (Letherby, 2003), placing emphasis on the 
research approach and framework (Beetham \& Demetriades, 2007). Feminist research also acknowledges that the product of research cannot be separated from the means of its production. There needs to be sensitivity towards research participants and an acknowledgement of our own presence in their lives, as well as acknowledging that the subjectivity of the researcher significantly affects the outcomes of the research (Letherby, 2003).

Letherby (2003, p. 4) notes that the "single most distinguished feature of feminist scholarly work has been its overtly political nature and feminism's commitment to material and social change has played a significant role in undermining traditional academic boundaries between the personal and the political". Feminist methodologies often seek to draw in concerns of women and listen to their views, endeavouring to include the voices of those who have experiences of different situations and whose experiences have typically been marginalised (Sharp, 2004). As such, this research wishes to recognise these knowledges that have been marginalised, creating a space from which women's concerns are heard and appreciated as "legitimate ways of seeing and knowing" (Hammers \& Brown, 2004, p. 89). In the case of Rapa Nui, it would be easy to approach a research project that deals with processes of decolonisation on the island, and come away having spoken only to men and heard only men's perspectives. Cynthia Enloe's (1989, p. 1) words, speaking about international politics, resonate with this idea when she says, "if we only employ the conventional ungendered compass...we are likely to end up mapping a landscape peopled by men." This research therefore seeks to employ a gendered compass when undertaking this investigation, in order to appreciate different perspectives and to recognise knowledges that may not be heard.

Feminist researchers also emphasise that research must be conducted in a way that is reflective, reflexive, open and honest. England (1994) asserts that feminist research frequently endeavours to have reciprocal relationships which are based on empathy and mutual respect and involve the sharing of knowledge between researcher and research participants. Feminist researchers have shown a determination to respect the views of their research participants, to include the voices and concerns of women and to validate their experiences throughout the research process (Sharp, 2004). I believe that the methods I have chosen to conduct this research, which are discussed below, have enabled me to do this. 
Like Letherby (2003), I recognise that my role and position within research, from the conception of the project, through to the final product heavily influences research outcomes as all research is ideological and we cannot separate ourselves from the world. As Stanley and Wise note:

Whether we like it or not, researchers remain human beings complete with all the usual assembly of feelings, failings and moods. And all of those things influence how we feel and understand what is going on..... Our consciousness is always the medium through which the research occurs; there is no method or technique of doing research other than through the medium of the researcher (1993, p. 157).

In recognising that all knowledge is situated (Haraway, 1988) and there are multiple worldviews present, as well as seeking to engage in decolonising methodologies, it is important to identify myself in this process and to be mindful of how I have influenced this work. However this is not an easy task as my ways-ofbeing and knowing are indeed influenced and shaped by my personal history and are not always conscious or stable (Kincheloe \& McLauren, 1994; Rose, 1997). Additionally, my ways-of-being in relation to my research participants, and theirs in relation to me, are constantly evolving and can never be fully understood (Gibson-Graham, 1984; Rose, 1997). However recognising that these dynamics are inherent when carrying out research has pushed me to be as reflexive as I can and mindful of my own understandings of what constitutes knowledge, the assumptions I carry with me, and what influence this has had on the research process and final product.

Feminist and indigenous epistemologies and approaches have most heavily influenced this research endeavour. However, I also drew from two other philosophies which I briefly highlight below.

\section{Participatory Action Research (PAR)}

While this project was not as collaborative or action-oriented as I had hoped (discussed further below), PAR approaches continued to heavily influence the epistemological underpinnings of this research. I was particularly compelled by the concerns of representation and power dynamics embedded in PAR approaches. PAR's approach starts from the understanding that "people - especially those who 
have experienced historic oppression - hold deep knowledge about their lives and experiences, and should help shape the questions" as well as "frame the interpretations of research (Torre \& Fine, 2006, p. 248). PAR attempts to avoid extractive research where local knowledges are not respected and little is given back to the community from where that data and knowledge was obtained. These approaches concerned with representation and social change align with feminist and indigenous epistemologies as PAR is "a collaborative process of research, education and action explicitly oriented towards social transformation" (Kindon, et al., 2007) in which "local and indigenous knowledges [are valued]" (Cameron \& Gibson, 2005, p. 4). ${ }^{24}$ While this research involved very limited PAR, I approached my research with these philosophical principles in mind, and strived to be as participatory as I could within my given limitations. I describe some of these approaches in more detail below.

\section{Appreciative Inquiry (AI)}

Like PAR, AI is a collaborative and participatory approach. It is "a simple but radical approach to understanding the social world" (Reed, 2007, p. 1). Premised on the idea that when something increases in value it appreciates, AI focuses on the generative rather than degenerative. Where I draw most from in $\mathrm{AI}$ is where it "focus[es] on the positive as a core value", choosing the positive as the focus of inquiry (Watkins, Mohr, \& Kelly, 2011, p. 115). While my research does not use the methodological processes of AI, I find this aspect of its philosophy useful and pertinent to my work. "Appreciative stories can be seen as 'magical constructions' that encourage reflection on meanings of friendship, wisdom, courage, justice and innovation. Furthermore the stories have the potential to move people beyond reflection to action" (Chu, 2007, p. 4). My approach to this research was one of appreciating women's efforts, looking for the positive contributions they make to decolonising struggles on the island and focusing on assets rather than on what they lacked or what problems they have, while being open to what they wanted to share.

The section above recognises and highlights some of the ways-of-knowing that I engaged during this research process. Different ways-of-knowing and subsequent

24 While PAR and feminist epistemologies share similarities, feminists have also critiqued participatory approaches for not paying attention to issues of gender (see Cornwall, 2003; Guijt \& Shah, 1999). 
ways-of-doing were relevant at different stages, and as a researcher this elasticity allowed for appropriate tools to be used within given situations. This resonates with what Denzin and Lincoln have called bricolage (N. Denzin, K. \& Lincoln, 2005). However, while different theoretical underpinnings have influenced this research project, a consistency I can highlight is my effort to conduct this work ethically and morally and my endeavour to 'do no harm' at every stage of the process. This again is not always a conscious act, as I see acting ethically as intuitive and specific to particular contexts. In taking this approach however I am committed to reflecting continuously on the research process where I fit within it and the situations that frame my interactions while always questioning how I can be most respectful within any given situation. Asking that question throughout this thesis, whether always successful or not, has been my mantra for undertaking this work.

\section{The process of carrying out my research}

This research was largely undertaken using unstructured and semi-structured interviews, as well as talanoa and participant observation. I also kept a reflective diary before, during, and after my field work took place and have quoted portions of it throughout the thesis. I was in Rapa Nui from the $21^{\text {st }}$ of June until the $8^{\text {th }}$ of August, 2011 spending approximately three weeks before and after that time in continental Chile. ${ }^{25}$

\section{Making connections, building relationships}

Makenu is a group that was formed in 2009 and emerged in the wake of a protest against uncontrolled immigration to the island. ${ }^{26}$ They are not an associated or registered group, they are self-resourced and they work according to their own agenda and priorities. Chapter Five describes how I first came in contact with the Makenu group once on the island. However, prior to my arrival I had been in communication with one of its members via email. I was given this email address

25 Many Makenu women when speaking about Chile would refer to it as 'el conti', the continent. I therefore sometimes refer to Chile as the continent as do they in some of their quotes in the subsequent chapters.

26 The women who participated in this study almost always, when referring to the topic of people coming to the island, referred to the issue as immigration (Chilean and foreigner alike). I saw this as a form of resistance. Therefore, I will do the same and refer to the flow of mainly Chileans to the island, as immigration. 
by a friend, which led to a limited form of 'snowballing' (Valentine, 1997). At the time of contact, I was in the beginning stages of making connections and 'feeling around'. Committed to engaging in collaborative research, I thought it was important to make contact before arriving on the island in an effort to begin putting things in place, as my timeframes once there were quite tight.

In my email to this member, I described my project and my wish to work with the group. I sent her a one page document with the project aims, objectives and research questions and I requested her feedback about what she thought of my idea and whether she thought the group would like to partake in the project. Just before my field work was to begin, I received a positive email from her stating:

\begin{abstract}
I think your topic of women and land is the best. I believe the struggle for the territory of our children is an issue that concerns us so much today, the tremendous immigration occurring in Rapa Nui presently, and increasingly we become less in number, a situation that the State favours $\left(\right.$ Ana - 1). ${ }^{27}$
\end{abstract}

This reply gave me confidence that the work I sought to do was important, had meaning and would contribute to these women's lives (Louis, 2007; Tuhiwai Smith, 1999), that it would not just be knowledge for knowledge's sake (Crazy Bull, 1997) and was a political act in which I, a non-indigenous researcher, was seeking to be an "allied other" (Mutua \& Swadener, 2004, p. 4).

In my original research proposal I stated that I planned to speak to "women engaging within the land movement in Rapa Nui... this will be my main unit of analysis... [And] will be coupled with a focus on women's organisations... [for example] this could be a women's group such as the 'Grupo de Mujeres'(group of women $)^{28}$ currently making important contributions towards land sovereignty on Rapa Nui or it could be a domestic violence organisation promoting women's rights" (Christ, 2011). As my original focus for this project was centred on women's concerns for their land, their role in these struggles, with a substantial

27 This is the first Spanish quote that appears in Appendix One. Each quote is numbered following this format throughout the thesis. This construction is described in greater detail below. The reader will also note that all primary research is in italics and quotes taken from books are not italicised.

28 I had heard about the 'grupo de mujeres' before arriving. What I didn't know was that the 'grupo de mujeres' was actually Makenu. 
focus on 'women's rights', my plan was to speak to 'women' who are 'activists' on the island. This is what led me to the women in Makenu. However, I had assumed that everyone who was 'active' on the island would be engaged in land struggles, as the media's portrayal had made the issue seem to be ubiquitously supported among the population. This is not entirely inaccurate, as most people in Rapa Nui do have opinions about Rapanui land, and most would agree that the land, or more explicitly the Rapanui territory, belongs to the Rapanui people not the Chilean state (Delsing, 2009, pp. 94, 206; F. W. Young, 2011, pp. 271, 283). However, I was challenged on these suppositions upon arriving. Sharing time with the women in Makenu made me realise that the 'boxes' I was creating for them to speak from did not seem to quite fit, but rather were filled with a host of assumptions I had going into the research.

Firstly, I assumed 'women's organisations' existed on the island, conceiving this through a western feminist lens, whereby a group of women working together would inherently mean a 'women's group' working on behalf of women, on 'women's issues'. This quickly proved to be fundamentally flawed. While there are many community groups on the island, Makenu is the only 'women's group'. However, while the group consists of mainly all women (48 women and one man) 'women' or 'women's issues' are not the primary concern for Makenu and it is not on behalf of women that they act. Additionally, while they are mainly a group of women, and have even been given the name 'the group of women' (el grupo de mujeres) by the community, they do not stipulate rules or regulations as to who may or may not be a part of Makenu, and anyone who would like to participate is welcome to join.

Secondly, Makenu's engagement on the island was not solely focused on land issues, at least not in terms of where they directed their strategic efforts. As the quote above by Ana articulates, land is important but immigration control is imminent. Tuhiwai Smith (1999) notes that the recovery of territories and indigenous rights are subject to prioritisation which is a selective process often responding to immediate crisis rather than a planned approach, as indigenous peoples are not in full control of their land and territory. This resonates with what this Makenu member was describing; the critical need for control over the Rapa 
Nui territory, to preserve the land for the future generations of children, competing with the ever-pressing issue of regulating immigration.

Spending time with the women in Makenu showed me that their concentration and engagement is centred on immigration control, yet their concerns are more widespread. While land, as we will see further in the following chapters, is fundamental to these concerns and women articulate this point in various ways throughout their stories, it is not the only element of Rapanui resistance and struggle. Rather, it is part of a bigger assertion of Rapanui rights, framed by processes of self-determination and decolonisation that involve efforts for political, social, spiritual, and psychological liberation. Wanting to explore the role of women in Makenu, their concerns and their engagement on the island, and represent their voices and actions honestly and with integrity, meant that focusing only on land was inappropriate and unrepresentative. Recognising the multiple layers of these women's resistance pushed me to change my central focus from land to the broader decolonisation processes in which they are involved, in order to best represent these women's experiences and contributions (Menzies, 2001).

This research was carried out with women in the Makenu Re'o Rapa Nui group, who are between the ages of 35 and 65 years old and are actively engaged in decolonisation processes in Rapa Nui. While this thesis recognises that women within this group will have various perspectives and there are multiple subjectivities within the group itself, it is from this space that they spoke to me about their concerns; how they prioritise, strategise, resist, and challenge the injustices in their lives. As my initial focus was land, I planned to and did speak to many women in the community outside of the Makenu group. These included: three elected/appointed members in the current government in Rapa Nui, two heads of State services, one former political representative, three members of the Hitorangi family, various Chilean academics in Santiago and Valparaiso, and various others who gave their time and shared their knowledge with me. I also engaged frequently in informal conversations with Chilean and Rapanui friends I met on the island. The information shared with me by these contributors helped me to better understand the ways in which the Rapanui society functions. It also helped me to appreciate the variety of perspectives and opinions that exist on the island across a plethora of issues, and to acknowledge that decolonisation is being 
carried out in various ways, in multiple spaces, in different families, groups, organisations and with an array of agendas and priorities.

\section{Creating knowledge}

Qualitative research is concerned with "elucidating human environments and human experiences within a variety of conceptual frameworks" (Hay, 2010, p. 5). As such, I used only qualitative methods for this project. This project does not seek to obtain generalisability or 'truth' but rather wishes to explore and offer more nuanced understandings of how some women engage in struggles in Rapa Nui and what their perspectives are for the future of their island. As such, quantitative methods were not appropriate.

\section{Talanoa}

This method is an appropriate tool for cross-cultural research as it asks researchers to engage closely with indigenous beliefs, protocols and cultural values. It also asks researchers to establish a good interpersonal relationship and rapport with participants. While not all aspects of talanoa were applicable in my research, the underlying values guided me as I moved through the research process.

Talanoa "expects researchers and participants to share not only their time and interests but also emotions" (Otsuka, 2006, p. 2). Talanoa refers to "a conversation, talk, an exchange of ideas or thinking, whether formal or informal" (Vaioleti, 2006). Going into the research I anticipated that I would engage in talanoa with each of my participants (either together or individually) before launching into the research more formally, as talanoa can break down the distance between participants and researchers (Vaioleti, 2006). However I found that most of the women I spoke with were quite happy to 'get down to business' and to tell me their stories without going through the more informal discussions of personal life that I associated with talanoa processes. They frequently would ask, "so, amiga, ${ }^{29}$ what is it that you would like to know?", which caught me off guard as I envisioned we would ease more gently into our discussion. However, while they did not mind

\footnotetext{
${ }^{29}$ This means friend in Spanish.
} 
telling me about their lives in our first meeting, it was only over time and frequent interactions that I was privy to the richer and more personal aspects of their lives and struggles, demonstrating the importance of building trust and respect within research relationships.

I also seek to share and to give back to my participants, which are key concepts in talanoa. As such, I will be writing up a summary of my findings and sending them to the research participants. I also strive to return to the island and present my research at a later stage. As Otsuka notes, "this not only shows the researchers' appreciation to the community, but also shares research findings with the community" (2006, p. 8).

\section{In depth interviews}

Alongside and in conjunction with talanoa, which draws upon the nuances of Rapanui culture, unstructured and semi-structured interviews were also used to generate information in this study. Interviews are "sensitive and people-oriented, allowing interviewees to construct their own accounts of their experiences by describing and explaining their lives in their own words" (Valentine, 1997, p. 111).

I had the opportunity to interview five women in the Makenu group. Some I only interviewed once and others partook in two or three interviews. All interviews were recorded on a digital recorder. A more structured interview followed the initial unstructured interview with the participants with whom I conducted more than one interview. This allowed for me to 'check back' with them to ensure I understood what they were expressing and that the interpretations I was developing from their stories were representative (this is discussed further below in the section on transcribing). By conducting the research in this way, I sought to build strong relationships based on mutual trust, in which more comfortable and open discussions could proceed.

As I attended most meetings and engaged on a variety of levels with these women, I have recordings of conversations and meetings with women who were not interviewed. Therefore quotes in the following chapters are from eight Makenu members, not only the five who participated in 'formal' interviewing processes.

\section{Participant observation}


Participant observation is concerned with understanding worldviews and ways of life in the context of everyday, lived experiences (Cook, 1997). While not originally a planned method of my work (though arguably we all use this method to a certain extent when conducting research) I found myself engaged in participant observation quite frequently during this research process. As I attended all meetings with the Makenu group, both for the group itself, as well as communitywide initiatives, participant observation was often employed. However I was confronted with the limitations that the language barrier presented in most contexts. As most meetings were conducted in Rapanui, or normally a mixture of both Rapanui and Spanish, there were large parts of discussions I could not understand and therefore was also not able to contribute. I did however gain insight into some of the workings of the community using this method as I "[sat] back and watch[ed] activities unfold in front of [my] eyes, recording...impressions of these activities in field notes...drawings, [and] photographs (Cook, 1997).

I also spent a lot of time with these women outside of our interviews. I attended all of their group meetings which were in the evenings twice a week, accompanied them to various community meetings (approximately 10), some of which I recorded, and on occasion, I did more informal "hanging out" (Kearns, 2005), be it at a curanto $^{30}$ or other gathering of family and friends. It was during these times that participant observation was most engaged, with limitation as described above, but where I was able to experience the more 'day-to-day' lives of these women. Through these interactions, our relations grew and allowed for more in depth interviews that were based on respect, trust and a sharing of emotions.

\section{Who I did not speak to}

While conducting this research I was frequently told I should speak to men on the island who play active roles in anti-colonial struggles. As discussed in Chapter Two, Gender and Development literature sees women as agents of change but is concerned with the social constructions of gender that lead to inequalities, insisting that research pay attention to both men and women for successful

30 This is a form of preparing food in which a hole is dug in the ground and hot stones are used to cook what is inside over a number of hours. Common among many indigenous groups, this is called a hangi in Aotearoa and pachamanca in Peru. 
projects to be achieved (Rathgeber, 1990; Razavi \& Miller, 1995). However, I chose not to include men's stories. This thesis is not about uncovering the layers of gender inequity that exist in Rapa Nui or presenting a picture of the complex gender relations on the island, but is rather about a feminist curiosity which asks: where are the women? And what is important to them? (Enloe, 2004). In addition to this, as was discussed in Chapter Two, indigenous peoples - men and women are oppressed by colonialism and they struggle together for their right to selfdetermination. I, as a non-indigenous researcher, am not interested in creating divisions amongst those working towards that goal by comparing or evaluating how men and women engage. For these reasons, this thesis centres Makenu women's voices in its central analysis.

\section{Transcription}

I transcribed the interviews that were recorded verbatim. However I found it an uncomfortable process, as the emotions and passion shared between me and the women was difficult to put on paper. I tried to remedy this by also transcribing the laugher, the tears, as well as the 'ums' and pauses, to remind me of the tone of our conversations, to help me later interpret and translate that which was being shared with me. This seemed essential, as without recalling the sentiment expressed in the interview, translations could be unrepresentative of what the participant wanted to express. Similarly, I have tried to keep the original words of my participants intact within the quotes I present, in order to convey some of this sentiment. While not perfect, I think it gives more life to the quotes I use, and perhaps allows us to more fully appreciate how these stories were happy, sad, frustrated, passionate and inspiring.

I also had assistance with some of my transcriptions from two Chileans. ${ }^{31}$ I asked them to maintain this style when transcribing the interviews. Once they had completed the transcription, I listened again to the interview, putting my own touches into the dialogue where I saw fit, as well as changing anything that was misunderstood by the transcriber as a result of not knowing the vernacular used in Rapa Nui.

\footnotetext{
31 They each signed forms of confidentiality, which can be found in Appendix Four.
} 
In line with PAR approaches to research, I was compelled to be particularly attentive towards issues of representation. In an effort to mitigate some of the power dynamics that are involved in this process, I set out to transcribe as much of the interviews as I could while on the island with the intention of then sharing them with my research participants for feedback. The approach was seen favourably by one participant. She noted:

Yes, it happened to me that... I made a comment that afterwards wasn't good for me. You know? Or it wasn't that it wasn't the truth, but I didn't like the expressions. So, I think it is good if we do as you say (Ana-2).

While this was my intention, my timeframes did not allow for this to come to full fruition for all participants as I had hoped, and I had to alter my original plan. While some of the participants received an abridged transcript of this while I was on the island, which included key points, quotes and a summary of the conversation for them to comment on, again my time was not adequate to make this happen for everyone. Upon returning to Aotearoa and transcribing the remainder of my interviews, I sent full versions via email to the members of the Makenu group who engaged in recorded interviews with me, and provided a summary including quotes and key concepts I took from our time together. This was to provide an opportunity for them to correct anything I had not understood correctly and to provide any additional information as they saw fit. No one made any comments or corrections to what I gave them.

Committed to self-representation for these women, I decided to include the original Spanish quotes in this thesis. I originally thought to leave them in the body of the text, so that those versed in Spanish could read and interpret from the original source. However, I found this made the stories difficult to read as there was so much text in between their quotes and my analysis it led to a less fluid presentation. Therefore, the Spanish versions of the quotes used can be found in Appendix One. To determine which quote corresponds to the one in the body of the text, when citing the women, I give each quote a consecutive numbering so they can be easily found in the appendix. These numbers therefore do not correspond to the quote number of that particular woman, but rather to the total number of quotes presented up to that point in the thesis. As this research is sensitive and I 
was unable to obtain permission for all participants for the use of their names in this work, I have opted to use pseudonyms. Unfortunately, I did not ask the women what name they would like me to use when identifying them, so the names presented here are of my choosing.

\section{Language}

Vanaya Rapanui is the indigenous language of the Rapanui people. Colonised by Chile, Spanish is prolific on the island, and increasingly the language used in daily life, especially among the youth (Makihara, 2005b). Having lived in other parts of Latin America at various times in my life (however, never in Chile and never in Rapa Nui) and learnt Spanish, I have a decent grasp of the Spanish language. I believed my Spanish skills were sufficient to carry out this research without the aid of an interpreter. This was important to me, as I saw the use of an interpreter as disruptive to the type of research I sought to undertake. Building relationships would have been more difficult if I could not converse independently and the richness of my interactions would have been limited (Devereux, 1992). And as Bujra (2006, p. 175) described in her experience, there is potential risk of "the rich flow of words [being] reduced to a desert".

However, it was the language of the coloniser that I was employing to conduct this research, not the local language. While I would have preferred to learn Rapanui and then carry out my research, this was unrealistic given my timeframes for conducting Master's research. At the very least, as Apentiik and Parpart (2006) suggest, I made every attempt to use the few Rapanui words I knew, particularly when greeting people. I wanted to show my respect and demonstrate that I knew 'where I was standing'.

Those in the Makenu group who spoke English always preferred to use English with me instead of Spanish (which I interpreted as a small act of resistance against colonial impositions). Most meetings were held in Rapanui and it became clear that Spanish was not the preferred language of discourse for all members of the group (but was the only language for others). So, while I believed I was breaking down barriers by engaging in a local language, having a translator perhaps would have been preferable in some instances, so that these women could have spoken to me 
in their language; the language that is the keeper of their embodied experiences, and thus a more appropriate outlet for expressing their lives.

Spanish was important for my daily interactions. It helped me develop a deeper understanding of the community and the environment I was in, as well as building rapport with these women. However, I recognise that my position as a non-native, Spanish speaking researcher engaging in research on the island brings problems with regards to my interpretation and representation of women in Makenu. The host of issues that emerge through these interactions means I will unavoidably make my mark on the voices I seek to represent in this study and will do so in complex ways. However, I have tried to mitigate this as best I can through executing utmost care and consideration when translating the stories in the following pages, and through the methods chosen to conduct this research.

\section{Translation}

All of the translations from Spanish to English in this thesis are my own. This process has occurred simultaneously to writing up, however these translations never seem to be complete, as the longer I reflect on the Spanish text the more layers of meaning emerge. This has been a continual process of fidgeting with words, adding, subtracting and agonising over what participants 'really' wanted to say and how I can best articulate those meanings and most appropriately represent their voices. "The translator...makes assumptions about meaning and equivalence that make her an analyst and cultural broker as much as a translator" (Temple \& Young, 2004).

As this chapter has shown, in the various aspects of carrying out this work - from my time in the field, to the analysing and the writing up, and final product - my role as a researcher has been integral and heavy handed. I hope this section, while highlighting the power I wield as the mediator between the voices of these women, filtered through my own worldview, history and personal experiences, and presented to you, the reader, who will once again filter, process and interpret, has also demonstrated my commitment to mitigating these power relations through a decolonising research practice, in which I strive to present my participants voices as representatively and ethically as possible, with the utmost respect, empathy, and cultural sensitivity. 


\section{Chapter Four: Rapa Nui - A history of resistance}

The past, our stories local and global, the present, our communities, cultures, languages and social practices - all may be spaces of marginalization, but they have also become spaces of resistance and hope (Tuhiwai Smith, 1999, p. 4).

\section{Introduction}

To understand the voices that are privileged in the second part of this thesis, and to appreciate the context from which they speak, this chapter seeks to provide an historic background to their claims. It has three parts. Firstly, it describes the precolonial period in order to foster understanding of the cultural and societal arrangements prior to European contact. To gain appreciation for Rapa Nui's colonial past, it then discusses some of the events and processes that occurred with the arrival of missionaries and businessmen, and the Chilean annexation of the island. Secondly, it presents more recent political processes and structures apparent on the island within the contemporary setting in order to conceptualise the environment in which Makenu women engage in Rapa Nui in their 'decolonisation for development' struggles. Lastly, I describe how Rapanui women have been involved in anti-colonial struggles in the beginning of the $20^{\text {th }}$ century up until the present day. Through this, I seek to acknowledge women's roles in these processes, while setting the scene for the women in Makenu Re'o Rapa Nui whose stories are centred in the following chapters.

\section{Section One: Pre-contact and early contact period}

\section{Te Pito o Te Henua}

Rapanui's pre-history is not an easy terrain to navigate. Written accounts of oral history (some of which were written down over a long period of time and even as late as the 20th century) provide a patchy understanding of ancient culture, beliefs and events that occurred on the island prior to European contact. The accounts were recorded by explorers, archaeologists, and ethnographers all coming from foreign lands and reconstructing the ancient life of Rapa Nui through their 
particular worldviews and understandings of place and time. Most significant in helping to develop these stories are individuals such as Alfred Metraux, a Swiss ethnographer; Katherine Routledge, an English archaeologist; and Father Sebastian Englert, a German Capuchin priest. However as Metraux (1940, p. 40) notes, "there is no other Polynesian island whose past is so little known as that of Easter Island".

Like most Polynesians, the people of Rapa Nui were explorers; great navigators of the South Seas. The story of how these Polynesian people came to inhabit an island in the middle of the Pacific starts with the legend of the first ariki mau (king) Hotu Matu'a, and his arrival at Anakena on the north coast of the island (Barthel 1978; Englert 1974; Metraux 1940; Routledge 1919). The dates of his arrival and the original colonisation of the island remain controversial. However, it is thought to be somewhere between the sixth and eighth-centuries AD (Fischer, 2005) with some putting it as far back as 300 or 400 AD (Van Tilburg, 1994) and others as late as $1200 \mathrm{AD}$ (Hunt, 2006). Some accounts say Hotu Matu'a had to leave the homeland of Hiva because he lost a great battle; others talk of a tsunami that submerged the land, forcing the people to search for new beginnings. Whatever the cause, the people of Hiva landed on one of the most remote places on earth - which they called Te Pito o Te Henua, or navel of the world.

It is said by the Rapanui people and scholars alike that the most important act of Hotu Matu'a (whose name literally translated means, 'the Great Parent') was his division of the land (Consejo de Jefes de Rapanui \& Hotus, 1988; Sebastian Englert, 1970; Metraux, 1940). ${ }^{32}$ The land was distributed into kaina (territories) ${ }^{33}$ based on patrilineal clans or mata. Approximately ten mata ${ }^{34}$ comprised of ure, or large sub-groupings of descent groups or lineages/tribes, claimed rights to specific territories and estates (Consejo de Jefes de Rapanui \& Hotus, 1988; Fischer, 2005) where they enjoyed a semiautonomous administration of their affairs (Sebastian Englert, 1970; McCall, 1976). Ure were well defined by their residence on the

\footnotetext{
32 According to Delsing (2009), the story of Hotu Matu'a, and the settlement of the island, is well known by young and old Rapanui alike. Each year at the Tapati festival they re-enact this important historical event.

33 Kaina was divided into rectangular shapes and was well defined by pipi horeko, which delineated the borders of the land specific to each clan (C. Cristino, et al, 1984; Sebastian Englert, 1970; Sebastian Englert, 2004 [1948]). McCall (1976, p. 30).

34 This number remains controversial.
} 
island, including where they produced, subsisted and enjoyed life, and were symbolically demarcated by the monolithic statutes the people called moai (Consejo de Jefes de Rapanui \& Hotus, 1988).

Along with their language, customs, beliefs and social structure (Fischer, 2005), it has also been suggested that at some point in the island's development, land division followed Polynesian pie-shaped settlement patterns (Delsing, 2009; Metraux, 1940). Strips of land extended from an inner island point out to the coast, thereby allowing for the concomitant consumption of land and sea resources for islander subsistence. ${ }^{35}$ This division of resources and corresponding division of labour ${ }^{36}$ produced the structure of the island's socio-economic interactions, which were maintained by the omnipotent ariki mau and high ranking individuals such as the nobles or lords (ariki), priests (ivi-atua), and warriors (matato'a) (Metraux, 1940) who by perpetuating a complex system of mana and $t a p u^{37}$ maintained the hierarchy of authority over the inextricably intertwined religious and political spheres. These coherent philosophies sustained social cohesion and the delicate social and environmental balance on the island. The system of tapu was related to the age of a person (seniority), gender, and clan affiliations (Delsing, 2004, 2009) which articulated the rules and restrictions of everyday life, and in turn helped govern the discrete kaina that each clan controlled and managed. Describing how mana and tapu came together to form the social code adhered to by the Rapanui, Castro (2006, p. 29) notes: "The ancestor created the prohibitions (tapu), without which social-cultural order would not have been possible. But the ability to establish these tapu lay in the mana that the ancestors had acquired and transmitted to the clans (mata) and lineages" (my translation).

From approximately 1000-1500 AD the island was in what is called the Ahu Moai phase, defined by the monolithic statues carved in an expression of ancestral worship, creating the large stone heads in which Rapanui is renowned. It is likely

35 Rochina-Ramirez (1993) purports, however, that the island interior is considered communal while the coastal territories were restricted to particular clans.

36 Fischer (2005) notes that the specialisation of the matas, that being agriculture or fishing, would have been fully developed by the fifteenth century at the latest.

37 Mana and tapu are not easily defined in English. They take on different meanings depending on the context in which they are being used and their complexity and meaning is fundamental to most Polynesia worldviews. Mana can be seen as a person who holds power, moral authority and prestige and Tapu can mean sacred or forbidden. 
that climatic factors as well as an unsustainable population growth on the island led to the loss of ecological as well as social balance. Many theories have emerged in an effort to understand and explain what happened in Rapa Nui that led to the extreme environmental and cultural downfall. There are some who have highlighted the climatic factors (a possible mini-ice age in the $16^{\text {th }}$ century) and the ravaging of scarce resources on the island which led to social upheaval (Bahn and Flenley, 1992; Diamond, 2005). Others discuss and believe that an ecological disaster did occur, while emphasising the atrocities that came with European contact, such as slavery and disease, as key components of the societal collapse (Fischer, 2005; Hunt \& Lipo, 2009).

The Ahu Moai phase was followed by the Huri Ahu (1500-1722) phase, or decadent phase (Kirch, 1984). The population, no longer consumed by the building of moai to venerate their ancestors, (potentially as a result of resource depletion) became engaged in a community-wide ritual that would come to decide their religious, political and social order. Worship of the sooty tern bird and the competition that accompanied it was what the Rapanui called, tayata manu, ${ }^{38}$ or the birdman ${ }^{39}$ which became the main system of organising up until the arrival of missionaries in the middle of the $19^{\text {th }}$ century.

As had occurred in the rest of the Pacific, explorers, slavers, entrepreneurs and missionaries all had important roles to play in the complex story of the Rapanui people and their evolving history. However, the state of Rapanui affairs at the time of contact made them particularly susceptible to outside influences. In addition, their remote isolation did not prepare them for external influences that were about to change their way of life in severe and complicated ways.

381866 was the last time tanata manu was held in the ceremonial village of Orongo, and it was the Catholic Church rituals that replaced it (Delsing, 2009).

39 This is an annual competition whereby each mata would put forth their competitor to fight for the honour of being the temporary secular and spiritual leader. The new secular rulers of Rapanui (the matato'a) challenged the legitimacy of the ariki mau and tried to wrestle power away from the Miru mata. "The extraordinary challenge toppled the island's ancient 'pantheon' of leading ancestral deities, replacing these with a single, all-embracing godhead. It also brought about a remarkable ritual that, through an annual 'sports' competition, heralded a new socio-religious culture. Yet ultimately neither innovation was to succeed wholly in wrestling complete authority away from the ariki mau (Fischer, 2005, p. 57). 


\section{A stolen sovereignty: Slavers, missionaries and Bornier}

Rapanui's first known encounter with Europeans was on Easter Day ${ }^{40}$ in 1722 when Jacob Roggeveen, a Dutchman, landed on the island. Word travelled about the land with the large stone figures and combined with the convenience of its location as a stopover for supplies, the island soon became popular for ships passing by. Between 1722 and 1862, 53 ships established contact with Rapa Nui (C. Cristino \& Fuentes, 2010). This continuous process of visitors to the island slowly grabbed Rapa Nui from its centuries of isolation and pushed it into the global political sphere of influence. ${ }^{41}$

Jean Bapiste Onexime Dutrou-Bornier, a French mariner and advocate for Rapa Nui to become a protectorate of France, first set his eyes on Easter Island in 1860. By 1866, Bornier had returned ready to take control of the people and resources, recognising the possibilities that existed on an island with no clear European jurisdiction. While the arrival of Bornier marked the beginning of a tumultuous time in Rapa Nui history, the island had just a few years prior been subjected to slave raids that ravaged the island population. ${ }^{42}$ These raids had gone on for a number of years. The fatal blow was in 1862 when Peruvian slave ships captured and kidnapped over 1000 islanders (Porteous, 1981), out of a population of only 3000-4000 (McCall, 1988). ${ }^{43}$

It is generally believed that most Rapanui (about 90\%) taken during the slave raids died within the first year or two due to appalling conditions both on the way to the mainland and once labouring on the plantations (Porteous, 1981). Included amongst the kidnapped were the noble and priestly class - the holders of ancient knowledge and customs. In a society with such a strong political hierarchy, certain knowledge, such as the knowledge required to read the script of Royorono, ${ }^{44}$ was bestowed upon only the most worthy and the most noble. When these individuals

\footnotetext{
40 Hence the name Easter Island in English, or Isla de Pascua in Spanish.

41 For firsthand accounts from the explorers who visited the island during the initial contact period see: Gonzalez (1770), Cook (1774), and La Perouse (1786) among others.

42 Slave raids were happening across the Pacific, not only in Rapa Nui. However, as Rapa Nui is the closest to Peru, it was a prime target.

43 Though McCall has in previous work asserted that this could have been half of the population at the time (McCall, 1976).

44 This is the Rapanui script, which consists of glyphs that have not yet been fully deciphered.
} 
left the island, so too did the collective, cultural-historic memory of the people, leading to a social, political and cultural collapse. ${ }^{45}$

The atrocious conditions endured by the Rapanui in Peru ${ }^{46}$ and the decimation of the population led some with power (namely the British and French) to persuade the Peruvians to stop pillaging the Pacific for labourers, and begin assembling the remaining few for repatriation (Porteous, 1981). ${ }^{47}$ The Peruvian authorities, heeding their calls in 1863, gathered the remaining Rapanui. Out of the approximate 1000 that were forced into slavery, only 15 or so were found alive and brought back to their motherland (McCall, 1994). However those repatriated back to the island brought with them the contaminations of the 'civilised' world. Islanders, who in their isolation were protected from such disease, were now confronted with small pox, tuberculosis and other diseases, with no immunities to combat them leading to a full scale pandemic.

Within a year of the slave raids and just prior to Bornier, the missionaries arrived on the island. Hearing about what was happening on Rapa Nui, both fact and fiction, Father Eugene Eyraud made his first trip in 1864. Christianisation missions were occurring all over the Eastern Pacific by a French missionary order known as Sacred Heart (Porteous, 1981) and in 1866, two more missionaries followed, solidifying the mission to the island (McCall, 1994; Porteous, 1981). By this time, as a result of the raids from four years prior and the diseases that were ravaging the island, the population hovered just over 1000 people (McCall, 1994). A struggling population, vulnerable as a result of the multitude of calamitous events in their recent history, meant that the Rapanui, whether of genuine accord or as a means of attaining basic necessities, were easy converts for the recently arrived Sacred Heart Catholic missionaries. ${ }^{48}$

45 When collapse is talked about in reference to Rapa Nui, I think of this time period (late 1800s) rather than what Diamond, Flenley and others call the 'collapse' - referring to the environmental degradation that occurred during the Ahu Moai phase.

46 This was inclusive of all the Polynesian people that had been forced to labour in Peru, not only the Rapanui. It was a French ship that would eventually bring them back to their islands, scattering them among the Pacific (McCall, 1994).

47 Porteous (1981) also points out that the repatriation of the Rapanui was given very little thought, and in fact some were even returned to Tahiti rather than to Rapa Nui.

48 As McCall (1994, p. 59) also notes, "in common with other Evangelists elsewhere in Polynesia, the missionaries pursued a strategy of sustaining both the material and spiritual needs of their struggling flock". 
There has not been much work that has discussed the gendered aspects of the missionising process that occurred in Rapa Nui and the consequences this has had on gender roles and dynamics on the island. ${ }^{49}$ However, Kahaleole Hall (2008) has suggested that regardless of the nature of the pre-colonial status of women within any given indigenous society, there is no question about the negative consequences that came about as a result of European missionaries. Also, the struggling Rapanui population, it has been asserted, would have been more easily converted by the missionaries as a means of survival (see Delsing, 2009; McCall, 1994). Like Kahaleole Hall, St Denis (2007) has contended, with regards to indigenous peoples, that colonialism and Christianity, through day-to-day practices, produced and reproduced ideologies about what it means to be a woman or a man, based on Christian notions, which are profoundly patriarchal. With the widesweeping conversions that took place, it can be assumed that aspects of these processes would have been occurring in Rapa Nui.

Bornier came to the island with a clear picture of what he wanted from the land and its people. The land of Rapa Nui, not rich and fertile like the islands found in the Western and Central Pacific, he thought would be better used to rear sheep than for agricultural production. He also thought the people would make good labourers for the plantations in Tahiti where his business associate resided. These were Bornier's two goals - to rid the island of the people and to claim control over the land for his sheep to roam (Porteous, 1981). Bornier obtained land on the island in 1868, just south of the missionary estate. Along with Brander, a Scottish resident of Tahiti and Bornier's business partner, ${ }^{50}$ the two of them purchased Mataveri, a sacred place of indigenous knowledge, located at the foothill of Rano Kau where the ascent to the ceremonial village of Orongo occurred each year until the $1860 \mathrm{~s}$ (it is now where the airport resides). This commenced the establishment of the sheep ranch and the beginning of Bornier's reign on the island.

With both the missionaries and Bornier vying for control of the island, tensions arose. This increased divisions between Rapanui who had been Christianised and

49 (see Arredondo, 2000a, 2000b; Delsing, Largo, \& Arredondo, 1998; Grifferos, 2000a for the work done relating to gendered aspects of Rapanui culture and society).

50 The Brander family was a Tahitian-based family who partnered with Dutrou-Bornier and is thought to have provided most of the capital for the sheep ranch (Porteous, 1981). 
those who had not, amongst the already divided Rapanui population. The missionaries who, for their purposes, had succeeded in their mission from 18651871, now intimidated and unable to defend themselves, nor able to carry out their mission work, were recalled from the island and finally departed in 1871 taking most of the Rapanui population with them (Delsing, 2009; McCall, 1994; Porteous, 1981). With no white catechist left on the island ${ }^{51}$ the governing of the Rapanui was left in the hands of Bornier and Brander, to carry out their plans for the island unabated. Forming a legal partnership in 1871 they embarked on the exploitation of the island through sheep farming and Bornier, establishing a Polynesian monarchy with his Rapanui wife, became the self-proclaimed king of the island (Delsing, 2009; McCall, 1994; Rochona-Ramirez, 1993). ${ }^{52}$ When Bornier was killed by Rapanui workers in 1877, there were little more than 100 people left on the island (Porteous, 1981).

\section{The annexation of 1888}

The ambitious Naval Captain Policarpo Toro Hurtado, looking for the prestige of securing a colony for Chile, and recognising the potential of the island's land for private business endeavours, petitioned Chile to acquire the island from the Tahitian company, still in the hands of Brander (McCall, 1994; Porteous, 1981). After a laborious process of negotiating with French political authorities, to achieve his mission of purchasing the landholdings from the Easter Island proprietors, Toro annexed the island in the name of Chile on the $9^{\text {th }}$ of September 1888 (McCall, 1988). The annexation documents, still being contested to this day, consisted of two parts; both written in Spanish as well as 'some form' of Rapanui. The Proclamation declared the cession of Rapa Nui to Chile. The Spanish version of the treaty is very clear, stating that the Chiefs "declare cessation forever and without reservation to the government of Chile, the sovereignty of the whole island" (Hito, 2004, pg. 3) and through the Acuerdo de Voluntades (Agreement of Wills or Treaty), the Chilean government promised the Rapanui education and development (Delsing, 2009). However, the commonly understood version on the

51 As Porteous states (1981, p. 16), "no permanent white ecclesiastical representative was to arrive until well into the $20^{\text {th }}$ century".

52 With the departure of the missionaries some aspects of the past were restored. The Orongo returned as a yearly event and wood carving by the Rapanui for trade with passing ships was re-established after being banned by the missionaries (McCall, 1994). 
part of the Rapanui is best illustrated by a story. Atamu Tekena, ${ }^{53}$ the ariki at the time, reached to the ground and pulled up a handful of grass, handing it to the navy officer. He then took a hand of earth from the ground and placed it in his European garment. This gesture, still vibrant in Rapanui oral tradition, indicates that the Rapanui had a profound understanding of what the annexation meant or should mean; the Chilean government could keep whatever was grown on the ground, or could use the land for their animals in exchange for friendship and protection. The land, the territory, the kaina, was not theirs to keep, but belonged to the Rapanui.

\section{Merlet and La Compañía Explotadora de la Isla de Pascua}

Around this time, Chile had also been negotiating with Brander to purchase the Brander-Bornier landholdings on the island. However, with internal problems, varied opinions about the value of the island and a weak government, Chile could not make decisions about its newly acquired territory (Porteous, 1981). The use of a private intermediary to manage the island was becoming the preferred means of control and by 1895 the proposal of Enrique Merlet, a Chilean businessman, to lease government lands was accepted by an impatient Brander ${ }^{54}$ (C. Cristino \& Fuentes, 2010). With Merlet ruling the island without interference, the Rapanui who had not come into Hangaroa under the guidance of the Christian missionaries, were rounded up at gunpoint and forced into the town centre. Their animals were confiscated and their plantations were destroyed (de Estrella, 1920; McCall, 1988).

The policy of leasing land and allowing private businesses to control the island without interference was a consistent theme in Chilean/Rapanui relations, and one that would carry on for the next 60 years. Merlet's "reign of terror" (McCall, 2000) came to an end when he went bankrupt and sold out to British interests - a company called Williamson Balfour, which created a subsidiary: La Compañía

53 Metraux (1940) and Conte Oliveros (1994) note, Atamu Te Kena Maurata was made a 'king' by the Bishop of Tahiti, Tepano Jaussen. Jaussen needed someone on the island to represent the interests of the missionaries.

Chile insisted that Merlet maintain contact with Chile and that three settler families were allowed to stay on the island to carry on the colonial base. Merlet intended to claim ownership over all the lands on the island, but was unsuccessful (McCall, 1988). However, Porteous notes that the BranderBornier estate, in conjunction with government lands, would have constituted nearly the whole island (Porteous, 1981). 
Explotadora de la Isla de Pascua (CEDIP) that would control the island until 1953,55 and was the effective sovereign of the island. ${ }^{56}$ Continuing to run the island as a sheep farm, CEDIP had the Rapanui build a fence around the township of Hangaroa, fencing themselves in so that the sheep could roam freely on their ancestral lands while they were unable to leave the township without written permission from the company until 1966. The Rapanui were imprisoned on their own island for over fifty years.

\section{Section Two: Chile's more recent engagement}

Our island has always been autonomous. The little development that you see is not due to the Chilean state. Every person that owns a bedand-breakfast, a hotel, has acquired it by his/her own sweat and blood. And now the state wants to regulate how we function? How can they regulate if they never help us? This is our history and every child of this land wants justice. This justice will come and that is why we have to be able to put order to things. No decisions about Rapa Nui should be taken from the continent. Our territory should be claimed. Look, this land is our mother, and the territory is our father. It consists of all of Rapa Nui, air, sea and land... (Erity Teave cited in Delsing, 2009, p. 274).

Chile's involvement in Rapa Nui since the time of annexation, while having vast impacts on Rapanui lives, customs and culture, was somewhat disconnected and uninterested. This drastically changed starting from the 1960s, with the Chilean state taking a much stronger interest in the island's affairs and seeking to incorporate the island into the national project. While Chile has signed international agreements and instituted laws since, which proclaim their recognition and commitment to respecting cultural difference and the rights of indigenous peoples, the island of Rapa Nui still functions within a highly centralised nation-state apparatus in which Rapanui peoples' right to selfdetermination remains a constant struggle. This struggle is a central component in the decolonisation of the Rapanui. Zanotta (1994) contends that the majority of indigenous movements in Latin America are not seeking independence but rather

\footnotetext{
55 At which point Chile took control of the island, and managed it through the Navy.

56 The company was registered on the $30^{\text {th }}$ of July 1903 for an initial period of 25 years (Porteous, 1981).
} 
demand recognition of their cultural rights, including the right to an autonomous way of life in which their cultural difference is respected and can be fostered within their territory. The issues identified within Makenu's decolonisation agenda resonate with Zancotta's articulations pertaining to culture, identity and right to territory; to achieving aspirations to develop and grow in ways that are consistent with and respectful of indigenous ways of being, knowing, and doing in order for healthy, strong communities to exist in the future.

In 1933, Chile inscribed all the land on the island and in 1953 decided it was time to more formally involve itself in the territory, having left it in the hands of private enterprises for the previous 65 years. With the departure of the La Compañía Explotadora de la Isla de Pascua, the island was run by the Chilean Navy. However the conditions on the island did not improve. As McCall (2000, p. 88) notes, "such an arbitrary and draconian system could not continue indefinitely" and Rapanui struggles (discussed in the following section) eventually brought some justice to the Rapanui people. In 1966, Rapa Nui became fully incorporated into Chile. ${ }^{57}$ Restrictions were removed, allowing the Rapanui to leave the Hangaroa township, elections were held and a special law was created providing a series of benefits to spur development on the island (McCall, 1995). Nearly 80 years after annexation, Rapa Nui formally became part of the Chilean nation-state.

\section{Ley Pascua of 1966 (Easter Island Act)}

Gomez (2009, p. 63) argues that it was not until after 1966 that the island was effectively colonised, "or that the process of colonisation truly started from a legal perspective", also noting that political decolonisation was occurring in colonies all over the world, including parts of Oceania, while Rapa Nui was pushed deeper into the colonial enterprise. The new laws imposed upon the Rapanui starting in 1966, while of benefit in terms of alleviating the poverty and destitution that typified the island prior, also brought Chilean influence into the lives of Rapanui more strongly than ever.

Law 16.441 or the Ley Pascua was passed in 1966, under the Christian Democrat government of Eduardo Frei Senior (President 1964-1970). The law mainly refers

57 In 1966, the wall came down in Hangaroa and Rapanui became Chilean citizens. More details about this are in the following section where a concentration on women's role is presented. 
to administrative aspects of governing the island and two of the most important aspects of this new law pertained to Rapanui status as Chilean citizens and their legal right to vote. While the law was supposed to create greater equality between Rapanui on the island and Chilean citizens on the continent, Delsing (2009) has argued that focusing on this equality has disregarded the very real inequalities that exist in daily life. Some examples she offers are important for understanding how this law opened up Rapa Nui to greater Chilean influence. These include: advantages allocated to Chileans who serve on the island in government posts with an increased salary of $200 \%{ }^{58}$, and Chilean (as well as Rapanui) exception from property and income tax - the only part of Chile where this is enjoyed. ${ }^{9}$ While provisional land titles had been granted under the Navy in $1917^{60}$ it was from the Ley Pascua and carried on by the Ley Pinochet that titulos de dominio (land titles) were instituted, introducing individual private property on the island and the granting of land rights to Rapanui and non-Rapanui alike (Delsing, 2010).

The Law, while creating more problems culturally than it resolved, did open up the island to economic development opportunities and infrastructure, though of course these were implemented based on Chilean aspirations for the island, not Rapanui development goals. Post-1966 the island experienced a number of important changes. With the arrival of the American Air Force Base, the Mataveri airport facilities were enlarged, opening Rapa Nui to an increased flow of goods, services and cultures between the island and other parts of the world. For an island that had not had any contact with the outside world besides one annual ship from Valparaiso each year, a weekly air service from Santiago and later Tahiti was significant (Porteous, 1981). Within one year substantial changes transformed the island. Chilean functionaries, American military and Chilean workers (approximately 750) all arrived (Delsing, 2009). The population between 1952 and 1970 rose from approximately 800 to over 1600 (Porteous, 1981). Chile, wanting to incorporate Rapa Nui into the mainstream of national life, had an elaborate plan

58 She also notes that Rapanui hardly had the chance to become professionals given their situation, and that the first of the Rapanui to gain a secondary level education did not leave the island until 1955.

59 With the passing of the law 300 Chilean nationals, mostly functionaries and their families, arrived on the island to institute the new administrative system for a population which at the time was less than 1000 people (Delsing, 2009)

60 For more about land titling, processes and concepts of Rapanui land, see (Gomez, 2009; RochonaRamirez, 1993; Vergara, 1939; F. W. Young, 2011). 
for social services, transport, housing etc. (Porteous, 1981).61 Tourism also began during this time. All of these introductions impacted Rapanui lives in new and unprecedented ways.

\section{Privatisation of land}

...Yearning to see Rapanui land as the property of all and every Rapanui...it is the longing of three generations to see the land returned to our patrimony. If we have entered this westernized game that consists of an individual system of property, which in a certain way goes against our ancestral customs, we have done so because it is the only thing we can do to appease the clamour of our people... (Miembros Rapanui de la CODEIPA 2005, cited in Delsing 2009, pg. 249).

In 1973, with the military coup that overthrew the democratically elected president of Salvador Allende (1970-1973), a military junta came to power in Chile (1973-1990). The junta was eventually dominated by Augusto Pinochet, an obsessive nationalist and expansionist. Pinochet sought to homogenise and integrate the population into the Chilean nation-state, paying particular attention to the most isolated areas of the country. In 1976, he visited Rapa Nui, handing out 182 land titles to islanders, suggesting that Rapanui feel more Chilean and seeking to strengthen Chilean claims to the island (Delsing, 2009).

Land was again an important area of concern, and in 1979 he issued decree 2885, known as the Ley Pinochet, in which land distribution was imposed on the islanders as part of a bigger policy of agricultural land privatisation the dictatorship was instituting on the continent (see Murray, 2002; Murray, 2006). This law triggered controversy amongst the Rapanui population, as the concept of individual private property was contradictory to customary land tenure arrangements. ${ }^{62}$

Some Rapanui were in fact in favour of the decree, most notably those who at the time were strongly involved in tourism, recognising the potential that individual private property allowed them in terms of business ventures. However, as Delsing

61 In 1969 the first development project was drafted by Chilean government institutions and twelve ambitious projects in total were developed between 1969 and 2002, with few having been accomplished (Delsing, 2009).

62 For discussions pertaining to land on Rapanui, the misinterpretations of Rapanui concepts and understandings of tenure arrangements, and Chile's involvement see (Gomez, 2009; F. W. Young, 2011). 
(2009, p. 171) noted, "the introduction of individual private property constituted not only a cultural but also an economic disruption". Those that were not in favour rallied around the Consejo de Ancianos (the Elder's Council) who sought to continue Rapanui social and economic arrangements based on systems of reciprocity and exchange between families (Delsing, 2009). While there was some disagreement over whether the decree was positive or negative, most if not all Rapanui oppose the idea that the land and territory belong to Chile - a feeling that continues today.

\section{Ley Indigena}

By the 1990s an assertion of rights through cultural difference became the centre of Rapanui struggles. This change in focus is illustrated through the introduction of the Ley Indigena (Indigenous Law) in 1993. This coincided with the transition in Chilean politics back to a democracy in 1990 (see Barton \& Murray, 2002). Instituted by the Chilean congress and President Patricio Alywin, its purpose was to recognise the cultural differences of indigenous populations throughout the Chilean nation-state, as opposed to the Ley Pinochet which strived for assimilation and homogenisation.

The law legislates about culture, development, education and participation. It recognises indigenous peoples as "the descendents of human groups that have existed in national territory since pre-Colombian times and that have preserved their own forms of ethnic and cultural expression, the land being the principal foundation of their existence and culture" ("Ley Indigena," 1993). It stipulates that indigenous peoples are the owners of indigenous lands, and that land can only be transferred between native Rapanui. While still adhering to concepts of individual private property, it is the first time Rapanui are named the owners of their land. It also created the National Corporation for Indigenous Development (CONADI), and in the case of the Rapa Nui it created CODEIPA - the Easter Island Development Commission. ${ }^{63}$

\footnotetext{
63 While the Development Commission was created within the Indigenous Law of 1993, as a result of a disagreement between the Elder's Council, CODEIPA did not materialise until 1999 after elections were held in the Council in 1998 (Delsing, 2009).
} 


\section{Development Commission}

CODEIPA was established to cooperate with Chilean institutions, particularly regarding the execution of development projects pertaining to cultural and archaeological patrimony as well as making recommendations to the State about the use and distribution of land. ${ }^{64}$ In 1999 the Development Comission gave plots of five hectares to families, in what was called the first entrega. The second entrega is currently being deliberated within the commission, as they seek to improve the method of returning land to those in need. ${ }^{65}$

CODEIPA is also the only body on the island where Rapanui are directly elected by fellow Rapanui.66 The law also recognises the Elder's Council as the indigenous representative body on the island, and the president has a seat in CODEIPA. CODEIPA is made up of Chileans and Rapanui: seven representatives of the Chilean ministries that operate on the island, plus the appointed governor, the mayor, the head of the Elder's Council and the five members elected by the Rapanui community ("Ley Indigena," 1993). ${ }^{67}$

While women hold many of the appointed positions on the island, ${ }^{68}$ they have had less success within elected positions. In 2011, about a month before my arrival in Rapa Nui, elections for the Development Commission were held. ${ }^{69} 1,248$ votes were cast ("Nueva sangre para viejos problemas," 2011) marking an historic level of participation for the island (Leal, 2011). There were 37 candidates, 13 women and 24 men (Leal, 2011). One woman was elected out of the five potential

64 Delsing (2009) notes, that it is land that is the thread through all Rapanui development projects. Also, it was frequently noted that the CODEIPA has little power as it cannot make decisions but can only recommend courses of action.

65 Many issues arose from the first entrega and none of the people I spoke to thought it was handled properly or distributed well, heavily criticising the subsequent land sales that occurred. This was not the goal of the entrega.

66 The mayor and municipal council members are elected as well, but both Rapanui and non-Rapanui can vote within these elections. The Development Commission however can only be elected by native Rapanui.

67 The mayor and municipal council members are also elected as well, but both Rapanui and nonRapanui can vote within these elections. The Development Commission however can only be elected by native Rapanui.

68 See Appendix Six: A table with the positions held by women and men on the island during my time on the island is presented. The majority of the department heads are women.

69 They were held $12^{\text {th }}$ of June 2011. 
positions being contested, making Anakena Manutomatoma the second woman to sit on the Development Commission since its inception in 1999.

\section{The Consejo de Ancianos}

The Consejo de Ancianos (Elder's Council) was created in 1980 in response to the Ley Pinochet. Alberto Hotus was the first president of the Council and is still its leader today. Hotus contends that members of the Council are the continuation of the chiefs on the island at the time of the treaty signing in 1888 (Delsing, 2009). ${ }^{70}$ Consisting of one representative from the 36 families on the island, the Council is the tribal representation of the Rapanui people and is recognised by the Chilean state as the Rapanui authority on the island. ${ }^{71}$ The Elder's Council, in past years in particular, has been a strong oppositional voice on the island, constantly making legal claims and developing arguments for the restitution of Rapanui land to the people, asserting traditional ideas of collective ownership. ${ }^{72}$ Divisions in the group started with concerns surrounding the Ley Indigena, and a portion of the Council split off from this group, forming a new group - the Elder's Council dos, which then later formed into the Parlamento Rapanui in 2001.

70 Delsing (2009) however notes that this is not supported by oral history or written accounts.

71 It was often noted that this institution has long been corrupted by the State and very few felt represented by it. Comments were made that maintaining the Council was desired by Chile as the Council was in theory supposed to represent the population, but in reality was more and more representative of Chilean interests.

72 In 1988 the Elder's Council wrote a book called Te Mau Hatu'o Rapa Nui: Los soberanos de Rapa Nui. Pasado, presente y futuro (Consejo de Jefes de Rapanui \& Hotus, 1988) whereby they assert their right to all of the island by tracing the genealogical connections of the 36 families to their corresponding kaina. 


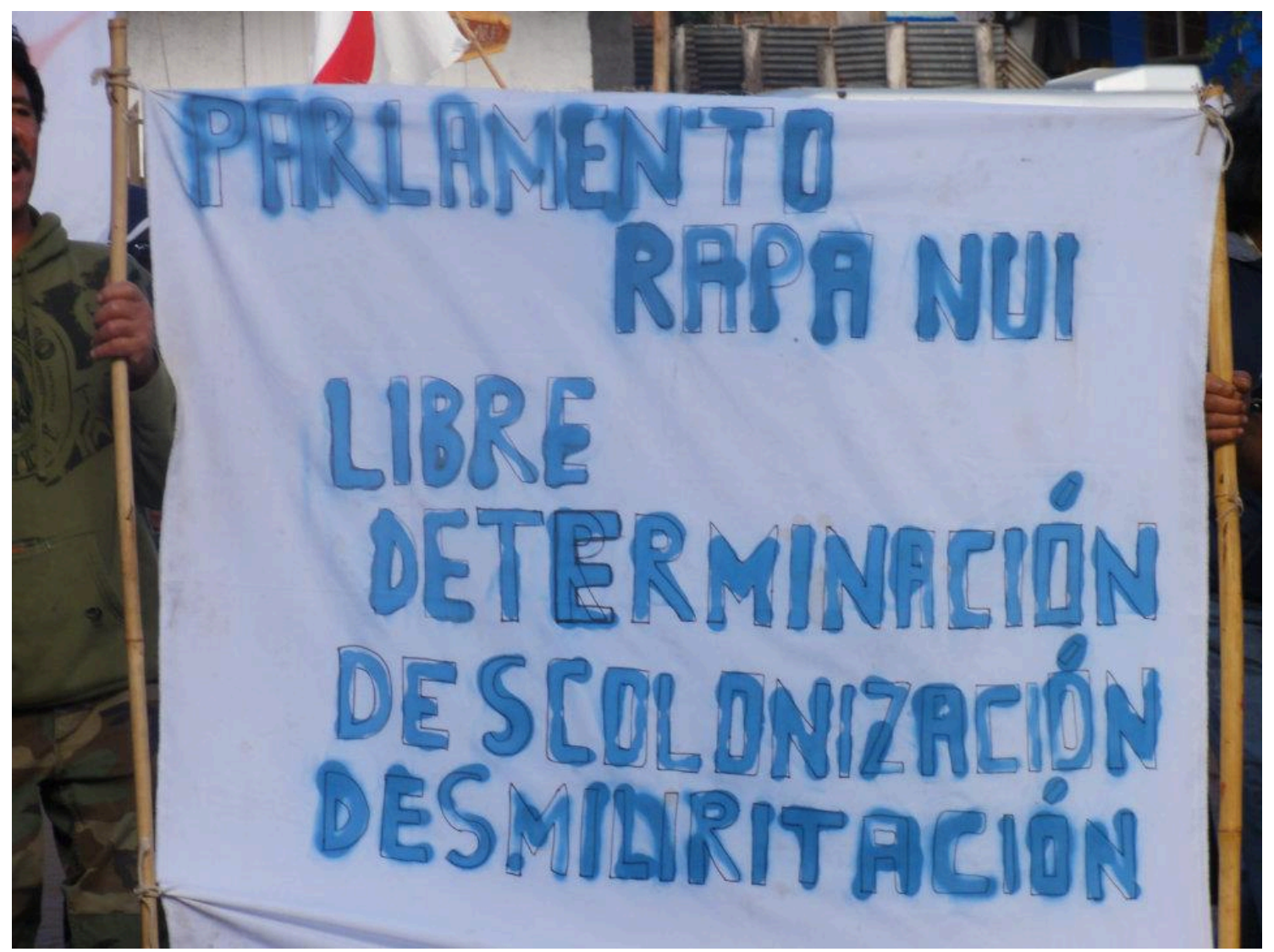

Figure 6: Parlamento Rapanui calls for self-determination, decolonisation and demilitarisation

(Karly Christ, 2011)

The Rapanui Parliament is one of the foremost oppositional voices against Chilean sovereignty on the island. Their principal demand is that the Chilean state return the territory to the Rapanui people, and that land distribution should be based on ancestral principles in which Rapanui people reconnect with the original kaina of their mata. They also assert their right to self-governance declaring autonomy in the Parliament's constitution: "we request our identity, and as a consequence we announce our autonomy via the creation of our own structures of governance" (Delsing, 2009, p. 273), formatively linking their right to autonomy with their right to identity. The Rapanui Parliament strives to work outside the structures of the Chilean nation-state linking with and requesting support from international groups, NGOs and Polynesian political and non-governmental groups. While some seek independence from Chile, this is not a widespread aspiration held by Rapanui people. Many would like to maintain an association with Chile, but strive for a 
greater degree of autonomy both culturally and politically, in which they have control over their land and resources.

\section{Indigenous and tribal peoples - ILO Convention 169}

In 2003, Chile became a signatory to the International Labour Organisation's "Convention 169" concerning indigenous and tribal peoples. As a signatory to the convention, Chile agrees to uphold the rights of indigenous peoples and to abide by certain protocols for engagement with indigenous peoples within its territory, namely through consultation and participation. The convention establishes the protection of the rights of Rapanui (and other indigenous peoples in Chile) over land and territory as well as promoting and protecting the cultural, social and economic rights of indigenous groups.

During my time on the island, a process was starting whereby the Chilean government came to explain the consultation process that was to ensue as part of their obligations under the convention. While many recognised the signing of the convention to be a positive step for Rapanui and an international tool that could work to their benefit, the women in Makenu, and seemingly many of the Rapanui that attended the meeting, were sceptical of the government's intentions and the prospective outcomes. It was expressed that they were tired of repeating the same issues over and over again, that they were never listened to and that the changes occurring did not reflect their concerns or goals for their society. One woman said it in this way:

We are given the choice of apples, oranges, and bananas. We say no to all of them, but they return to Santiago and say yes, look at how many attended the meeting - we have consulted. The media helps this. They go and show all the Indians sitting there - being consulted. Then go back and show all their pictures and then, they do what they want... what a joke (Maria-3). 


\section{Special territory, special status and immigration}

Also in 2003, Rapanui leaders came together with high ranking government officials ${ }^{73}$ and unanimously decided that a territorio especial (special territory) should be created whereby the island would still be linked to the central government in matters such as defence, justice and foreign affairs (Delsing, 2009). It took three years to develop a proposal, as divisions of opinions between Rapanui and Chilean officials as well as between Rapanui made it a difficult process. The goal finally articulated was:

To improve the living conditions of the inhabitants of the island, safeguarding equal opportunities for its development, and respecting the Rapanui tradition and its ancestral culture, which fills our country with so much pride and mesmerizes the rest of the world (Delsing, 2009, p. 248).

This proposal directly links Rapanui development on the island with a greater level of autonomy in Rapanui affairs, in which Rapanui culture is central to the concerns articulated and seen as pivotal to achieving their development aspirations. In July 2007, Ley 20.193 reformed the Chilean constitution allowing for the creation of the special territories of the archipelago of the Juan Fernández Islands and Rapa Nui (Delsing, 2009), and a Special Statute was to follow in order to determine the governing and administration of the island. This however has proved to be a long and arduous process that still has not hailed much by way of concrete results.

In 2005, a proposal was put forth to the Rapanui public for a "Special Statute for the Administration of Easter Island". It was divided into sections - development issues, forms of finances and administration of Rapanui lands. At the end of the development section there is a brief mention pertaining to the immigration issue on the island but it is not dealt with adequately (Delsing, 2009). This led Rapanui leaders and others to reject it, as it did not include sufficiently robust policies to address the issue of immigration on the island which was seen as critical to sustaining Rapanui culture and environment and ensuring equal opportunities for

73 This group of Rapanui were called the grupo de personalidades and this meeting involved former president Patricio Aylwin and eight high profile Chilean political party members, as well as the Rapanui governor, mayor, head of the Elders Council and CODEIPA members. 
development. Also, the autonomy considered, contrary to CODEIPA's recommendations, was only for administrative autonomy, not political selfgovernment. As Delsing (2009, p. 258) has suggested, this made clear that Chile was only interested in administrative autonomy in accordance with the Chilean Constitution and the concept of a unitary state, and not the political autonomy sought by the population.

While Chile has reformed its political constitution to allow for the existence of the special territories, the special statute which will determine how the island is administered has still not been instituted, as Rapanui demand that the issue of immigration be a central part of its foundation. A law has been put before the Chilean Congress. However this had been 'sleeping' under the Chamber of Deputies for about eight to 10 months, at the time I was on the island in $2011 .{ }^{74}$

\section{Section Three: Rapanui women's acts of resistance}

As with indigenous peoples the world over, Rapanui people have never just 'accepted' colonisation or been passive recipients of colonial impositions. Indigenous peoples have a long history of resistance, in which they struggle over how to live in the multiple worlds that have been created by the colonial project (Simmonds, 2011). This has manifested in peaceful struggles, as well as armed opposition (de Ishtar, 1994). Rapanui women have played integral and important roles within resistance efforts on the island. Here, I highlight some of Rapa Nui's most critical moments of opposition in the last century, and do so by centring women within the analysis. Women in Makenu have come from a long line of strong, forceful Rapanui women who have voiced their concerns, made their voices heard and sought justice for their families and their community.

\section{Angata's uprising}

Under the control of CEDIP, life on the island was hard. People were frequently without clothing and food. Starving islanders who considered stealing a sheep

74 Recently I received word from some of my research participants that some version of the law has been accepted by the government. However one participant recently wrote to me and stated: "it is not what we have asked for, but rather what Piñera wants, so we are still working on this" (Ximena4). 
were dissuaded by the threat that they would be banished to the continent if caught. Water was scarce and used for the livestock, and leprosy was endemic (Porteous, 1981). These appalling living conditions led the Rapanui to revolt in 1914.75

On the $30^{\text {th }}$ of June 1914 , an old semi-crippled, ${ }^{76}$ catechist woman named Angata arrived at the house of la Compañía's manager (Delsing, 2009). She had had a dream, and in this dream God told her that the island and all of its riches belonged to the Rapanui, not the British company, and that the following day they would slaughter the animals and a large feast would ensue (McCall, 1992). Angata's son wrote a letter articulating the same message and handed it to Edmunds, the naval governor and one of the Compañía's most prominent officials. The following day, the visiting British archaeologist Katherine Routledge, ${ }^{77}$ her husband and Edmunds all armed themselves, awaiting the onslaught of the Rapanui (McCall, 1992). As the story goes, a fog came over inhibiting the Rapanui from seeing their armed opposition. No shots were fired and the Rapanui took 10 heads of cattle and feasted that evening (Delsing, 2009).

Angata had many visions and in a conversation with the spirits she was told that the Rapanui needed to divide the island and return to their lands, taking up residence in the place of their ancestors which had been abandoned for nearly a generation (McCall, 1992). It was, as McCall has called it, "thirty-seven days that shook the world", where one woman, supported by her followers, demanded that the island be returned to the Rapanui, all their lands restored and their government reinstalled. At a critical moment, when the besieged visitors stood to lose a lot, including their lives, the General Baquedano, a Chilean naval training ship, came into view on the horizon. This quelled the uprising, Angata died six months

75 See Delsing (2004) for a discussion about the role of Catholic missionaries in the reassertion of Rapanui identity. She argues that while Catholic missionaries may have influenced the disintegration of Rapanui cultural beliefs and paradigms, they have also helped to drive Rapanui resistance and identity formation.

76 McCall (1992) notes that Angata was married to a cruel man called Manuheuroroa. During their time in Mangareva, he beat her leaving her disfigured; a hunchback for the rest of her life. In retaliation, Angata's cousins killed him.

77 Katherine Routledge was a British archaeologist who was supposed to stay on the island for only six months. The onslaught of World War One turned that into 18 months and during that time she conducted research on the island and produced the well known book, The Mystery of Easter Island (Routledge, 1919). 
later, and after one last feast of pigs in her honour, there was no further open resistance (Delsing, 2009, p. citing Routledge 1919). Angata's revolt was the last time until 1964 that the Rapanui challenged the imposed order of their island in overt ways (Fischer, 2005). As we see, 50 years later, women prove once again to be critical within these struggles.

\section{Women in Alfonso Rapu's rebellion}

47,000 sheep, 1,000 cows, some 50 Chilean military men and, in 1964, 1,000 Rapanui survivors, who live in the most incredible misery and without freedom (French enthnographer Maziere cited in Delsing, 2009).

Historic accounts of the rebellion of Alfonsu Rapu say little about the role women played in the revolt that occurred on the island in 1964. Therefore, little is known about these women, how they joined together, and what underpinned their motives.

During the 1960s, three important circumstances coincided. A Canadian medical team of scientists, the Medical Expedition to Easter Island (METEI) ${ }^{78}$ arrived, regular flights from Rapanui to the outside world commenced and the USA built a military base on the island (Grifferos, 2000b). And, after over fifty years of forced imprisonment on the island, some islanders were given passage to the continent for study. One of these was a young man by the name of Alfonso Rapu. His time on the Chilean continent illuminated for him the disparities that existed in his island community, and the atrocities that his people endured in everyday life. He expressed:

I lived in a world (Santiago) where people had certain rights, and then I came up to another world, my world, and there were no rights. We were animals locked up in this place, because at 8 o'clock a bell rang and you had to go to bed...During all the time I was studying I felt that anxiety to want to go back, to make the island a real world. They were living in a world without destiny, without a future, without anything (interview with Alfonso Rapu in 2002 cited in Delsing, 2009).

78 This study was "the most exhaustive medical and scientific examination that has ever been conducted on a South Pacific Island population" (Fischer, 2005, p. 212). 
Rapu returned to the island in 1963 at the age of 22, with a teaching certificate in hand. Working in the school on the island, Rapu emerged as a strong community leader and agitator and began petitioning for the Rapanui to enjoy the same rights as those on the continent. In December of 1964, a letter was written to the President articulating a long list of demands, alongside criticism of the practices of the Chilean navy, ${ }^{79}$ which had been ruling the island since $1953 .{ }^{80}$ These complaints included unpaid labour, suppression of the Rapanui language and confinement to Hangaroa among others (Porteous, 1981). The navy had been allowing elected, male, Rapanui councils to help govern the island ${ }^{81}$ and shortly after this letter was drafted, Rapu was elected mayor.

However, Rapu feared repercussions from the Chilean government for his ongoing dissent. With the support of the Rapanui community, he went into hiding for several weeks. On the $5^{\text {th }}$ of January, Chile sent marines to Rapanui to help restore order. Promised a fair hearing, he came out of hiding. They took him into a small room and interrogated him, telling him he was detained in the name of the Chilean government and that they would take him to the continent. Rapu describes this incident:

When I left, about 10 minutes later, surrounded by marines with guns, some 100 to 200 women appeared and two marines got stuck in the middle and they were pointing their guns right at my head, it was dark and there were shots in the air and a lot of shouting. So, I told the women to take me to the camp of the Canadian doctors, journalists, foreigners who could see what was happening. We were saved from a massacre (interview with Alfonso Rapu 2002, cited in Delsing, 2009).

It was Rapu who was the leader of the revolution of 1964-65 and also the impetus for the 1966-67 protests according to historic accounts (Fischer, 2005). However, as we see from his story above, women were critically involved. In what is easily

79 Delsing (2009) notes that sexual abuse by naval officers on the island was abundant. Medical facilities were where many abuses occurred and as every Rapanui body was checked each year for leprosy, this was hard to avoid. She also notes how sick Rapanui women were often raped in their hospital beds.

80 Germán Hotus wrote this with Rapu and others.

81 Only men could vote in these elections and the membership of this advisory body was subject to the approval of the military governor (Porteous, 1981). 
projected as a male-dominated conflict between Rapu and the marines, women demonstrate their active resistance within these struggles and show that while their role has often not been central to the account it was pivotal.

\section{Women revolt at Hanga Piko in 1966}

Another incident took place two years later on the $16^{\text {th }}$ of December 1966. It was once again in support of Rapu, who, as a result of the model of legislation being used by Chile to conduct the town elections on the island, would have been prevented from running in the next mayoral election (Grifferos, 2000a). The governor at the time, Enrique Rogers, returning from a trip to Chile, arrived on the island expecting a customary welcoming. However, he was met by a large crowd of angry Rapanui women who launched stones and insults at him from the shore. Women shouted, "go away Rogers; we don't want you on the island" and "You have never received us, neither as mothers, nor as women" (Grifferos, 2000b, p. 379). Rogers became angry and gave orders to attack. Approximately 40 Chilean carabineros $^{82}$ rushed in, beating the women with batons (Fischer, 2005; Grifferos, 2000b).

These historic accounts are examples of the ways that women have been involved in the past and contributed to resistance struggles. However my listing them here does not draw enough recognition for their acts of courage or their role as leaders in their own right. Women stopped the marines from taking Rapu, in an impressive act of resistance on their part that showed tremendous bravery and commitment, yet it is frequently the foreigners that are highlighted as the 'saviours' in this scenario. While there is no doubt that the foreign presence was absolutely critical, women's roles are continuously left out of the accounts and analysis of what happened on that night, and their contributions only briefly mentioned within a few lines in most texts. The revolt at Hanga Piko receives even less recognition.

\footnotetext{
82 Carabineros are the Chilean national police force and gendarmerie.
} 


\section{Maururu ${ }^{83}$ Ana Lola}

In the early hours of the morning on the $27^{\text {th }}$ of July 2010 , an 84 year old woman emerged from her home in Hangaroa, set with determination. The workers in the Feria $^{84}$ had not yet arrived for a day of selling their wares and the sun had not yet soaked the barren volcano of Poike. Crossing the main street in Hangaroa and heading towards the sea, Ana Lola Tuki Chavez entered the Bienes Nacionales (National Property) government building that resides on her grandfather's land. Outside, she placed a Rapanui reimiro flag, an emblem of Rapanui sovereignty, initiating what would come to be one of the largest resistance efforts against Chilean colonialism in recent years. ${ }^{85}$

The people of Rapanui woke to that reimiro flag waving high outside a site that had long been claimed by Chile, and with the inspiration of an old woman's tenacity, they became emboldened to rise up against the injustices they too felt towards Chile's illegal occupation of their lands and territory. Throughout August, a series of land seizures occurred across Hangaroa, with groups organised by clan entering various government offices and one privately owned hotel. By the $4^{\text {th }}$ of August there were 11 occupations, eight of which were led by women and three by men, totalling 110 people. 86 Over the course of the month this number grew rapidly, with El Mercurio, a centre-right Chilean newspaper, reporting that 35 plots of land and the buildings on them had been occupied. Amongst the buildings occupied were: the museum, the Municipality, the Civil Registry, the offices of Banco Estado, Entel, the Ministry of Public Works, Department of Foreigners and Migration, Sernatur, private homes, the Hotel Hanga Roa and the runway of the Mataveri airport. Most of the protesters camped out in the front gardens or patios of the buildings where, like Ana Lola, they put up the red and white reimiro flags, as well as other banners and tents, staking claim to their heritage.

\footnotetext{
83 Maururu means "thank you" in Rapanui.

84 This is the market in Rapa Nui where one can buy items such as produce and fish as well as handicrafts.

85 This story was told to me by Ana Lola's daughter. Many people I spoke to also told me that Ana Lola was the inspiration behind the land occupations that occurred during this time.

86 (see "Ocupantes de terrenos exigen al gobierno 4 medidas para terminar movilizaciones," 2010)
} 
On the $3^{\text {rd }}$ of December the situation turned violent when the Chilean government called upon its military to forcefully remove the Rapanui from the lands and building they were occupying. The approach taken by the government to this situation demonstrates how little has changed in Rapanui/Chilean relations, which since annexation have been typified by abuse. Police were armed with pellet guns which they were not afraid to use. Various international observers have voiced concern for the Rapanui including the UN Rapporteur on the Rights of Indigenous Peoples, James Anaya; American Samoa's delegate to the U.S. Congress, Eni Faleomavaega; U.S. Senator Daniel Akaka of Hawaii; as well as members of the Inter-American Commission for Human Rights. All have been calling upon the President to refrain from using violence against his own people.

Amongst the occupations was the Hotel Hanga Roa which has received the most media attention during and since the uprising. The case of the Hotel Hanga Roa is special as it is the only land on the island whose title resides in the hands of a foreigner, which according to the Ley Indigena is against the law. Speaking about the family's struggles, one Hitorangi family member described the frustrations they experienced:

Nothing happened. Year after year. 140 years of the same. They send another politician, another politician. And nothing. Only promises. Pure promises. And people are tired. A politician came here, "Yes, let's see your problem". We say that on the way there, on the plane to Chile, there is a cloud that will clear the memory... All governments until this government - This government said "the change, vote for us. The change, the change". Now, we voted for change. The first ones to arrive went to shoot us. That was the change. The other ones lied to us; the other governments lied to us. This one, this one came to us with... with weapons. They shot us (Hitorangi family member - 5).

This time period marked another critical moment in Rapanui contemporary history where the injustices felt by the people have reached a boiling point. Many women and men struggled during this time to claim their rights to their land and territory and to regain what they believe is rightly theirs. It was frequently noted by people I spoke with on the island that the women were staunchly involved in these protests and that women were the carriers of the movement. In the case of 
the Hitorangi family, it was noted by the Hitorangi women I spoke to that it was the women in their family who were the strongest fighters, but that their role as women was to support their men and to regain the land of their family, so that their children would have a place to live, prosper and grow in the coming years.

\section{By way of conclusion}

At the end of the last century, when Rapa Nui was incorporated into the Chilean state, the island was left with a little over one hundred people as the bearers of Rapanui cultural heritage. Contemporary culture has been developed from the collective memory of these people, preserving a common language and other cultural attributes, such as a system of familial relations with strong family ties, systems of reciprocity between families, and the importance of land as a fundamental sense of identity and social status. As with other Pacific Island peoples, Rapanui identities, customs, beliefs and practices have resilience and have endured colonial changes (Griffen, 2006). Yet it is not uncommon for indigenous peoples to inhabit two worlds - the colonisers and their own - and as Simmonds (2011) points out, indigenous peoples are constantly negotiating the tensions of living within these two worlds. Preserving the aspects of their culture and identity that they would like to maintain, incorporating new ways of being that are positive and rejecting those that are not is an ongoing process that involves awareness, commitment and perseverance.

Acts of resistance occurring in overt and covert manners have been a part of daily life for the Rapanui since the beginning of colonial times. While the stronger, more animated protests tend to be the ones that make it into the history books, small acts of resistance build awareness and sustain opposition. Contemporary issues on the island continue to be secondary to uncovering the 'mysteries of the moai' and within the small amount of work that is being done, there is little attention being paid to women. Yet, as this chapter has indictated, women in Rapanui have historically been at the forefront of colonial resistance, fighting for their rights to their land, their territory, and to their identity as a people. To this day, women continue to persevere and are committed to resisting the colonial impositions in their lives. In the following sections, we hear stories from women in Makenu Re'o Rapa Nui, a group of activists on the island, about how they are involved in 
decolonisation struggles. These chapters explore what issues are important to them, what they wish to achieve, and how they are going about continuing a struggle that started long before their time and will continue long after they have passed. 


\section{PART II: MAKENU'S STORIES OF STRUGGLE}

The processes of decolonisation are not universal. Where there are clearly commonalities, there are also specifics that need to be identified as a part of the overall decolonisation agenda. Our colonial experience has been one of denial. Denial of our reo [language], denial of our tikanga [cultural practices], denial of our whenua [land], denial of our taonga [treasures], denial of our whakapapa [genealogy]. Colonial forces have attempted to deny us all of those things that contribute to our notions of who we are and where we fit in the world. The ways in which these attempts were made varied depending on context and location, as such the effects have been diverse and multi-layered. Decolonisation then includes a peeling back of the layers. Layer by layer. Constantly reflecting on what we find (Pihama, 2001, p. 288).

\section{Preamble}

Indigenous women in the Pacific are engaged in what Tongan poet and scholar Konai Helu Thaman has called a potent mix of bitterness and sweetness of family, colonisation and the land. Women constantly negotiate these tensions, working within and against their own community (Jones, et al., 2000). The next three chapters describe decolonisation as articulated by the women activists with whom I spoke. They uncover the multiple concerns these women have for their island, accentuating how their family and future generations on the island are the central inspirations for their efforts, and the political as well as cultural processes in which they are involved. While reading about Makenu's concerns and aspirations, the challenges they have experienced and the strategies they use to achieve their goals, I encourage the reader to consider what focusing on women within these struggles brings to the discussion of decolonisation, and how by focusing on these women's experiences we are able to more fully understand the complexities and nuances of decolonisation processes. 
The voices and contributions of members of the group with whom I spent the most time are those most privileged in the following pages. As this thesis does not strive for an objective account or to uncover the 'truth' about women's roles, but rather understands the knowledges created to be established through these women's particular perspectives, it does not find this 'imbalance' epistemologically problematic. As noted in Chapter Three, I have tried to retain the full integrity of the quotes used; changing them as little as possible, but enough that they are fluid and comprehensible. Direct quotes are in italics to make clear the voices of the participants. The Spanish versions of these quotes can be found in Appendix One.

Despite my best efforts to represent my participants well, the passion and commitment with which these women described their situations to me is almost impossible to represent on paper. As intense emotions are not easily portrayed in written form and translation results in a layer of meaning being widled away, I would like to note here that each participant demonstrated an unwavering commitment to these struggles. Achieving a high quality of life with ensured wellbeing in their community was seen as directly, though complexly, related to the political and social decolonisation of their island. As such, before presenting the voices of these women, I would like to convey to the readers of this thesis that the stories they shared with me were rich and textured, happy and sad, engaging, thoughtful and often incredibly inspiring. 


\section{Chapter Five: \\ Makenu Re'o Rapa Nui - "the Voice of the People"}

\section{Introduction}

It was a wet and fairly chilly night at the end of June. I had only been on the island for about a week when I attended a book launch for "La Compañía Explotadora de Isla de Pascua: Patrimonio, Memoria e Identidad en Rapa Nui".87 It was held at the Sebastian Englert Museum located in Tahai about a 20 minute walk outside of the town centre. The museum, which is dedicated to the conservation of Rapanui cultural patrimony, often hosts talks and exhibits about Rapanui archaeology and culture. After an interesting introduction by Cristian Moreno Pakarati and a few speeches, the crowd erupted in chatter and wine was poured. A man sitting next to me gave me one of the books to take home, proudly informing me that many of the accounts were from his family. We began to chat but I had trouble understanding him at times and at a critical juncture in the conversation he asked a woman sitting in front of us to translate a word I did not know. She was a Chilean woman, about my age, who spoke perfect English. When I told her about my project she asked me if I had met with Makenu Re'o Rapa Nui, yet. When I said no, she said, "that is who you need to talk to. I am going to a meeting at 8 tonight... you should come along" (Reflective Diary 29 June 2011).

This chapter has two aims. First, to describe how women in Makenu are engaging within decolonisation struggles, and the strategies they are using. Secondly, it assists the reader in 'contextualising the research findings that are discussed in the subsequent chapters as it provides a deeper understanding of what the group Makenu Re'o Rapa Nui is and whose voices are presented in the following pages.

87 See (C. Cristino \& Fuentes, 2010). This book contributes to historical evidence during the time of the Compañía on the island, and seeks to explain the forced cultural change that occurred as a result of these socio-political and economic factors. There are a few contributions in the book by Rapanui scholars. 


\section{The Birth of Makenu Re'o Rapa Nui}

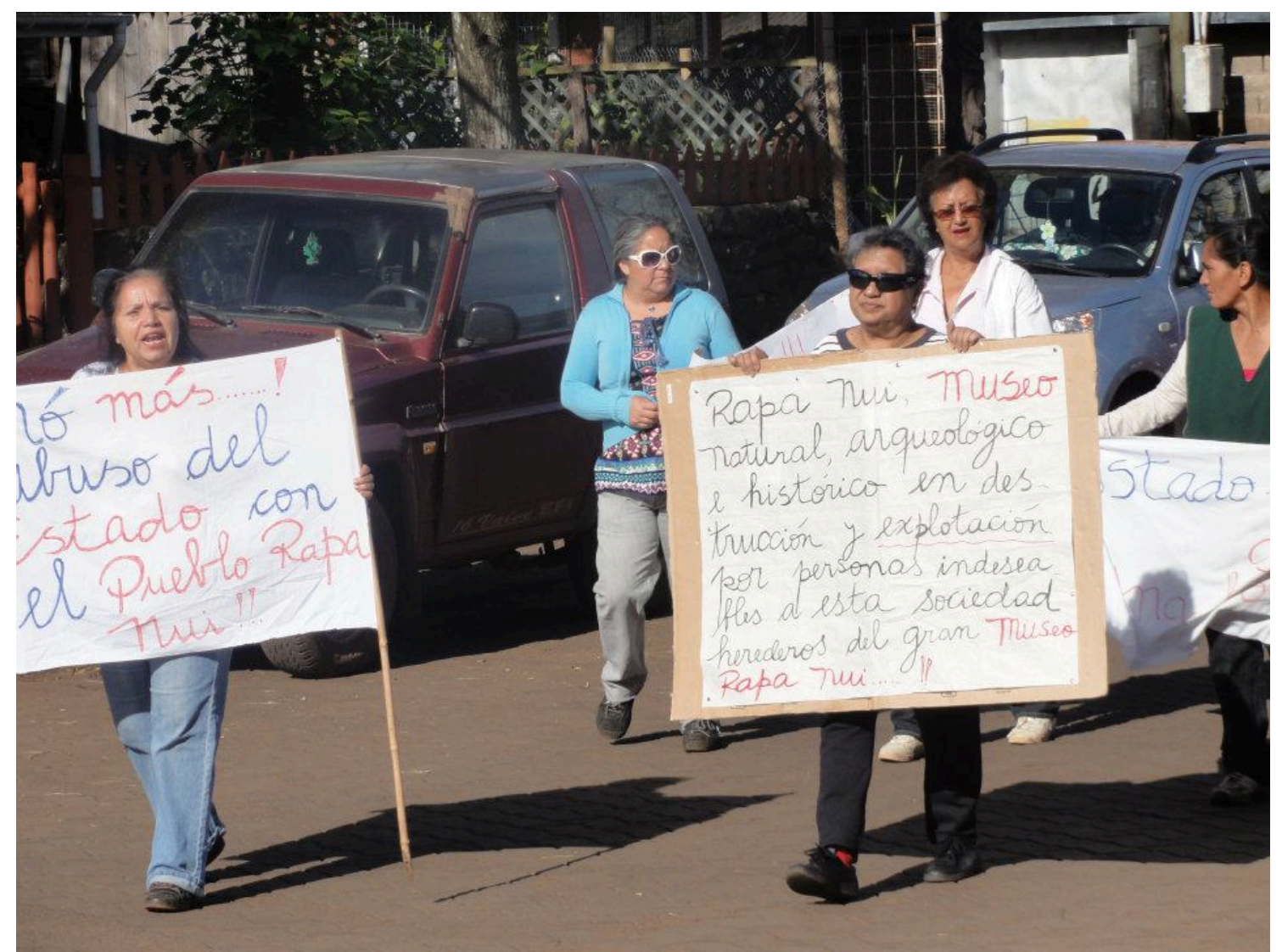

Figure 7: Protest, $23^{\text {rd }}$ July 2011

(Karly Christ, 2011)

In August of 2009, the Parlamento Rapanui, an organisation of mostly men whose group formed out of the Consejo de Ancianos (as discussed in Chapter Four), initiated a protest against the unregulated immigration of Chileans and foreigners to the island. They took over the runway of the Mataveri airport with the support of other community members, including many women.

A day into the protest, the Chilean government began proposing solutions to address the islanders' concerns, offering to have representatives from the Parlamento fly to the continent to discuss the matter with appropriate government officials. As a result of these offers, the Parlamento decided to end the protest and begin negotiations in Santiago. A Makenu member describes this and some of the women's reactions: 
There was a takeover at the airport with the Parliament, which is another group we have in the community... Well, it was them who initiated the protest. And we, without being members of the Parliament, we thought it was a good protest, which had support, and so we went there, to the airport. The protest was about immigration, that is, we wanted to stop it once and for all... they all come and they just stay, stay... which means the work, and the future... of the kaina [is at risk]. And, uh, that day, there were a lot of discussions with the State, and, well, the head of the Parliament, reached an agreement with people of the State. [It was agreed] that they (the Parliament) would travel to resolve the issue - the problems [would be addressed] over there. In Santiago, Chile.

It is just that, nothing happened for three years. And, us, the group of women said, "no". Because always the problems here, our problems, which started with the kaina, have not been resolved in many years, and we always have to go there, go there, go there. This time, we wanted them to come here. And so, we stayed for two nights at the airport... and in the end... they removed us (Ana-6).

As this story illustrates, some women did not agree with the way in which the situation was being handled and did not believe that the issue would be resolved in Santiago. Demanding that the government come to the island, the women staunchly held their ground and did not leave the runway; continuing the protest for two more days. Finally, the government realised that promises to address their concerns in Santiago were not enough to stop the protest. Heeding the pleas of the women, Chile sent a representative to the island. The Parlamento never went to Chile, and the government officials who came to the island were forced to acknowledge not only the original leaders of the initiative but the women who were still actively protesting. ${ }^{88}$ Coming from various families, ages and professions, these women were empowered by this experience, as they began to fully appreciate their shared common goals and the passions for achieving them.

88 It was noted amongst members of Makenu that this was a source of tension with the Parlamento, feeling as though they had been side-stepped in what began as their protest. I noted in my diary, "It was interesting to hear how women spoke about it. As though they not only had won the attention of the Chilean state in these matters, which was their primary objective, and to which they were exceedingly proud, but they also showed enormous pride for their achievements as a group of women - women who stood their ground and demanded more than what men were asking for" (Reflective Diary 10 July, 2011). 
Centring their family, community and the survival of their island in their struggles, on the airport runway in Hangaroa, "Makenu Re'o Rapa Nui" - "The Voice of the People" was born.

\section{Finding strength amongst the challenges}

In a hot kitchen near the town's centre, these women meet twice a week. The roaring fire heats the oven where pan $d u l c e^{89}$ is baked. The smell of this sweet baked bread and tea mingle with cigarette smoke, as women hand roll and share them throughout the meeting. While the group formally consists of 48 women and one man, ${ }^{90}$ there is a core group of about 10 people who consistently attend these meetings (at least during the time I was on the island). ${ }^{91}$ Ages range from about 35 to 65 years old, and all of the women are Rapanui except one Chilean who has lived on the island for over 20 years and is married to a Rapanui man. ${ }^{92}$ The language used is mainly Rapanui though Spanish is peppered throughout conversations. Members who do not speak Rapanui, of whom there are only a few, seem proficient enough to understand the conversations. However they communicate in Spanish when they address the group. While the gatherings are casual in feel, they are treated as formal meetings. Everyone in attendance must sign into the record book and loose minutes are kept to document decisions and important discussions that occur. Everyone has the right to speak and contribute, and they are proud that they have no hierarchal structure; no elected or appointed leader of the group and an equal right to participate and have one's voice heard. Some members take up important roles that are required for the fluid functioning of the group, such as the record and minute keeper, technical administrator, and others who tend to speak on behalf of Makenu resuming natural leadership roles within the group.

89 This is a kind of sweet bread.

90 Makenu is not made up exclusively of women. While most of the members are women, they do not have any policy that says men cannot be a part of their group. All are welcome to participate.

91 As was noted in my methodology, I did not speak with every woman in the group but only those that attended the weekly meetings. Of those registered, this is only a fraction. However they are those who are the most active.

92 It should be noted that all Rapanui would be of mixed heritage as colonialism and globalisation have taken their course on the island. The members of the group who do not speak Rapanui have at least one Chilean parent and spent a lot of their life on the continent. 
Along with their non-hierarchical structure, women in the group also expressed great pride in their grassroots orientation. Some showed particular disregard for government bodies, emphasising their ability to work autonomously and explicitly for the community, noting how being a government representative could present a conflict of interest. They expressed that they are able to act as they like and say what they please without any restrictions that others may experience working within the formal political structures on the island.

Interestingly, some women, while stressing their autonomy, also highlighted this in terms of their marital or relationship status. Some identified as single, independent community workers, expressing that their status as a single woman was one reason they were afforded the ability to engage within these struggles in the ways that they do. Not having men in their lives, at least not as partners, was identified by some as an important aspect of their ability to act. ${ }^{93}$ This, however, is not to say that these women did not have any pressure or criticisms from other men or community members. Some women expressed the difficulties they experience as activists within the community and the effects this has on them. A few women noted how they were treated poorly by some men and women because they did not agree with their actions and the role they were undertaking. According to participants who described this treatment to me, the problem was either articulated as a disruption (where some community members desired to maintain the status quo in order to simply enjoy their lives rather than continuously battle with the Chilean state) or along gender lines in terms of what is 'appropriate' involvement for women. When I asked one member what the hardest part of the struggle was for her, referring to her community, without a hesitation, she said:

The treatment more than anything else... The ill treatment. And sometimes they yell at you, that you are crazy - that you should go home

93 As I noted in my diary, "comments are often made about how machista the island is... in reference to MANY things. These women often claim that they, and other women, are the backbone of the struggles for Rapanui rights... that they are the ones making things happen, despite men's desires to keep them out of these efforts and to silence them"(Reflective Diary, 20 July 2011). It is important to note that not all women in the group are single and while it was a common feeling within the group that the island was very machista, the grounds for the comment in my diary was not articulated by every member of Makenu. 
and do something at home. The same people... always, the same people. Go to your house and do something - something better (Ana - 7). ${ }^{94}$

While women recognised the inequality that existed based on their gender, it was not gender they cited as their main impediment for achieving their goals. It was also not the questioning of gender and their rights as women that centred in their critiques of development possibilities. However, they recognised the marginal position they were sometimes afforded within their community and the domestic issues that existed based on gender lines. They, however, chose to endure the maltreatment they received in order to carry on their struggle, which challenges these injustices through their actions.

Most of the women I spent time with did not have partners. Most have been married, and are now divorced (or widowed), and all have children. It was the children, and the importance they placed on their role as mothers, that was consistently articulated as a primary motivation but also a responsibility for the work that they do. It was the children and the future well-being of the island that inspired these women to act and continue to act even when faced with adversity within their community. When I asked one Makenu member what she thought the role of women is within their struggles, she nicely articulated this point, stating:

The most important thing is that we are fighters, without fear and with the determination that we are given through our motherhood... Looking to the future and seeing what you want to leave to your children (Ximena-8).

This quote expresses how women approach their struggles from an empowered mothering, whereby women are not passively engaging but are doing so with agency (Sunseri, 2008). This participant shows that her role as a mother empowers her to take on the enormous challenge and profound responsibility she feels towards her community. Another member similarly noted:

Pay attention, do not miss or underestimate the essence of women, as mothers. And the essence of women as mothers to self-determination over everything that is eternal everything that is around. The land, their

\footnotetext{
94 This participant also noted that those making comments such as this were always men.
} 
children, right to the simplest thing - they manage, they always have to be aware... (Alicia - 9).

Protecting Rapanui land and cultural identity in order to ensure the welfare of the community and the future well-being of their children was central to these women's engagement. When I asked them why women were so involved and why women were working so hard it was always their motherhood that they pointed to as a source of strength and impetus for their actions. It was not 'women's issues' or gender inequalities that invoked them to act, but rather their desire to preserve the integrity of their people, to reinvigorate their cultural identity, and to ensure a healthy life for future generations.

\section{Working together and working apart}

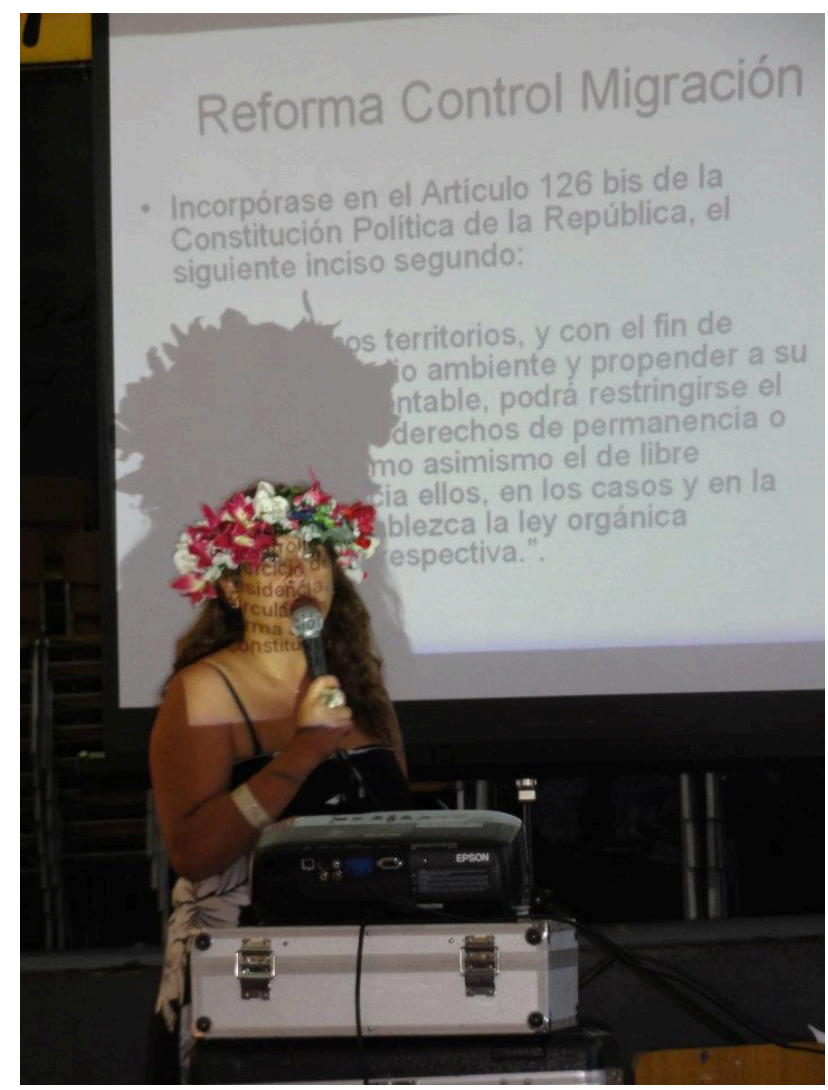

Figure 8: A Makenu presentation to the Rapanui community, international lawyers and international observers about immigration. Seminario, Hangaroa, 1 August 2011 (Karly Christ, 2011)

The approaches this group uses to voice their concerns and to involve themselves in these struggles have been extensive and effective. The women of Makenu come from various backgrounds and are involved in a range of jobs and volunteer work. 
For example, one member of the group is a teacher in the local school, another operates a guest house/hotel, one is a tour guide, and another assists with the work of two missionaries who have been on the island for over 30 years. ${ }^{95}$ Working as a group, they try to keep their focus on the topic of immigration control and the political processes around it, while building awareness within the community on topics of importance to Rapanui lives. Outside of the group, women are involved in smaller community initiatives that seek to promote Rapanui wellbeing and preserve a positive Rapanui identity. Both arenas of their work however are underpinned by the same aspirations for self-determination; for Rapanui development that is reflective of their visions for the future, in which Rapanui culture is respected and nurtured and their ability to "be" Rapanui is fought for. Some of the ways women involve themselves both outside and inside Makenu are included in the initiatives listed below, showing the scope women have for involvement in what is happening on their island and what they seek to preserve, change and create.

\section{Academia de la Lengua Rapa Nui}

Some members of the Makenu group are involved in a language academy that promotes the use and preservation of the Rapanui language. With so much immigration to the island, as well as Chilean government structures, such as schools and political organisations in which Spanish is the language of discourse, Rapanui has been experiencing a shift towards Spanish (Makihara, 2005a) with many of the young people today speaking Spanish as their native language. While recognising the importance of speaking Spanish as a means of economic survival on the island, and a way to engage in the global economy through the tourist industry, the maintenance of their ancestral language was deemed important for the maintenance of a positive Rapanui identity and living culture.

The work of the academy includes the development of a Rapanui dictionary, creating neologisms, the recuperation of toponyms, and promotion of the language in society, as well as within the institutions on the island. ${ }^{96} \mathrm{~A}$ few members of the

\footnotetext{
95 Nancy and Robert Weber are American missionaries and linguists. They have been on the island since the 1970s. They have been working on translating the bible into Rapanui.

96 See the website for more details ("Academia de la Lengua Rapa Nui," 2010).
} 
Makenu group hold prominent positions within the institution and one Makenu member, with help from others, wrote the first Rapanui text book on the island.

\section{Traditional medicine and practices}

Some members of the group also participate in the revitalisation and maintenance of traditional medicinal practices using native plants found on the island. Women are the keepers of ancient herbal remedies and their role is critical in preserving these traditions. Multiple women told me that the whole island has healing properties, and everywhere one can find medicine. The best place however is in and around Rano Kau, one of the three volcanoes located on the island. Accessing the medicine of the volcano was sometimes a problem as it sits within the limits of the national park and has visitation hours set forth by the Chilean government. This was a concern raised by people I spoke with as it was a direct affront to Rapanui being able to obtain the plants they need, particularly the Matua pua'a plant which is the most prominent plant within Rapanui healing practices.

\section{TV and radio programmes}

Women in the Makenu group have used radio and local television programmes to help inform and educate the community on various issues affecting them, both in their capacity as Makenu members and as individual proponents of various issues of concern. For example, sessions on medicine and Rapanui healing practices have been covered in television programmes and radio programmes, discussing the valuable properties medicinal plants on Rapanui have, how to prepare them, and the ways they can be used.

The Makenu group has also used the radio to disseminate information into the community, and I was told they used to have a radio programme every Tuesday. In their time slot, they discussed issues confronting the island, and often sought to make sense of the new laws or initiatives being suggested by the central government or government institutions on the island. As women told me the language used by Chile was sometimes difficult for people to understand, both because it was Spanish, not their mother tongue, and because the confusing legal jargon made it hard to grasp the meaning and significance of certain policies being proposed. Makenu tried to unravel some of the complexities within these laws and policies, filtering them through their worldview and making them more accessible 
for their community. Despite what they thought was a valuable method for educating and informing the community, their time allocation was shut down by the municipality. The women claimed this was a result of their pro-Rapanui sovereignty standpoint, in which Chilean policies and actions were critiqued and criticised. The government, sick of the confrontation and disturbance occurring as a result, cut their programme time attributing it to budget cuts.

\section{Sharing and learning: A transparent working etiquette}

Raising awareness and being transparent about their efforts, perspectives and priorities were central tenets in Makenu's approach and commitment to participating in these struggles. They articulated that this was one of the important reasons why they achieved respect from the community. As one Makenu member told me:

We have to say as it is. We must not deceive people. We must tell the truth. And there's a lot of abuse, abuse of power, like in all places... The Makenu carry much weight. Why? Because it has... it has shown the things that it has done. The Parliament, they hide many things, rather than displaying them. It isn't good to hide things... It is better to show everything. It is the only way to win the people... To be transparent... (Alicia -10).

Makenu took pride in the ways they undertook their work. They saw their commitment as being 'with' and 'for' the people. The centrality they placed on sharing information, educating and working to build capacity and awareness in the community was expressed as critical and foundational to their struggles. The women in Makenu recognised and demonstrated, through the ways in which they participated in these struggles, that an aware and informed community was the only way to decolonise their island. 


\section{Summary}

Makenu women are critical players within the struggles occurring on the island. Centring their focus on children and future generations, they find strength in their role as mothers, to work for their families, on behalf of their community, to rebuild and sustain a healthy society. Their involvement is extensive and their concerns are wide; their involvement is politically, as well as culturally deep. Immigration is of central concern to Makenu as the inflow of so many people is having major repercussions on their culture and their ability to maintain their uniqueness as a people. However as this chapter shows these women are engaging in various ways to reinvigorate Rapanui culture and identity; seeking positive change firmly based in Rapanui worldviews.

In the next chapter Rapanui kaina is the centre of women's stories. These articulations demonstrate the importance of 'land' within their decolonisation agenda, and the centrality of land within their development aspirations. 


\title{
Chapter Six: \\ Decolonising Kaina - experiences of local development
}

\begin{abstract}
Fundamental a focus on human development as the goal of economic and social processes reaffirms the centrality of people realizing their potential to be creative, useful and fulfilled members of society; the acquisition of material wealth is a means to that end, not an end in itself. It harks to earlier (pre-capitalist) values of self realization through creativity, reciprocity, and a rich spiritual life (Gita Sen cited in Emberson-Bain, 1994, p. ix).
\end{abstract}

\section{Introduction}

For Pacific peoples, an intimate relationship with the natural environment, including natural resources such as land and sea, has traditionally existed (Emberson-Bain, 1994). This intimate and deeply spiritual relationship is fundamental to Pacific peoples' beliefs, customs and identity, providing the basis for their social, economic, legal and political institutions (Bolabola, 1986; Crocombe, 1987). Land, in particular, provides not only a source of sustenance and economic livelihood, but is also where histories and cultures grow, and the cultivation and maintenance of indigenous knowledge is rooted; serving as the heart of community life. The importance of land is therefore not only crucial to the survival of Pacific peoples physically but also in profoundly cultural ways. Mason Durie discusses the importance of land in Māori lives:

Māori identity is secured by land; land binds human relationships, and in turn people learn to bond with the land. Loss of land is loss of life or at least loss of that part of life which depends on the connections between past and the present and present with the future (Durie, 1998, p. 115).

The women in this study expressed similarities with other Pacific peoples, in particular Pacific women, in terms of the value they place on land, the central role it plays in their identity formation and the rooting of their place in the world (Bolabola, 1986; de Ishtar, 1994; Fairbairn-Dunlop, 1998; Huffer, 2008; Tongamoa, 1998). Trask has spoken of land in her native Hawai' $i$, noting how "land is the mother and we are the children" (Trask, 1996, p. 906). This speaks to the way in 
which these Rapanui women articulate their connections to their land presented in the quotes below. Appreciating the ontological beliefs that structure these women's connections to their land is important when considering their engagement with anti-colonial struggles on the island today as women work towards positive development for their people.

Regaining control over Rapanui kaina was identified as a critical component of these women's resistance against Chilean colonialism and their struggles for selfdetermination. As we saw in Chapter Four, women historically have been fundamental to anti-colonial resistance on the island, and have played pivotal roles in recent struggles pertaining to land. While many of the women in Makenu that I spent time with were supportive of the land occupations that occurred in 2010, few engaged in these protests. Land was nonethless articulated as central to their struggles, and in this chapter we begin to appreciate the importance of land as well as how their struggle for immigration control is fundamentally linked to their concerns for their land, or more rightly, their kaina.

\section{Land, the womb of a culture}

For indigenous peoples, land is the womb of a culture and the descendents, preserving it in time. (Lili-11).

Many of the women with whom I spoke, described the connection they feel to their land, and the spiritual beliefs that underpin their demands for its restitution in important and notably gendered ways. When I asked why women were so involved in struggles regarding land on Rapa Nui, it was always their role as mothers and the bearer's of life, their innate connection that they shared with their kaina that lead them to protect it. Intimately related and central to their motivation was their children and the future generations on the island, who would also need to be fed physically as well as culturally from the kaina. The land, the children, and their role as mothers have given these women the strength they need to resist the oppression they feel. One woman talks about her connection to the land, illustrating this relationship:

Well, thinking about that land is life, and feeling grateful, because it is part, it is part of the earth, because we will return to make part of her... too. That is, one has an origin with the kaina, and has an ending with it as 
well... to be born and then return to, to get you inside... and catch you again. Look, how beautiful... because, because you have your baby in your uterus... so warm. And then... you go back and she welcomes you... the kaina of another form, that is, another time (Maria -12).

This participant describes the intimate and beautiful connection between women and land that she feels. The womb of the woman carries life, just as the earth gives life to its creatures, providing sustenance and nurture. What happens to the earth also happens to women (Fiske, 1996); the cultural connection that has traditionally existed between women and kaina, as this woman has described it, is fundamental and strong. Reaffirming cultural attributes such as this was empowering for women, as culture provides a necessary foundation for a positive Rapanui development within the contemporary setting.

Another Makenu group member illustrates further some of the connections to the land that she feels as a woman, while describing how 'land' is explicitly linked to the Rapanui territory, kaina. Understanding 'land', or kaina as not just 'land' but as a complex system of beliefs in which the identity of this woman is largely predicated, helps to appreciate the effects that land dispossession has on indigenous peoples, particularly women.

Land... Henua is the surface. But that, that has to do with the western definition... In other words, land, surface... What is on top... And kaina what is below... in other words, territory. Henua - if you think about it, Henua is placed on the maternal kaina. The placenta is Henua. And this placenta rests, is settled on the kaina, on the territory. In our... in our mother's body. Because what is above is fed by what lies underneath. And the exact same thing occurs inside our mother kaina (mother earth), and Henua, the placenta, which surrounds the baby (Ana - 13).97

97 During this discussion, when I was asking for clarification on what these terms mean to her, she asked me if I remembered at the seminar, where approximately 100 people were gathered, a few days prior when she had questioned other community members about these concepts. Realising she had asked in Rapanui, she recognised I would not have remembered. However she suggested this was a widely held belief. She said: "Do you remember that I explained something like this in the seminar? When I spoke I said, ah, but how can you understand... I did it in Rapanui! Sorry. It was to reinstate this concept in our people. And so I asked "Is that right?" And the people said "yes, it is like that" (Ana-14). 
The concept of land as mother that is described in the above quotes shows the deep importance land holds in these women's lives, and the significance kaina carries in the cycle of all Rapanui people's lives. Spirituality in itself is to be connected to the land therefore making land the very foundation of Rapanui existence and being. The land, just like a female body, is where nourishment and sustenance is gained, creating an intimate link between women and the Rapanui territory.

Recognising the important connection they have with their kaina as Rapanui, but specifically as women, participants also importantly noted that this relationship is changing and that these beliefs articulated above are not felt by some Rapanui, particularly younger generations. As a result of colonisation, the respect and appreciation for their land as the mother of all Rapanui is diminishing, leading to practices that are unfamiliar and contradictory to Rapanui beliefs about land and the importance it holds in Rapanui lives.

Many participants recognised the land as the mother of all life and acknowledged the sacredness of kaina and the interconnectedness they share with it as women. Like Fiske (1996, p. 74), who states, "the earth is the original mother of nations; nations must go back to the Earth to find their healing", these women's struggle is not only to regain their kaiga physically, but is an effort to rebuild and reaffirm the cultural and spiritual beliefs that are connected to it in order to ensure the future generations have a rootedness in the world, based on knowledge systems that foster their growth and development as a people.

\section{Holistic economic development?}

Land is increasingly viewed by some Rapanui as a commodity from which their material well-being can be improved. While the participants in this study all agreed that land can and should provide economic security for the population, they also all agreed that the selling of their land was the wrong way to achieve this. The growing culture of consumerism and materialism that is stimulating land sales is articulated in various ways by these participants. Self-determination on all levels including greater political autonomy to make decisions about their land was promoted alongside the 'undoing' of colonialism's influence on Rapanui culture, as fundamental necessities to ensure Rapanui well-being and positive Rapanui development. 
One member articulates how cultural changes are pulling at the threads that hold the Rapanui community together. She states:

[It is] super complicated. The land is what is dividing us now. It's amazing, but it has produced, is already beginning to produce the breaks. It's starting to produce super-strong social breakdowns. Because some people think the land belongs to us, [that it is] individual property, and the more land I have, the more powerful I am... (Maria - 15).

She notes the social consequences of this changing perception and treatment of Rapanui land and the effect it is having on the community. Underpinned by the development of a consumerist culture on the island, the social breakdowns she refers to are resultant of Rapanui people losing the intimate relationship they once had with their land.

Under the Ley Pinochet in 1979, the concept of private property and individual land titling was instituted for the first time in Rapa Nui (Delsing, 2009).98 This titling disrupted Rapanui management systems and land administration between and within clans. Similarl to Maria's comment above, another participant also notes that land is increasingly seen as a material good, not, as she advocates, what should be seen as a fundamental basis for Rapanui peoples' development.

The people began to receive the paper (land titles), from the state, to be safe... And, also it produces a significant change regarding the meaning of kaina with respect to the person, you know? The people begin to seize the kaina, like it is a material asset. It is no longer a kaina where I develop myself, as an individual, as a person - what I need to develop myself... But rather more like a material good (Ana-16).

This quote neatly articulates the contrast between neoliberal models of private property and economic development, and what she believes is positive Rapanui development. While all these women recognised the pivotal role land has to play in the future development of their island, it is clear they do not subscribe to a capitalist, growth-based model of development and they astutely disagree with the sale of their most precious resource. Recognising what development anchored in

98 Delsing (2009) also notes that loans and housing subsidies were used by Chile to lure people into asking for titles. 
indigenous and local knowledge should constitute (Gegeo, 1998), these women critique the current practices on the island, advocating for a people-centred approach in which Rapanui are able to determine their own sustainable agendas, control their resources and work towards achieving self-determination as a people.

Another Makenu member notes, with respect to the changing culture and ideology regarding land, how her struggles are in fact a fight against her own people. She says:

The worst of the fight is against my own people. Do you know why I say this? Because the stability they have themselves, with themselves, they do not grasp that this is beautiful, paradise, beautiful, their own island. It... it is beautiful. So, they have to focus on that... to appreciate it. Love and love its people... they want to touch what the eye sees... They want to have the same thing. To have the same, you have to sell your mother. Basically the same, poh. Do you understand? That is my fight against my own people. Because if you sell your piece of land, it is like you are selling the mother (Alicia - 17).

The selling of land for trucks, scooters, and material items was frequently and forlornly noted by the women with whom I spoke. Heavily concerned about the selling of land for these dispensable items, they grieved for the future generations who were being robbed of their land by community members who, as this participant articulates, are "selling their mother".

As some Rapanui acquire more and more land, a finite resource on the island, inequalities and poverty proliferate as landed and landless classes have developed. The Ley Indigena of 1993, while prohibiting foreigners from owning land on the island, makes no provision for land exchanges between Rapanui. ${ }^{99}$ Land returned to Rapanui during land redistributions such as the first entrega, ${ }^{100}$ has been the

\footnotetext{
99 Many women noted that a law should be created forbidding the sale of land on the island amongst Rapanui people. This articulates the complexity of decolonisation processes, as these women are working within Chilean systems to achieve their aspirations, while simultaneously condemning Chilean laws and structures for their continued oppression.

100 For discussions on land redistribution and concepts of land and titling, see (Andueza, 2000; Gomez, 2004).
} 
source of the land that has been sold, allowing some to accumulate many parcels, leaving others with none. ${ }^{101}$

The continued dispossession of Rapanui from their land, beginning at the time of the missionaries, then through divisive titling, national park limitations and systems of law more generally, has allowed for and promoted a cultural understanding of land as a property; a material asset in which individual economic gain is attainable and increasingly desirable. Makenu women's perspectives resonate with Trask's comments when she asserts that "Hawai'i, our ancient and erotic land, is the female object of degraded and victimized value. Our '...aina, or lands, are no longer the source of food and shelter, but the source of money. Land is now called 'real estate,' rather than Papahanaumoku, 'she who gives birth to islands'” (Trask, 2000, p. 1). While different from Hawai'i in that only Rapanui (and the Chilean state) can hold title and 'own' land on the island, the values that guide Rapanui treatment of this precious resource are changing to the benefit of only some Rapanui, and outsiders (mainly Chileans) who support the projects of wealthy Rapanui landowners.

101 In conversations with members of the Development Commission, I was told in the next entrega they would try to make a provision, whereby it will not be allowed for land received through the Development Commission in the entrega to be sold, and families will be placed on the titles rather than individuals. 


\section{Summary}

The type of development that has been occurring on the island is fundamentally critiqued by the women in Makenu. Through their stories we begin to see what positive development on Rapa Nui would look like; one that centres on people, not merely material gains, and is concerned with well-being, which involves regaining and reaffirming cultural and spiritual beliefs. Where land plays a critical role in Rapanui development, not as a material asset to be sold and accumulated, but as a foundational basis for reinvigorating and maintaining Rapanui culture and identity.

The next chapter discusses the issue of immigration on the island, a key concern for women in Makenu. Immigration presents multiple challenges to the Rapanui population, many of which resonate with the discussions articulated in this chapter. Immigration and kaina are intimately linked. This is further shown through the stories in the following chapter and drawn out in the final section. 


\section{Chapter Seven: Unfettered immigration}

\section{Introduction}

Rapanui peoples' ability to maintain their cultural identity, to defend the integrity of their kaina, and to keep the equilibrium of their delicate environment is articulated to be largely predicated on managing the flow of people who inhabit this small and fragile place. On an island of its size with such a tiny population, the Rapanui are being outnumbered. Rapanui peoples' ability to maintain their cultural attributes without some controls over what occurs on their island is increasingly difficult as more people arrive daily. Lacking a strong self-government has inhibited their ability to deal with matters of immigration (Delsing, 2009) and their tight integration into the Chilean nation-state has made this an increasingly difficult endeavour. In the following section, we see how immigration challenges not only their cultural integrity but also their environment, in which the very survival of the island and people are at risk.

\section{Population flows}

Below, I present some data on immigration to the island in order to fully appreciate the current situation on the island with which these women and all Rapanui people are confronted. In Rapa Nui's last census in 2002, 98.36\% of the total estimated 3,791 people on the island lived in Hangaroa ("Censo 2002, Chile,"). The next census is due in August 2012, and estimates for the island's current population are placed much higher. Below is a table with these predictions through until 2024.102

\begin{tabular}{llll}
\multicolumn{4}{c}{ Years } \\
& 2002 & 2014 & 2024 \\
\hline Population & 3.791 & 5.570 & 7.638
\end{tabular}

Table 1: Ministry of Housing and Urban Development - population estimates ("Estimaciones de poblacion," 2007).

102 Estimates for the population on the island while I was there already put the number close to the 2014 rates. A current population of approximately 5000-5500 was the estimate I heard from various people. 
For an island of only 166 square kilometres, these predicted population increases are substantial, as well as the fact that most of the island lives in and around Hangaroa with most other parts of the island lacking the infrastructure for an expanding population - such as electricity and running water.

The chart below shows the population density over approximately the last 100 years, demonstrating the drastic increase that has occurred over the last two decades. It is interesting to note the substantial rise in population density around 1966 which was when Rapanui people became citizens of Chile. This is when the fence that enclosed them in Hangaroa came down, and the airport was built, integrating the Rapanui into an increasingly globalising world. ${ }^{103}$

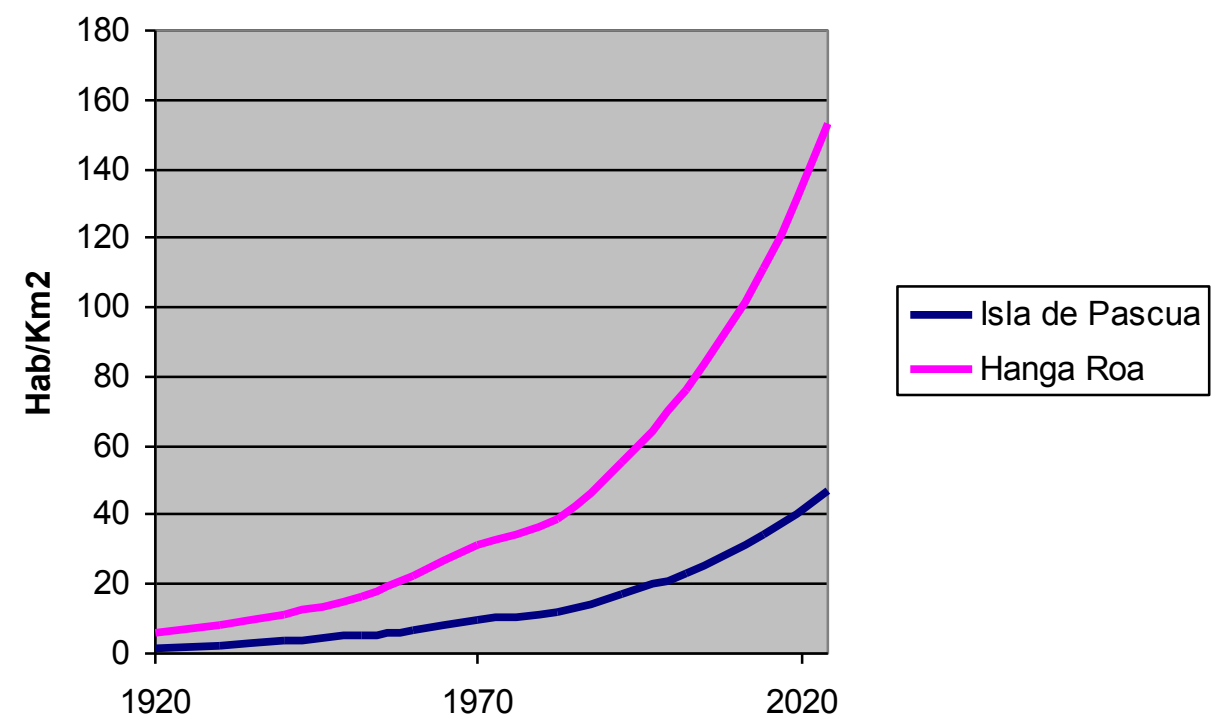

Figure 9: Ministry of Housing and Urban Development - population increase Ministry of Housing and Urban Development ("Estimaciones de poblacion," 2007). ${ }^{104}$

According to the Census in 2002, the island population would have grown by $35 \%$ in the last seven years, reaching the current population which is estimated at about

103 The drastic increases in population seen in the chart can largely be attributed to the increase of flights from Santiago to Rapanui, which would have increased by $170 \%$ between 2004 and 2009 ("¿Proyecto de Ley para restringir acceso a Isla de Pascua?," 2009).

${ }^{104}$ The $Y$ axis of this graph stands for the number of inhabitants per square kilometre and the $X$ axis is the years beginning from 1920 until 2020. 
five thousand. Of this number, only $40 \%$ are ethnic Rapanui ("¿Proyecto de Ley para restringir acceso a Isla de Pascua?," 2009).105

Bearing these statistics in mind helps to gain a greater understanding of and appreciation for some of the concerns that the women shared with me regarding immigration to the island, and the matter of urgency from which they spoke about it. In the following story, there are three Makenu women talking about immigration, which befittingly articulates the common sentiment that I heard from many of the women I shared time with while on the island and from other community members as well.

Ana: If somehow we, we as a people, we can ask for territorial and human protection, that is, all the heritage, so that they don't continue to determine how... what to do with the island, what to do with our patrimony. I mean, we have to get involved, right? Being consulted to reach a determination... Because here, it is an issue of consciousness with our people... Of awareness among the people, and a matter of what remains of Rapanui people; there are not many of us. And this immigration that has come to us has been like they have dropped a ton of people over. And obviously the State, the State must find a way to legislate on this territory to also benefit those immigrants, who are Chilean, also. Immigration is urgent, urgent - because they really are arriving daily in by plane, bringing relatives of the people who live here...

Ximena: And with bad habits on top of that.

Ana: And it makes me disgusted to go to the airport.

Marisol: So, the state policy, I think that the state is going to begin to think about how to protect as well... with this large number of people that are coming.

Ximena: This is like Haiti... This is like Haiti. Throw all the rubbish of Chile, Chile's backyard. Throw everything here.

105 The changing demographics were not brought to my attention only by my participants, but by many non-Rapanui who know the island well (on and off the island). They too claimed that Chileans are outnumbering the Rapanui, and comments such as, "you barely see any Rapanui on the streets anymore" and, "it's all just pure Chilean Spanish that you hear" were frequent (pers. comm.). 
Marisol: They all come, all week with 15 to 20 people that are family members, the brother-in-law, the neighbour, everyone. And they all go to the house where their families live... a free house, and delving into our island, making a mess, rubbish... It's terrible, terrible.

Alejandro: It is urgent, an urgent question - immigration control.

(Makenu group meeting, Makenu Ana, Ximena, Marisol, and Alejandra 18)

The sadness, frustration and anger that these women feel, reverberates throughout this discussion. They illustrate not only the severity of what is occurring on the island and their perceptions of this problem, but also their unwavering resolve to address it as a fundamental requirement for their island's survival. It is also important to note here that these women are not opposed to Chileans as such, and do not advocate for the removal of all of the foreigners on the island, as the comment regarding legislation for those who already live on the island suggests. However as long as the Rapanui remain under the Chilean constitution without terms which afford them greater self-governance and control, the issue of immigration is left up to the State to handle, not the Rapanui people. These women are frustrated by that reality, as the quote above clearly articulates.

One of the most substantial pieces of work Makenu developed was a survey of sorts, in which various issues were discussed and the perspectives of the Rapanui community were requested. 106 It was called, "Informe Technico: Aplicacion instrumento de consulta al Pueblo Rapanui (apapa I te mana'u)". Its purpose was stated as: "This report accounts the application of a social research tool called 'Apapa ' $\mathrm{i}$ te mana' $\mathrm{u}$ ' and is aimed at learning the opinion and perception of the Rapanui people regarding the issue of immigration control and the so-called 'Special Status of Government and Management of the Territory of Easter Island', that the Chilean state is trying to impose on the island of Rapa Nui" (my translation). This informe consulted over $70 \%$ of the population who are between 16 and 90 years old, with the average consulted being 39 years of age.

\footnotetext{
106 This piece of work can be found in Appendix Seven.
} 
The initial results of this survey were announced at an assembly of Rapanui people held on the $15^{\text {th }}$ of September 2009 in the auditorium of Lorenzo Baeza Vega School, the same day Chile completed the ratification process of the ILO convention 169. The purpose of the informe was to help substantiate Rapanui claims towards immigration and their island's governance. Serving as a sort of census amongst the Rapanui population, highlighting their opinions and their demands, the information generated by this document is pertinent. It should provide a valuable tool for bargaining and negotiating with the Chilean state, which claims consultation with the population, as it cohesively brings together Rapanui sentiment about important issues confronting the island. While Makenu sought to generate opinions from fellow community members, in order to better understand how they felt about the issues of immigration and the Special Statute, the initiative itself was also an awareness raising tool as it brought these issues into the forefront of Rapanui considerations, while building consensus and unity amongst the population.

The informe conducted by Makenu showed that $99.9 \%$ of Rapanui believe there should be a control of immigration to the island, and $98.4 \%$ believe a regulation should be implemented to monitor who can enter the island and for how long they can stay (relating to tourism).

The flow of people to Rapa Nui has been consistently on the rise over the years, as the charts and graphs above clearly show. Not formerly a 'settler colony', Rapa Nui is increasingly inhabited by Chileans who are today estimated to hold the majority population on the island. Chile's tight control over Rapa Nui and the lack of autonomy they have to make decisions is compounded by the arrival of such large quantities of Chileans to the island, making it increasingly difficult for Rapanui to maintain their culture, language and values - their identity as a people. Ana notes this, stating:

Well, there came a time, there was a time... when I think that - when they come in such quantity, when the people come, another idea also comes, another way of life arrives (Ana - 19).

This 'other way of life' that is arriving in such quantities, is what is making it difficult for Rapanui people to maintain their customs and beliefs, as Rapanui 
children are growing up in a different cultural space, one which is increasingly more Chilean that Rapanui. In one interview, a participant expressed her frustration with the manner in which Chileans come to Rapa Nui, noting from her perspective how immigration and the mixing of cultures makes it difficult for Rapanui to maintain their own cultural systems and beliefs. She expresses:

They are ruining our culture, they are mixing with our culture and they don't care, they don't care to learn anything about Rapa Nui - nothing. Nothing! You talk to them and you can't speak to people that don't have any idea where they are standing. They don't want to adapt to our culture (Alejandra-20).

While most Rapanui will have a Chilean in their family, and certainly do not believe all Chileans are 'bad', as this quote might lend itself to be interpreted as, the fundamental difficulties that immigration presents to Rapanui culture and their survival as a people is at the heart of what this woman critiques. It is the lack of control and ability to regulate these flows that make it increasingly difficult to maintain their identity within their own territory. Being the minority in their own land presents particular problems for them as a people, and these are perpetuated in political, cultural and environmental ways.

One Makenu group member discusses how it is not Rapanui people that are benefitting from kaina and the development that is occurring on the island, but rather the government and mainland Chileans. She explains:

So, for me, they are using, they are taking advantage of kaina for their benefit. Taking it, taking it from here to the outside. They are not working in our territory, so that this community can develop. No, do you know what I mean? They grab hold of all of the profits and they take them away. All of it, but they leave the poop here, poh. AND, they don't pay taxes. And that is why, I think, that they have found a gold mine here. They don't pay taxes! So they are people who have, who have economic power, and riches and more... at our expense. Our riches is our kaina, you know? And this... this bothers us... (Ana-21). 
This participant highlights how a tax-free environment for Rapanui as well as Chileans, allows businesses to make indeterminate amounts of money with no obligation to contribute to the community in substantial ways. If Rapanui are not able to make decisions about how their island is managed and the flows of people that are allowed to access their resources, they are vulnerable to outside influences, Chilean and foreign alike, and will not necessarily benefit in ways that help support community development.

\section{Immigration and Rapanui Kaina}

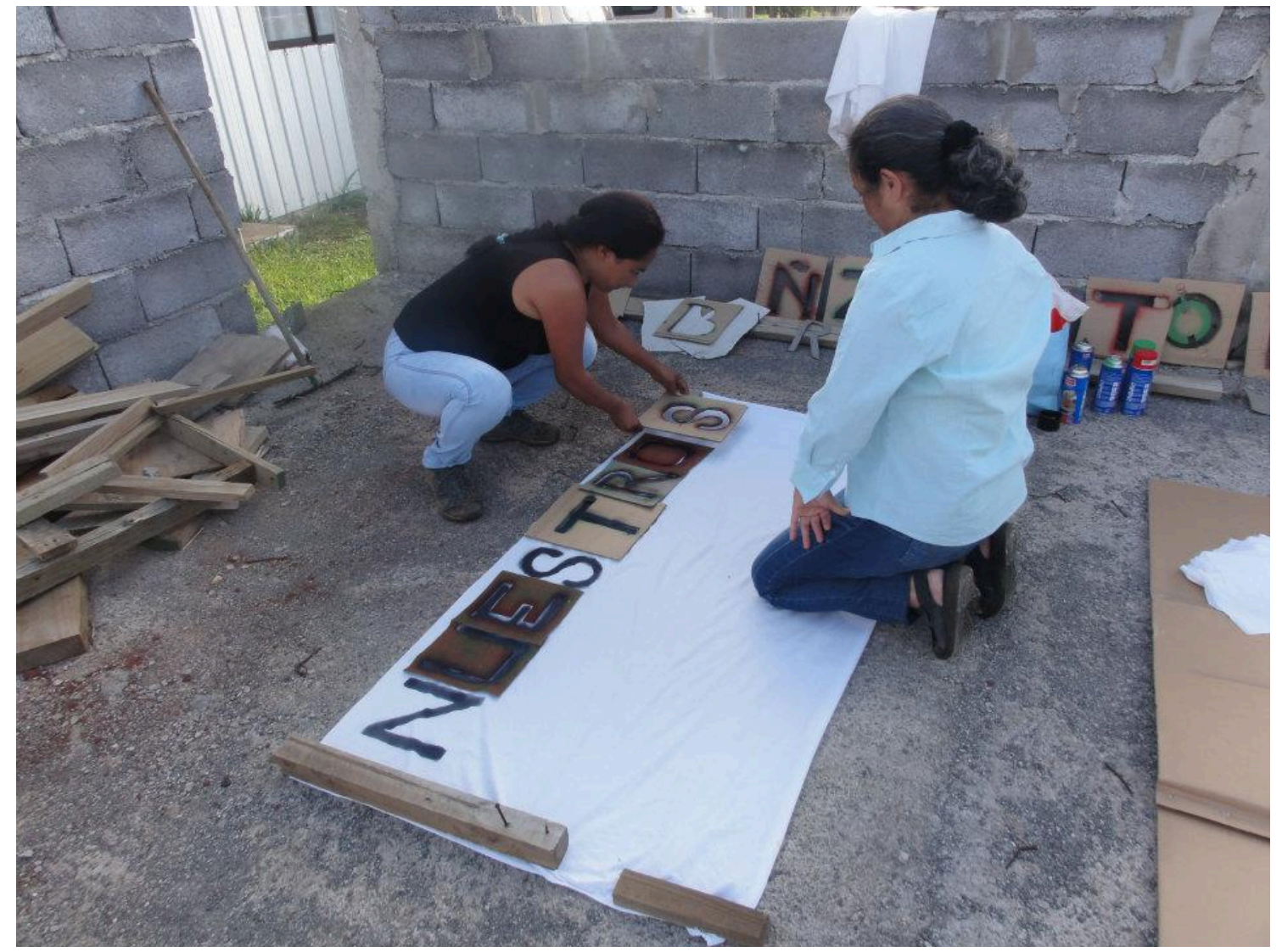

Figure 10: Preparing for the $23^{\text {rd }}$ July protest

(Karly Christ, 2011)

Issues pertaining to the immigration topic were largely underpinned by concerns for kaina, the ability of future generations to have access to their land, and Rapa Nui's environmental sustainability. Agricultural production, spaces for living, and the island's ability to cope with environmental issues arising from overpopulation were critical concerns discussed by participants. The collapsing of services on the island were noted, such as the lack of proper rubbish disposal, which was said to be a threat to the the water table; high demands for electricity which are unable to 
be met, leading to frequent blackouts; inadequate hospital services; serious problems of overfishing; insufficient education supplies and facilities; and shortages of daily provisions. These problems are exacerbated by the dramatic levels of immigration to the island and are leading to serious environmental problems. Women's concerns relating to immigration were underpinned by their concerns for cultural and environmental sustainability, focusing on the island's resources and its ability to cope with such human impact.

In the quote below, this Makenu member articulates how intertwined kaina and immigration are, and the challenges that the Rapanui people face. She states:

So, we see, in some way how this threatens us... the arrival of many people to Rapa Nui. And each time, this territory, this kaina is diminishing, and going to diminish... So in this moment, the group of women is focused on, well, to protest the control, the number of immigrants who arrive here, and stay on Rapa Nui... each time we have less to be able to 'be'. We are able today, still, to plant and harvest for sharing. Share with our family, with people who protect us... It is a situation that I think is almost logical. If while you are pregnant you have several babies, the babies compete for food that comes from their mother. And I compare that with this home, that there exist limited resources to feed ourselves - biologically and spiritually. So, if we continue to feed as we have been, producing nearly a decade of people, we are going to collapse at any given time (Ana-22).

This Makenu member highlights very specific issues of sustainability that confront the island. The support kaina can offer is limited, unable to nurture all of the people who feed from her, physically as well as spiritually. Using this beautiful analogy of a mother and her babies and how they compete for food in the womb allows us to appreciate how she interprets the effects of unregulated immigration to the island. As immigration continues, Rapanui quality of life gradually decreases, and living becomes increasingly a matter of basic survival.

The rights of Rapanui children to the land left to them by their ancestors were frequently discussed with regards to immigration and the pressure it was putting on Rapanui kaina. Immigration encroaches not only on the environmental capacity of the island but also deprives Rapanui of their birthright. 
One Makenu group member makes clear links between the topic of immigration and the issues of their land. She states:

It's because we... for us... When we stopped the plane, it was immigration. Why immigration? Because the land does not need that much. Land is the basic one. We know. It is the struggle - the land (Alicia - 23).

This woman claims that for the Makenu group, while fundamentally they all believe that the 'real' struggle on the island is for Rapanui land, their concentration on immigration is a means to protect their kaina and the physical as well as spiritual connections they have to it. The last two quotes particularly link the issue of land and immigration to a fundamental struggle for the same thing in which decolonisation is critical to ensure Rapanui development in the future is positive. Focusing on immigration is one strategy for achieving more control over their island and their kaina, as well as their culture, and is seen as the most pressing issue. The situation that the unregulated flow of people presents in Rapa Nui is a matter of urgent concern in which other priorities of these women are encapsulated, such as cultural reinvigoration and recuperation of the Rapanui territory.

Makenu members have identified some challenging issues that confront their island and their people. The passion and frustration these women have echoes throughout each quote I have presented here. To deal with the challenges they face, they have been resourceful and dutifully committed. Some of the ways in which they are dealing with this topic are cited below. 


\section{Visiting San Andrés}

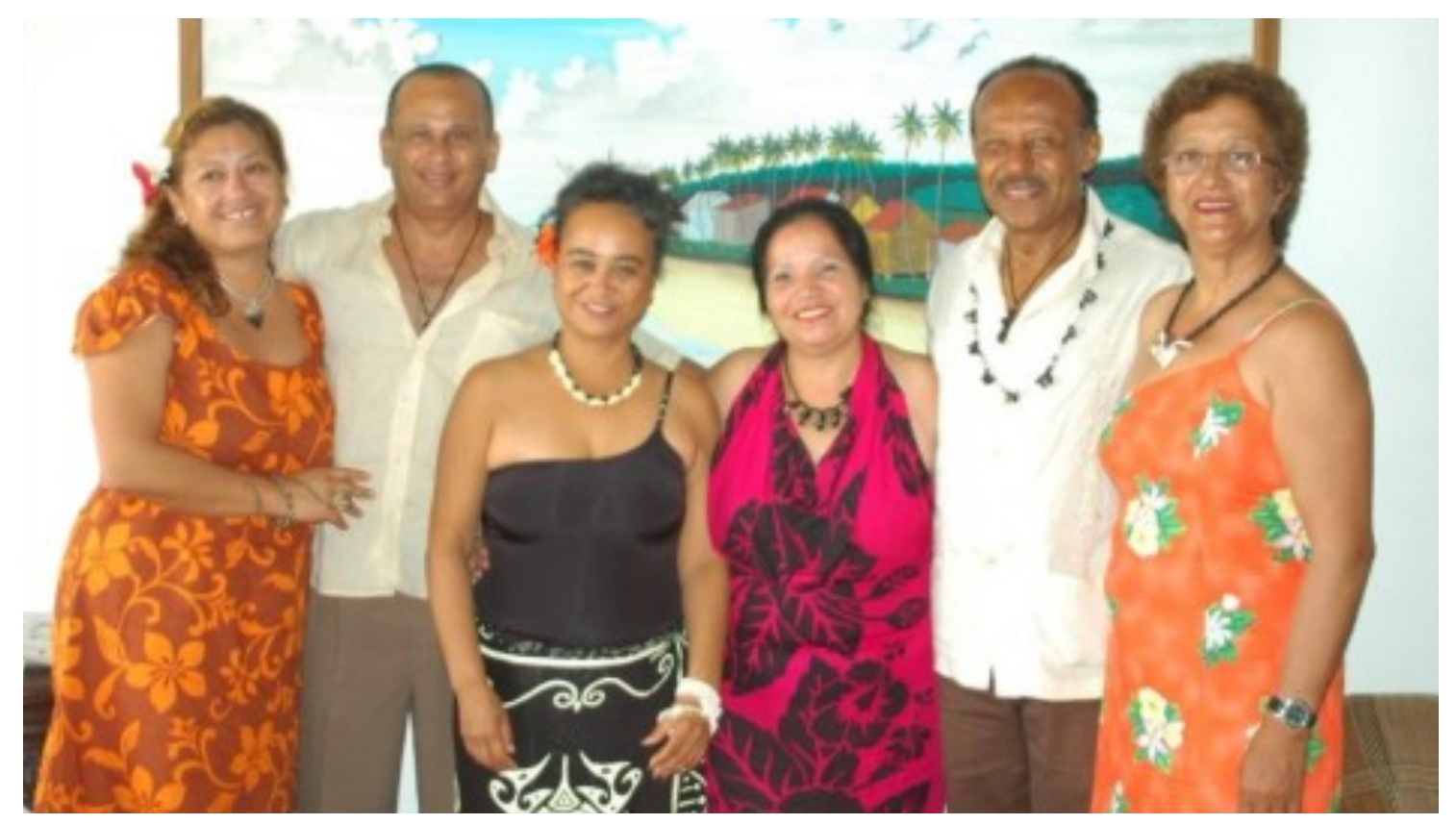

Figure 11: Four women from Makenu in San Andrés, Colombia

("Occre: modelo internacional," 2010)

In 2010, four women from the Makenu group flew to the San Andrés islands to see how their population flows are managed and what their policy might offer the Rapa Nui situation. These women in Makenu went there to "learn from the experiences of San Andrés, which has had a special law since 1991 for population control" (member of Makenu, Valeria Pakarati, cited in "Occre: modelo internacional," 2010, my translation ). The Colombian archipelago is located in the Caribbean Sea, approximately $200 \mathrm{~km}$ from the coast of Nicaragua and $800 \mathrm{~km}$ northwest of the coast of Colombia (Mow, 2006). In 1991 the Columbian government recognised special rights and statutes to a diversity of populations and their territories (Valencia, 2011) which included a policy on population control. With a total land area of $57 \mathrm{sq}$ kilometres, these islands are a little more than a quarter of the size of Rapanui but have a population of more than 83,000 people. Like Rapa Nui, native islanders are an ethnic minority.

Makenu has been consistently trying to make links with international organisations and other indigenous groups involved in similar struggles. Frequently reading about how other indigenous peoples have had success or failed in their efforts, they endeavour to inform themselves about all the possibilities and opportunities that might exist for their island. 


\section{Drafting a migration law}

The Makenu group, in conjunction with a Chilean lawyer whom they trust, drafted a proposal for the constitutional law of migration for the special territory of Rapa Nui in December of 2010 ("Propuestas para Ley Orgánica Constitucional de Migración al Territorio Especial Rapa Nui," 2010). This proposal was developed to assert Rapanui expectations of such a law and push the issues forward. ${ }^{107}$ Some key aspects of the law detail the requirements for becoming a "permanent resident" within the Special Territory. It states that there should be a limit and a policy which regulates the entry and stay of people on the island. It asserts that all Rapanui people shall have the status of "permanent Rapanui resident." It articulates how foreigners and Chileans alike can obtain the status of permanent resident, and it details what would lead to a loss of privilege.

As was discussed in more detail in Chapter Four, the special statute as it now stands does not include a policy on (im)migration, which is why it has so frequently been rejected by the Rapanui population. Seeing immigration as one of the critical issues confronting the island, a special statute that does not set forth a policy addressing this issue is incomplete, and does not take into account Rapanui aspirations for their island as a special territory, in which a special administrative status is warranted. Additionally, as the informe conducted by Makenu shows with regard to the special statute, $86.6 \%$ of the population indicated that they were not consulted with regards to the special statute, a process that was supposed to heavily involve the Rapanui population. Given the consultative commitment on the part of Chile, particularly through being a signatory of ILO 169, this issue should have been addressed sooner. Women in Makenu are working hard to push this issue with the government, seeking to make their voices heard within the state structures that determine the future environmental and cultural viability of their island.

\footnotetext{
107 This proposal document can be found in Appendix Six.
} 


\section{Summary}

The issue of immigration is a fundamental concern for women in Makenu as it is a clear affront to Rapanui quality of life and cultural integrity, as well as raising important issues of sustainability. Immigration is on the rise and for an island as small and fragile, this is of grave concern on various levels. The inability of Rapanui kaina to provide for the amount of people on the island both physically and spiritually presents immense challenges to creating and maintaining a healthy and sustainable lifestyle for Rapanui families and their future generations.

The issues and concerns Makenu women expressed throughout the previous three chapters are largely articulated through development discourses in which a critique of current practices and the type of development they are experiencing is offered. These issues and concerns are constructed and prioritised by the forces and stresses of colonisation and decolonisation. Makenu women seek political decolonisation, in order to achieve self-determination and a development agenda that is meaningful and people-centred, in which a positive Rapanui identity is fostered, and justice, equity and well-being are of central priority. 


\title{
Chapter Eight: Decolonisation for development - Makenu's approach and critiques
}

\begin{abstract}
The political right to a "traditional cultural identity" inscribes itself in modernity but at the same time modifies the existing conceptions of "tradition" and "modernity". It refers to the right of peoples to autonomously design their cultural and development profile, on the basis of a "collective political will" (Zanotta, 1994, p. 75).
\end{abstract}

\section{Introduction}

The aim of this thesis is to explore how women in Makenu Re'o are engaged in decolonisation struggles on Rapa Nui. As was asserted in Chapter Two, women's roles and contributions to anti-colonial resistance have frequently been left out of studies of decolonisation, yet they play an important role within these processes. I contend, based on the stories and voices presented in Chapters Five, Six and Seven, that women's involvement in these struggles is important not only for Rapanui decolonisation but for positive Rapanui development. Therefore to understand development processes on the island, women and decolonisation must be central to the analysis.

This chapter presents my reflections on the stories in the previous chapters, based on what I have seen and experienced, and the knowledge I have gained through the process of conducting this research in conjunction with the literature in Chapter Two. The first part of this chapter discusses the development critiques offered by Makenu in the previous three chapters, before describing further what positive development means for the women with whom I spoke. In the second part, I illustrate the cultural and political decolonisation processes that Makenu are engaged in, as well as the key strategies they use, helping further accentuate how paying attention to women contributes to a fuller understanding of the decolonisation processes occurring on the island. Lastly, I offer some final reflections pertaining to native feminisms and Makenu, my own feminism, and my approach to this research. 


\section{Rapa Nui's modernisation}

I believe that development destroys something... to choose something because it has an economic status - it is dangerous (Ana - 24).

Development processes have rarely been the centre of research pertaining to Rapa Nui. When development has been discussed within scholarly works, it has frequently been considered as Rapa Nui's "modernisation process" (see Porteous \& Shepard-Toomey, 2005; Shepard-Toomey, 2001). Since Chile annexed Rapa Nui in 1888, the island's exploitation and the type of development promoted has been determined by the Chilean state through various government organisations located on the island as well as in Santiago, and the Chilean navy (Porteous, 1981; Shepard-Toomey, 2001). It has focused nearly exclusively on the economic development of the island. As such, Rapanui ideas for development have seldom been the centre of these initiatives and it is through the Chilean State that development aspirations for the island have been realised, often ignoring Rapanui visions and concerns within development programmes and projects (ShepardToomey, 2001).

It is not within the scope of this thesis to critique the development programmes in Rapa Nui, or to highlight all the various projects that have taken place. ${ }^{108}$ Rather, my intention is to reflect on some of the concerns Makenu articulated and their critiques of current development occurring on the island today. In doing so, I hope to illuminate what some of the attributes of positive Rapanui development might look like, through the perspectives and experiences shared by Makenu. The intertwining of decolonisation and development aspirations becomes increasingly obvious in this section where their development critiques are notably linked to colonial imposition on the island.

As was described in Chapter Four, while the infrastructure was improved and the island was opened up to economic development, the development in Rapa Nui post-1966 was culturally problematic (Delsing, 2009). Chile's approach to developing Rapa Nui was to incorporate the Rapanui people into the mainstream of national life (Porteous, 1981), whereby political and economic reconstruction of

\footnotetext{
${ }^{108}$ However, this is an interesting area of research that could be conducted in the future.
} 
the island was essential. The approach taken to developing the island is resonant of ideas of 'modernisation' and 'progress' which constituted the foundational basis of development ideology, and is consistent with concepts of 'catching up' and generally imitating those more 'developed' (Dodds, 2002). While it is undeniable that living standards and the abject poverty that existed in Rapa Nui prior to 1966 has been lifted, it has not come without a cost. The women in Makenu seem to acutely recognise this point and express it through their articulations of the development they see and the development that they wish for themselves and their community. The growing inequality on the island, the environmental concerns of unregulated population growth and the centrality of reinvigorating Rapanui culture and identity, all play foundational roles in Makenu's critiques and aspirations for their island.

Makenu members ask important questions pertaining to the economic development occurring on the island including: Who benefits? Who suffers? What trade-offs have been made? What is the consequential balance of power and privilege between and among members of their community? (Cornwall, 2003; Reid, 2004). These questions, and their answers to them, are what has guided their critiques and led them to take the positions that they do regarding the development of their island.

\section{Rapa Nui's growing inequality}

A critical concern for the women in Makenu was the growing inequality between members of their community. In a society where reciprocity was a central tenet of social relationships, it was expressed that through the expanding desire for greater material wealth and the growing consumerist culture on the island the gap between rich and poor is increasing. Social relationships within and between families is changing. Land was frequently articulated as the basis of this changing cultural engagement, as it was increasingly perceived as a material asset; one that can bring greater power and wealth to the person who wields it. This was repeatedly articulated by women in the group as a fundamental problem. Through these changing cultural ideas, alongside the colonial systems in place to support them, landed and landless social classes are being created on the island, which previously have not existed (Delsing, 2009). One member, who has daughters who 
are approximately 30 years old, noted how the changing cultural ideas vary between the generations stating that:

I would have to say that from the point of view of my daughters' generation, that if development is about the quality of life, or I mean, there is consumerism, if that is development, if that is the quality of life... I mean consumerism is incorporated in the idea of quality of life... they (young people) are thinking about consumerism. They are thinking in, I don't know poh... a new scooter, a way to get out of here. Of others things 'over there'. In work that rapidly gets them a better economic status... and for us, we are a generation more, more attached to our kaina. More attached to the idea of sharing. I share and that makes me happy... I am satisfied in sharing, in sharing with others. And not just accumulating for myself (Ana $-25)$.

Economic development on the island has been predicated upon the growing tourism industry, which along with mounting immigration has brought different cultural notions to the island. All of the women in Makenu I spoke to recognise that tourism is the central means through which the Rapanui people can economically sustain themselves, and is required in order to fulfil their desire for selfdetermination. However women in Makenu critiqued how some people are engaging within the industry. These critiques mainly pertained to the buying and selling of land and the material gains being made at the expense of Rapanui cultural values and ways of life. Makenu women want a type of economic development that honours their culture and is conducted in a sustainable manner, in which deciding between cultural integrity and economic security is not a choice they must make.

As previously discussed, the majority of the proceeds from the island's national park, the biggest revenue source on the island, are returned to Chile. The tourism infrastructure on the island, such as the hotels and restaurants, all lie in the hands of local Rapanui, not foreign investors or the Chilean State. ${ }^{109}$ However, some Rapanui seeking to expand their tourist enterprises have purchased land from fellow Rapanui, and have embarked on business arrangements with foreigners willing to economically support their endeavours. Some members of the

\footnotetext{
109 The exception to this is the Hotel Hanga Roa.
} 
community have done exceedingly well for themselves, with a few Rapanui becoming millionaires. Members of Makenu asserted their discontent with the level of wealth acquired by some, in which the greater community was not benefitting, through neither the traditional systems of reciprocity nor through taxes that could support development on the island. To this end, one Makenu member noted how the money from the archaeological tourist industry, which is the primary source of tourism revenue and is controlled by CONAF, 110 suppresses Rapanui ability to maintain basic infrastructure. This is coupled with the lack of taxes which results in the stifling of Rapanui development capabilities. She explains:

So, this money, we don't keep here. It leaves from here, to let's say Chile. And perhaps, I think that if only the money from CONAF, no more, from the tourism, stayed here, the island could develop -- in roads, in services, much more than, what is today, their headquarters (CONAF). Look, at the resource of our school. You have seen our school. We don't have enough furniture, and the municipality, that has to do with the school. And, and the municipality says that they have a low budget, to try to solve all the problems in education, health, roads, social work...they say, that if there are no taxes either, we cannot... they don't have money to repair the roads, or to repair our school. So, it's a vicious circle (Ana-26).

I was told during my time on the island that $60 \%$ of the profits made from the national park and tourism flow directly back to Chile and only $40 \%$ remains on the island. ${ }^{111}$ The quote above from this Makenu member suggests that Rapanui people, if able to benefit from their own patrimony would be able to direct those funds in ways appropriate to the needs of Rapanui people. While not suggesting that taxes be implemented without other areas being addressed,112 some women suggested that the wealth and benefits made by some should be shared among the population, rather than expanding the inequality that exists.

\footnotetext{
110 National Forestry Corporation (Corporación Nacional Forestal de Chile)

${ }^{111}$ Makenu members noted that the amount that stayed was significantly less until they protested and demanded more money remain in Rapanui. I was unable to find any statistics on how money flows in and out of the island. However this 40/60 figure was mentioned to me by multiple Makenu and no less than three people outside of Makenu.

112 One area would be the cost of living. It was noted by participants that the Rapanui people would not be able to live if taxes were implemented because the cost of living is so high.
} 
Land is the key resource that has the ability to sustain Rapanui for generations to come. There are now many people on the island who do not hold land and some who possess a lot. Some of those without have taken up residence illegally outside Hangaroa in the national park, or other parts of the island where they have ancestral connections. Additionally, as a result of these land transactions, there are currently 1,180 people who are asking for land in the next entrega, of whom only 250 will be allocated land (pers comms). Some people received land in the last entrega, but then sold it or as the case with some young people, had it sold from under them by a family member. While the concepts of private property and individual title to land have been beneficial for some Rapanui, for others it has been detrimental both economically and culturally. Simmonds (2011) notes, social issues are created within the community as indigenous people are forced to live in two worlds in which they must constantly negotiate tensions. While some members of the community agitate against these cultural changes, others welcome them. As one Makenu member articulates, she believes it is unawareness for some that leads them to sell their precious resource.

They don't have a sufficient awareness that land is not to be sold, poh. You cannot sell the land. And with young people... So much! So many young people sold their land. And the businessman buy, buy, buy. Buy land. And obviously at some point, here, you will see that some people are going to have a lot of land - and others not, poh... and this is a problem (Ana-27).

Kaiga, it was noted, is the birth right of the Rapanui people, yet many Rapanui on the island currently do not have land in their possession and this number is increasing. The lack of land has led some young people to rent houses; a custom that these women expressed was not a Rapanui cultural attribute. Land intended for these young people and the generations that follow them was sold by them or other family members in exchange for a car, truck, scooter, or a big screen TV. One member notes:

It is almost absurd. It's almost ridiculous that young people of the island have to pay rent. Renting is not a concept of ours, to live. Because it is assumed that there was enough for everyone (Alicia - 28). 
The Indigenous Law of 1993 only allows native Rapanui to own land. However the offspring of Rapanui are all entitled to land on the island regardless of who the other parent might be. If a Chilean woman has a child with a Rapanui man that child is entitled to land, and so the mother stays and lives on the land of her son or daughter. This has led some people to refer to Chilean women as "cinco hectáras" or five hectares. This references the five hectares policy of the first entrega and gestures that Chilean women procreate with Rapanui men so that they can own land on the island. Regardless of how this occurs, the pertinent issue is that more and more people are entitled to land on an island where the resource is, of course, finite. This was a consistent concern, as the more people that come to the island and have children with Rapanui, the more the island needs to accommodate the distribution of this scarce resource.

Additionally, this problem of inadequate quantities of land is exacerbated by the imposed restrictions of the national park. As was discussed in Chapter Four, the Rapanui were rounded up in the 1890s and forced to build a fence in what is now the township area of Hangaroa; unable to leave this small parameter in order to allow for undisturbed sheep raising to take place on their ancestral lands. The fence came down in 1966, however now, in the name of archaeological preservation, nearly $50 \%$ of the land in Rapa Nui is national park, made so without consultation of the Rapanui people (Delsing, 2009), and approximately another 30\% is a government farm. Once again the Rapanui are restricted by where they can and cannot live on the island, with only a fraction of the land residing in Rapanui hands. With the pressures of immigration, the areas in which Rapanui live must be expanded to accommodate the growing population. However most parts of the island lack electricity, running water and infrastructure, and while there is land available for this expanding growth, it does not change the overall environmental carrying capacity of the island. This means that issues of environmental concern are or should be critical to understanding and undertaking development on the island.

\section{A struggle for sustainability?}

While women in Makenu recognised the need for economic development, acknowledging that tourism was the Rapanui lifeline, they expressed frustration with how these processes were undertaken and identified specific issues of 
environmental and cultural sustainability that confront their island. Tourism aside, it was the unfettered flow of immigrants that concerned Makenu the most and was considered to be the most pressing issue they needed to address. The unregulated immigration occurring in such a small and resource-fragile place is proving to have disastrous effects on the island's environment. This unsustainable population growth is leading once again to the loss of ecological as well as social balance. Makenu's concerns for their environment and culture ran in parallel, articulating these challenges as a struggle to sustain their ability to be Rapanui.

The island's fragile environment and limited resources are pressured by the arrival of unregulated immigrants, mainly Chileans, to the island. These resources are unable to keep up with the demands of the growing population. For years the group Makenu has been fighting for a law to help regulate this issue, emphasising the magnitude of the problem of allowing immigration to continue unregulated. As was briefly mentioned in Chapter Four access to land, access to water, overfishing, inadequate electricity, and a myriad of other issues are presently confronting the Rapanui people and presenting themselves as fundamental for the island's development. As some women, as well as other members of the community with whom I spoke, noted, the island is fragile. It collapsed once and it is going to collapse again if these issues are not addressed.

If we continue... as we have been, producing nearly a decade of people, we are going to collapse at any given time (Ana-29).

These issues were articulated by Makenu members who worried about the future of their island and the destruction that is being caused by the overpopulation occurring. Another woman noted how without control over the flow of people and greater control over their island and its resources, she worries for the island's environment.

They are coming here, they are making money with MY MOAIS - that are OURS. They are going to contaminate the island and then they are going to say, see you later. Who's going to take care of that problem - ME! They don't have to worry about the environment, they don't care. And since the 
island is tax free ${ }^{113}$... they are going to put everything in their pockets and go. They're not going to take care of my environment (Alejandra-30).

Linking control of land and resources directly to the island's environmental sustainability was a consistent theme amongst the women with whom I spoke. As expressed by the participant above, the ways in which the Chilean state is allowing tourism, immigration and economic development to occur on the island is harming their environment and not benefiting the Rapanui people in substantial and positive ways, and is rather more symbolic of perversions to development whereby social inequalities are growing, living standards for some are declining, there is environmental degradation, and community fragmentation (EmbersonBain, 1994). These women articulated how without greater autonomy, which would allow the Rapanui more control over their island, indigenous stewardship practices of land and resources are not able to be fully exercised, and ensuring environmental sustainability on the island remains an issue of grave concern. As Overton (1999) notes, to be sustainable, the environmental, economic, and social systems must be able to exhibit a high level of stability and integrity over a long period of time. For women in Makenu ecological, economic and social issues were articulated as high concerns in the immediate future of Rapanui environment and culture.

Another member of the group notes how she agrees with the concept of 'development' on the island and that she wants the island to 'progress'. However she disagrees with how this has been undertaken, noting environmental concerns that must be addressed and emphasising the equality that must accompany development that is occurring. She notes:

I do not deny that the island must have a development. Now, pay attention. A development must have studies of water, environmental impact studies, land surveys... dedicated to informing the people. You cannot come and do a development according to your looks - no, poh! So, I totally agree that the development... that it progresses. It is good! But, it

113 Rapanui is tax free, so there is no substantial funding contributed to the municipality budget. It only gets what the government contributes at a basic level. However, it was also noted by participants that if there were taxes on the island they would not be able to live, as everything is three to five times more expensive than on the continent. 
has to keep... it has to take into account these studies and it has to be equitable (Alicia - 31).

Referencing studies that have occurred on Rapa Nui to investigate the environmental capacity of the island, this Makenu member articulates her frustration with how these findings have been ignored and development has been able to continue without any consideration for how the environment can cope with these issues.

Tuhiwai Smith (1999) notes how indigenous peoples go through a selective process in which immediate crises are addressed rather than planned approaches, as the ability to control is often limited. Immigration as the umbrella for these other concerns is one such issues as it affects various aspects of Rapanui life, and fundamentally threatens Rapanui survival. In line with Tuhiwai Smith's assertion, one woman in Makenu notes how there are many issues that confront them, but as a group they must prioritise. She says:

Look, if we start to engage with issues regarding the sea, with the forest, I mean, we are not many. We will wear out (Ana -32).

Environmental issues largely brought about by unregulated immigration are critical. However women in the group also expressed concern not just for the physical environment's sustainability, but for their cultural sustainability as well. Now a minority in their own land and at the whim of Chilean policies, Rapanui people struggle to maintain their culture and language. Spanish is the language most heard around the streets of Hangaroa and it was noted by numerous participants that some families are more 'Chilean' or 'European' in their ways now. While Rapanui was not a settler colony ${ }^{114}$ at the time of annexation and in subsequent years, in the last few decades the levels of Chileans arriving have grown exponentially.

Cultural development is occurring largely within the Chilean framework, not within the Rapanui one. The language taught in schools is Spanish and the younger generations are being taught Spanish as a first language within their homes, as frequently one parent is not Rapanui. It was noted that Rapanui language is taught

\footnotetext{
114 Settling Rapa Nui was attempted at various points in its colonial history, but was never successful (for more about this, see Delsing, 2009, p. 97)
} 
in schools as though it is a second language, given only a minimal allocation of time each week within the classrooms.

Karly: The children are not taught in the Rapanui language?

Ana: They teach in... yes, they do in folklore. I think it is basic, it gives the basics, but it is only a few hours... it is like the hour of English. It is taught like a foreign language. It is not as if they are doing all the learning of all of their subjects in the areas of education in Rapanui. And, um, it is important. It is important to validate our language in education; so that we can maintain it, poh. If it is validated in the sense that they feel, with ownership that they can communicate in their own language then they are able to have their own roots (Ana-33).

Immigration to the island was seen to perpetuate these issues, as the more Chilean influence present on the island, the harder it is to maintain Rapanui cultural uniqueness and identity. The disconnection between some Rapanui, their language, their history and their culture is widening and this was articulated as a grave threat to them as a people. One Makenu member articulates this threat:

For us, the women, it affects us... and this is strongly influenced by people outside our territory, that arrive and are of a different manner than Rapanui, and, emm, we are threatened (Ana -34).

Environmental and cultural concerns were largely articulated through issues Makenu have with immigration policy. The blending of Chilean and Rapanui culture, particularly among the youth, has led to a loss of Rapanui identity that Makenu is actively struggling to regain. The environmental and cultural components of immigration present acute problems for the island, in which Makenu position themselves at the forefront of these issues. 


\section{Rapanui development from within}

We can see from the perspectives of the women in Makenu that their aspirations for the future of their island are not solely predicated upon economic benefits and in fact are frequently critiquing the type of development that is focused on material well-being and economic gain as its central means and ends to achieving 'development'. If we think of development as "good change" (Chambers, 1997), which insinuates improvement and benefit, these women have launched scathing critiques towards the type of change that is and has been occurring in Rapa Nui, and have pointed to the negative effects this change is having on their community. Less focused on issues of poverty per se, Makenu's approach and view of development, like Korten (1995), seems to be rather based on issues of justice, sustainability and inclusivity whereby development is about achieving human potential, alongside economic possibilities that do not threaten their environment, culture, or identity as a people.

Women in Makenu acknowledge that their ideas and the aspirations for their island are not universal across the island, and like Thomas (2000, p. 23) seem to acknowledge that development embodies "competing political aims [and] social values". They assert that development should be about equality, bringing benefit to the community and ensuring the well-being of future generations on the island. Their ideas of development are not based around profit but are rather centred on a development that is environmentally sustainable, culturally enriching, "people centred" (Korten, 1995) and adds meaning to people's lives. Makenu women envision a society where their future generations are able to live and grow, in harmony with each other and with their environment. As Young (2002) suggests regarding women engaging in development, the women in Makenu do not accept a model of development that places self-interest as the focal point, and they do not privilege profit-making over meeting the needs of the majority. However, like Sunseri (2008), I suggest their engagement is not only selfless, defined by sacrificial acts of putting their community first, but also provides benefit to the women themselves as it empowers them, while importantly setting an example for younger generations of women who will come after them. This too, importantly, is development - it is good change. 
The women in Makenu acted from an empowered position. As Connell (1987) has noted, empowerment occurs through the building of a positive self-image and selfconfidence, and is fostered by the building up of group cohesion in which decisionmaking and action are undertaken. While issues of empowerment are complex, the women in Makenu strived to collectively reflect and make decisions as a group and despite challenges that they faced within the community, they continued, building their confidence and asserting themselves as active agents of change. Scheyvens (1998) has noted that women's associations are a way for women to find a means of challenging oppression, disadvantage or lack of power that they may feel. I contend that women's involvement within this group, and their involvement in decolonisation struggles more broadly, is in fact a mechanism which strengthens their empowerment and is beneficial to not only the women themselves, but to positive community development.

Makenu women strive for development that is created for Rapanui, by Rapanui and is based on social equity and cultural integrity. They struggle to decolonise so they can reassert their cultural identity. Culture, as Bhavnani et al. $(2003$, p. 8) note, is viewed as "everyday experiences, practice, ideology and politics". Viewing culture in this way allows for a dynamic understanding of cultural meanings and relationships, which centre in Makenu's struggles. And, similar to other parts of the decolonising Pacific, as Teaiwa (1999) suggests, culture seems to provide a necessary aid for development.

Makenu's aspirations for their 'decolonisation for development' agenda seek to nurture the social as well as physical environment in order to achieve and sustain well-being for the future generations on the island. They advocate for a Rapanui society that is built upon Rapanui notions rather than colonial ones, whereby the future fate of the island rests in indigenous hands and is fostered by indigenous ways of being, as central and critical to development processes (Gegeo, 1998). Many women in the group referred to the influence and necessity of a Rapanui worldview guiding their development aspirations and practice and like Durie (2003) they embraced a type of development in which economic, social, and cultural components are centred alongside aspirations for greater autonomy. 


\section{Makenu's two prong approach - a political and cultural battle}

Decolonisation focuses on the 'undoing' of colonialism. It is the unravelling and the deconstructing of cultural, political and economic systems put in place by the coloniser. Yet while decolonisation is deconstructive in a sense, pulling apart and peeling back layers of colonial imposition and oppression (Pihama, 2001), it is also a process of creating and inventing, wherein lies an opportunity to construct a new vision for the future and a new pathway for indigenous development. The group Makenu has been involved in decolonisation struggles on a variety of fronts, working together and working according to their individual passions within the complex and layered process that is decolonisation. Their efforts focus on regaining control over the Rapa Nui territory, which they have largely engaged with as it relates to immigration and cultural reinvigoration whereby they strive to reassert a positive Rapanui identity that is sustainable and can be fostered.

Said (cited in Zierott, 2005) has described the method of engaging in decolonisation processes as two-pronged. These prongs require the recovery of the geographical territory as well as the recovery of 'cultural territory'. The methods that Makenu uses and the issues that they identify resonate with these ideas of a two-pronged method of engagement. The decolonisation process is not only about recuperating land and territory but is a deeper and more complex undertaking that involves decolonising ideologies and as Hoskins (cited in Pihama, 2001) notes, it engages all senses. Like Zierott (2005), Makenu recognises that revitalising culture and reasserting indigenous identity(ies) is required as restitution of indigenous land to dispossessed peoples is not sufficient, as dominant ways of thinking and seeing the world based on colonial impositions have altered indigenous ways of being.

While social decolonisation processes rely heavily on the recovery of indigenous language, history, culture and identity as fundamental to the struggle for decolonisation, this is not a reconstruction of pre-colonial cultural arrangements and circumstances. It is rather a conscious and intricate weaving together of past and present that maintains the cultural integrity of the people, from which they are able to reconstruct their identities, using their agency and strengthening their voice, while improving upon any new cultural developments inherited from the 
coloniser. As a reconstruction of the past devoid of colonial influences is an unattainable and fruitless exercise, this process is one of deconstruction and creation, as well as integration and fluidity. Maintaining the cultural integrity of the Rapanui people by upholding aspects of Rapanui culture that are beneficial to all members of society, and discarding those that are not is recognised by Makenu as a necessary component of the decolonisation process. Clea Hoskins (2000), discusses reconstruction as not a reconstruction of past conditions but as the actual process of self-determination "for the re-establishment of ourselves as an independent people".

In Said's view, oppressed peoples should be able to resist and to recreate themselves as postcolonial and anti-imperialist subjects (Ashcroft \& Ahluwalia, 1999). As Green has stated, "identity is the raison d'etre for the politics of decolonisation" (2009, p. 43). Makenu work towards reinvigorating Rapanui culture in order to disrupt the colonial and dominant cultural representations and attributes that exist on the island, in which Rapanui identities and knowledges continue to be marginalised in the face of continued colonial imposition, while simultaneously engaging in political processes that work toward gaining greater territorial control. Like Said, it is the construction of identity that allows for freedom and constitutes its liberation attributes, even if people are still experiencing repressive forms of domination, such as colonial discourses that keep them marginalised or, in the case of Rapa Nui, colonialism in its fullest form.

\section{Strategies for change - education and awareness raising}

One of the most important and engaging contributions Makenu makes to the decolonising struggle is their involvement and commitment to educating and raising awareness within the community. Makenu make it their job to know what policies and initiatives Chile is formulating and the affect that these policies will have on Rapanui people. Reading, listening, learning and informing are some of their central and critical strategies. They work not as an insular group but rather function as a community education mechanism that promotes greater awareness and understanding. They are increasingly linking themselves with broader indigenous movements, international laws and human rights discourses, from which they can base their claims and assert their collective rights to their island. 
Their role as educators and awareness raisers were the strongest aspects of their group's contributions to the struggles on the island. While trying to concentrate their attention on specific initiatives and issues confronting them, particularly immigration on the island, they filtered laws, propositions and actions on the part of the Chilean government that were being presented to the Rapanui people and sought to make sense of what they meant for the people and the island. As Trask (2000) has noted, when awareness is raised decolonisation can begin. Makenu are important for achieving this goal. They critique what they find to be negative and they pursue what they believe is positive, pushing decolonisation and social change in their community.

Alongside community awareness, they also upheld a strong commitment to working transparently and engaging the community in the work they sought to do, trying to gain consensus and build bridges between divisions. Their initiatives were frequently participatory, and always driven by their desire for community well-being. In order to achieve this, it was recognised in the group that the community awareness of issues confronting them needed to be raised and as a community, Rapanui people needed to decide what was right for them, what type of development they wanted on their island and how they could best achieve it.

\section{Decolonisation: ensuring a 'feminine space'}

Decolonisation struggles in Rapa Nui, as this research has shown, critically involves women who are committed to its cause, passionate about their aspirations and hopeful of what it can produce for the future of their island. The presence and significant contributions of women within anti-colonial efforts have rarely been recognised, as the vision of decolonisation has been considered a masculine space; what Lazreg (1994) called a "world of warring men" (cited in Levine, 2010a, p. 3). Equally, when independence has been achieved, although essential players in these struggles, women have rarely been benefactors of the 'liberation' process, which instead of fulfilling its promises of emancipation, has tended to reinscribe them in new forms of patriarchy (Chatterjee, 1993; Levine, 2010a). Like Butalia (2004), Levine (2010a) and Chatterjee (1993) have discussed in their respective places and contexts, women in Makenu are also playing important roles in these processes and are actively part of the decolonising struggle. It is not a situation where 'colonised men face colonising men' nor is it 
just a "world of warring men" (Lazreg, 1994) but is a space where men and women are struggling for their rights to lead their lives the way they choose, free from oppression and in line with their cultures and traditions.

Current Rapanui government structures on the island privilege men and men's perspectives, providing men with power over the Rapanui 'political sphere'. As Young (2002, p. 322) has noted, women are frequently left out of the sphere of politics. In the case of Rapa Nui however, as we saw in Chapter Four, women are very much a part of the Chilean political system that is functioning on the island and hold many of the positions within the Chilean state apparatus, including governor and mayor. ${ }^{115}$ However there is a gap in the Rapanui government structures and elected positions on the island. The Council of Elders, which is positioned to be the voice of Rapanui families on the island, consists of only men. The Development Commission just last year elected only its second Rapanui woman. The Rapanui Parlamento consists mostly of men, and while they claim inclusivity, many members of Makenu expressed their discomfort in participating in this group; noting how it was machista and disagreeing with its work ethic in which secrecy and exclusivity, they thought, left the Rapanui community out of what should be community considerations and deliberations. While the Council of Elders has been an important voice of resistance in the past, and the Rapanui Parlamento is at the forefront of decolonisation efforts currently, exercising a strong anti-colonial voice, they stand to lose a lot if they do not include women and their aspirations within their struggles and engage with their perspectives in substantial and meaningful ways. Struggles for emancipation against oppression and the results of that battle must not exclude half of the population. If women do not enjoy the sweet fruits of sovereignty struggles (Jones, et al., 2000), their fight for liberation will continue. Only this time it will be against their men and the patriarchal structures that marginalise and oppress, rather than embarking on healing processes as a people and reconstructing their nations.

Discussions by feminist historians asserting that women's roles in decolonisation struggles have been silenced, despite their active engagement and their inclusion in newly forming nations, is pertinent as decolonisation struggles are still taking

\footnotetext{
115 See Appendix Six.
} 
place in our historic moment in Rapa Nui. Decolonisation, as these scholars purport, can betray women through the reconstruction of government structures in which an ideological system that upholds and privileges masculinity is perpetuated (Enloe, 1989). As Smith (2006), Ramirez (2007) and others have discussed, decolonisation can only be fully achieved if women are included, allowed to enjoy the fruits of their labour, and are receivers of the emancipation that decolonisation has promised to deliver.

The women in Rapanui with whom I spoke articulated what they would like their Rapanui governance structures to look like, what constitutes positive Rapanui development, and how decolonisation allows for these concerns to be addressed. These women participate in decolonisation struggles with the hopes that one day their people and their community can live a life free from injustice and oppression. Ensuring that women are paid attention to within these struggles and are able to be part of the dreams and aspirations that decolonisation promises is critical not only for the benefit of women on the island but for the community at large.

\section{Native feminisms and Makenu, native feminisms and me}

Part of the literature in Chapter Two focuses on native feminisms, discussing how women within the context of decolonisation are articulating their struggles, their concerns and their motivations for change. These feminisms offered critiques of white feminism, highlighting how women within these communities were concentrated on the decolonisation of their people, not necessarily on issues that pertained particularly to women or 'women's issues', which is where much of western feminism places its emphasis (M.A. Jaimes \& Halsey, 1992; Monture Angus \& Turpel, 1995; Trask, 1996). Some scholars asserted that decolonisation was not about women or 'women's issues' but was rather a struggle launched by indigenous peoples for the benefit of their communities - men and women alike (Trask, 1996; Turpel, 1993). Others contend that in order to decolonise, the inequality and oppression of women in indigenous societies needed to be addressed within the decolonisation agenda not as a separate or subsequent issue once decolonisation is achieved (Ramirez, 2007; Smith, 2006).

While the feminisms I presented in Chapter Two do not spring from Rapanui women's experiences, and I am aware of the importance of culture and context 
from which they are created, these feminisms have heavily informed this work. They have helped me to appreciate the layers involved in decolonisation struggles, the multiplicity of women's perspectives and experiences, and the various ways in which women in colonised parts of the world engage, striving for similar outcomes in which they are able to live, as a people, with dignity and respect.

Native feminisms have challenged my assumptions about gender roles and relationships and have pushed me to engage more closely with the worldviews of the research participants when undertaking this research, as well as when analysing my findings. These scholars have challenged my feminism, and pushed me to further consider the assumptions I have brought to this research. In conducting this study, I have centred women's perspectives and have put forward a gendered analysis of their struggles. However through that process I have come to realise that they are not necessarily using the same analysis or categories as I am, especially around gender. And as became clear, women in Makenu hold perspectives on development that differ from the GAD paradigm, and the ways development has approached gender. Women in Makenu are not only calling for 'gender equity', and the 'sexual liberation' that feminists in the North have tended to work towards, but are prioritising economic livelihoods based on justice and equity, in which their own agendas for development can be pursued. And like Radcliffe and Pequeño (2010, p. 987) note, their "critiques go beyond questioning the western-centric accounts of 'gender' to call for the decolonization of their territories, cultures and societies". This is an important realisation to come to as I reflect on decolonisation struggles in Rapa Nui and how these women are constructing these struggles. These feminisms have also inspired me to more strongly engage with indigenous ways of knowing and doing, which has been an important tenet of my research praxis, while deepening my understanding of indigenous struggles and illuminating Makenu's engagement on the island.

While native feminisms informed my understandings, feminism was not part of Makenu's discourses for articulating their struggles. I did not hear the word 'feminist' or 'feminism' used to identify themselves or to describe how they engaged, nor did I hear any critiques. Their struggles were not articulated as 'women's struggles' nor was it on behalf of women that they engaged. These women approached their struggles with a sense of purpose that was far larger than 
themselves and more holistic than focusing on issues that confront only the women in their society. Their motivation and concentration was made quite clear it was the children, the future generations and the sustainability of their culture and island that inspired them to act.

However, I did note that the women I spoke to acutely recognised the inequalities that exist on the island with regard to gender. They articulated some of the oppression they felt as a result of the patriarchal and machista attitudes in which they were confronted. It was not rare that issues of domestic abuse and violence, often associated with alcohol consumption, were mentioned as real issues facing their society or the pain they experienced from the criticisms they received from their community. Yet despite the pressures they felt, the women in the group maintained their engagement, keeping their convictions strong in order to achieve their aspirations. By working as they do, I contend Makenu push the boundaries of these social constraints, challenging the status quo and testing what is deemed 'appropriate' within their given context and culture, upsetting some of the existing power relations that exist within their community (Visvanathan, et al., 1997).

Makenu's engagement with development on the island is framed by their struggles for decolonisation, pushed by these forces, compelling them to act. However the issues they identify within the decolonising framework are largely articulated through development goals. In this discussion, I sought to tie these ideas together, further accentuating how they are inextricably intertwined and helping to better understand how women navigate their 'decolonisation for development' initiatives. Community well-being is placed at the centre, as they struggle to achieve a type of development on the island that is anchored in the knowledge base of the people, and consistent with the local needs and priorities of the population (Gegeo, 1998); recognising that to fully achieve this, they need greater control over their island they need decolonisation on political and cultural fronts. The emphasis these women place on the revitalisation and protection of Rapanui culture, language and identity, the honouring of traditional knowledge and knowledge systems, environmental sustainability, and the need for changes in their political systems and governance, demonstrates the profound ambitions they have, alongside an acute recognition for the multiple spaces in which decolonisation processes must occur in order for positive Rapanui development to be fully achieved. 


\section{Chapter Nine: Final reflections}

\section{Summary of my findings}

My research aimed to explore the role of Makenu Re'o Rapanui in decolonisation processes by identifying and describing how they engage in these struggles, while highlighting their concerns and aspirations. By centring women's perspectives within the analysis, I contend, we are able to understand decolonisation processes better, and are afforded a fuller and more holistic understanding of the range of possibilities that exist for Rapanui's future development.

As was discussed in the introduction to this thesis, 'decolonisation for development' is the term I use to most appropriately describe the engagement of Makenu women within decolonisation struggles on the island. By using this term, I suggest that it is Makenu's resistance to colonialism that frames and centres their development aspirations and priorities, and it is the decolonisation process that pushes these aspirations forward. This research speaks to the question, "what aspirations for 'decolonisation for development' have women in Makenu Re'o Rapa Nui articulated?" by illustrating how these two processes are working together to formulate the political and social concerns expressed by women in Makenu. Their articulations of 'decolonisation for development' aspirations involve the 'undoing' of colonialism in order for positive Rapanui development to be achieved. These women work towards positive Rapanui development, centring it on their ability to live on their island in a manner that is consistent with their worldviews, in which their language, culture and ways-of-being are fostered and given the space and opportunity to grow.

Makenu's aspirations are grounded in their pursuit of justice and equality for Rapanui people. They strive to ensure that a strong sense of self-worth among their family and community is cultivated by reinvigorating and rooting Rapanui ways-of-knowing and ways-of-doing, positioning their knowledge as valid and valuable, in order for a dignified living culture to continue on the island. Concerns for their language, culture, land, environment, and traditional practices are how they articulate their decolonisation agenda, clearly linking development issues to 
decolonising processes. The women I spoke to in Makenu demonstrate that in order to attain the development they strived for, continued decolonisation political as well as cultural - is imperative.

The strategies the women in Makenu employ within these struggles are multifaceted. In answering the question, "what strategies are women employing to have their voices heard in the decolonisation struggle?" I was frequently impressed by these women's engagement. They often work long hours, meet continuously, and constantly formulate ways to best approach their work. Makenu's strategies are both political as well as cultural, understanding that decolonisation must include more than recovery of land and territory, and increased political control, but also involves decolonisation of the mind (Tuhiwai Smith, 1999).

The strategies provided below are more complex, nuanced and abundant than they let on, and they are always evolving depending on the context and given situation. They are also not mutually exclusive and in fact overlap as well as complement each other. Some of the strategies include, but are not limited to:

Protests (two while I was there). They participate in protests organised by others, and also organised protests themselves.

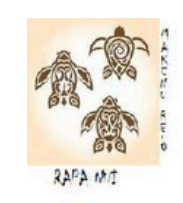

\title{
INVITACION
}

\begin{abstract}
NUESTEA DRGANIZACIÓN “MAKENU RE'O RAPA NUI", TIENE EL AGRADO DE INVITAR A TODA LA COMUNIDAD RAPA NUI A PARTICIPAR EN UNA MARCHA PACIFICA, PARA EL DIA VIERNES 14 DE ENERO DEL PRESENTE, A LAS 10:00 HORAS. LUGAR DE CONCENTRACIÓN FRENTE A LA IGLESIA SANTA CRUR.

ESTA MARCHA TIENE COMO FINALIDAD EXPRESAR NUESTRA DISCONFORMIDAD. ANTE LOS MALOS TRATOS, APROPELLO, ABUSO Y MILITARIZACIÓN APLICADA EN EL TERRTIORIO RAPA NUI.

RECORRDD: IGLESIAAV. TE PITO TE HENUAATAMU TEKENA-TU'U MAHEKE-PASAJE KIRI REVA, FINALIZANDO CON LA ENIRECA DE UNA CARTA A LA SRA. GOBERNADORA.
\end{abstract}

Figure 12: Makenu's invitation to the community to protest their "objection to the abuse and militarisation of the Rapa Nui territory" on the part of Chile 
As part of these protests they make placards. Given the tools and systems they had in place, it became clear that this was not a one-off but a regular occurrence. The placards they made were written mainly in Spanish, but also in English, in order to draw international attention to their claims and struggles.

The group frequently writes letters to Chilean officials in Santiago, launching complaints regarding a variety of issues they are passionate about, particularly pertaining to the issue of immigration, emphasising their status as owners of the Rapanui territory, and highlighting their rights under ILO 169. They also endeavour to connect with other indigenous groups on the Chilean continent as a means of helping them to push their agenda forward. Seeking to understand the engagement of other indigenous groups, they hope to improve their engagement strategies, learn about what international tools were available to them, as well as further their understandings of the challenges that they face in their struggles against the Chilean government.

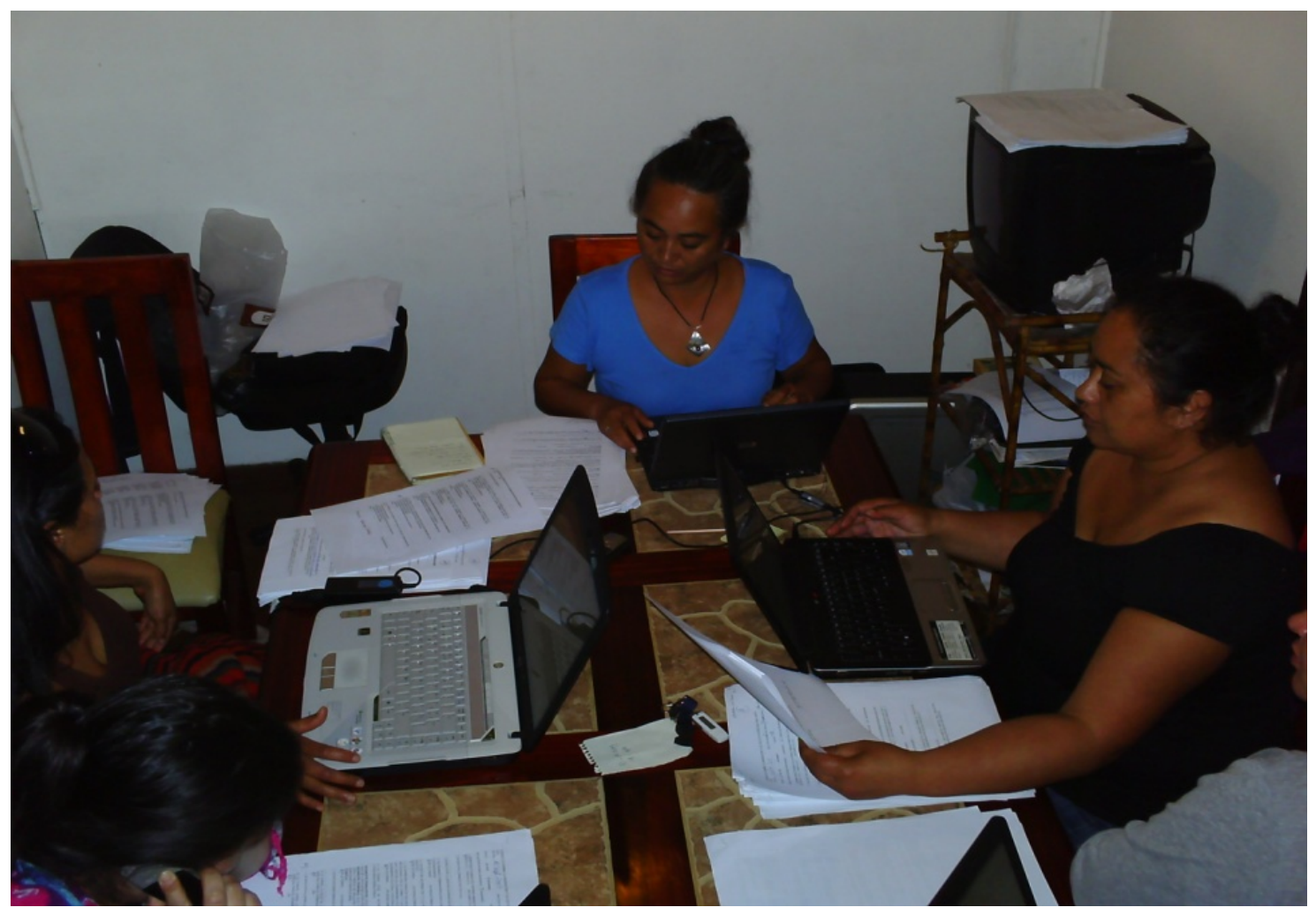

Figure 13: Women in Makenu working

(Source: Makenu Re'o Rapa Nui) 
For example, four women from Makenu went to San Andrés, Colombia in order to educate themselves on how other small and environmentally fragile islands with a large immigrant population were managing their immigration. They sought to understand their migration law and how it was working for them, to help inform their stance on what an immigration law should look like in the case of Rapa Nui.

They drafted a 'migration law' with the assistance of a Chilean lawyer, whom they trust, outlining how they would like to see the issue regulated (See Appendix Five for the law).

They held a weekly radio programme, as well as more ad hoc programmes, using the radio as a central tool and strategy for their engagement and desired outcomes. They sought to disseminate information into their community as best and frequently as they could. For Makenu, community awareness was a strategy as well as a goal in their decolonisation agenda.

The women conducted a survey in the community in order to garner an understanding of how the community perceived various issues that affect them, such as the special statute, immigration and land policies (a full version of this survey can be found in Appendix Seven). Working transparently is a critical strategy for Makenu. They believe the only effective way for them to engage on behalf of the community is to be open about the work they do and to be as participatory as they can. This is not only to gather support for the initiatives they put forth but to build awareness amongst the population and to involve members of the community to take part in important issues that affect their lives.

Makenu's work as a group is largely concentrated on the flow of immigration to the island. Their desire to control and regulate it is underpinned by concerns for kaina and their island's sustainability, and overarched by the more political goals of autonomy that they aspire towards whereby they are able to exercise their right to pursue their own development in their own territory.

Decolonisation is an ongoing and laborious process that takes commitment and perseverance. Exploring the question, "what have been some of the challenges and successes women have experienced within decolonising efforts?" has shown that it is not easy and that the challenges are multiple and ongoing. The stories in the previous pages articulated the heavy hearts of some of the women who spoke 
about the challenges they have experienced as active participants within these struggles. They frequently expressed the challenge of keeping up with policies coming largely from Chilean initiatives, some of which requested the "consultation"116 of the Rapanui people. The persistent flow of information and programmes that arose on the part of Chile kept them constantly on the defensive, struggling to keep up with everything that was coming their way, and trying to ensure that nothing could slip past without a critical eye. However, Makenu also recognised that they could not engage with everything they disagreed with, as they would burn out. They had to prioritise how and to what they chose to dedicate the most time and energy (Tuhiwai Smith, 1999). For Makenu, this was immigration.

Comments were commonly made regarding the incessant need for repetition on the part of the Rapanui in articulating their opinions and demands to the Chilean state - a reality that these women found exhausting and frustrating. They asserted that they had been saying the same thing for years, and for years it fell on deaf ears. The very proposal of a consultation process, based on previous experiences, was seen as a waste of time as nothing changed.

Like the sentiments expressed by Jones, Herda, and Suaalii (2000), the women in Makenu illustrate in their stories how they must work within and against their community. The aspirations that these women hold are not universals across Rapa Nui and many opinions about Rapanui development exist on the island. This is something that Makenu have to reckon with and face on a daily basis as they engage in these struggles to the praise of some and the scathe of others. While they seek the opinions of the community, and search for agreement, this is not always possible.

Makenu women bear the triple role burden of productive, reproductive and community work (Moser, 1993). This is important for understanding their engagement and the multiple pressures they feel within the various roles and spaces that they occupy. However, despite multiple pressures and balancing that needs to occur on a daily basis, these women go about their business with integrity and persistence. And while they were hurt by the injustices they felt, on the part of

\footnotetext{
${ }^{116}$ I put this in quotes as the consultation process between Chile and the Rapanui people was frequently balked at by the women as a sham which suited only Chilean needs and not the needs of the Rapanui.
} 
fellow community members and the Chilean state, these women did not complain of their plight but kept their energy focused on achieving their goals.

Some of Makenu's more tangible successes include: their successful protest of the pending arrival of cable television on the island. Seeing it a threat, as it would perpetuate Chilean culture and language at the expense of Rapanui language and culture, Makenu fought against this initiative and won. Cable television is still not available on the island.

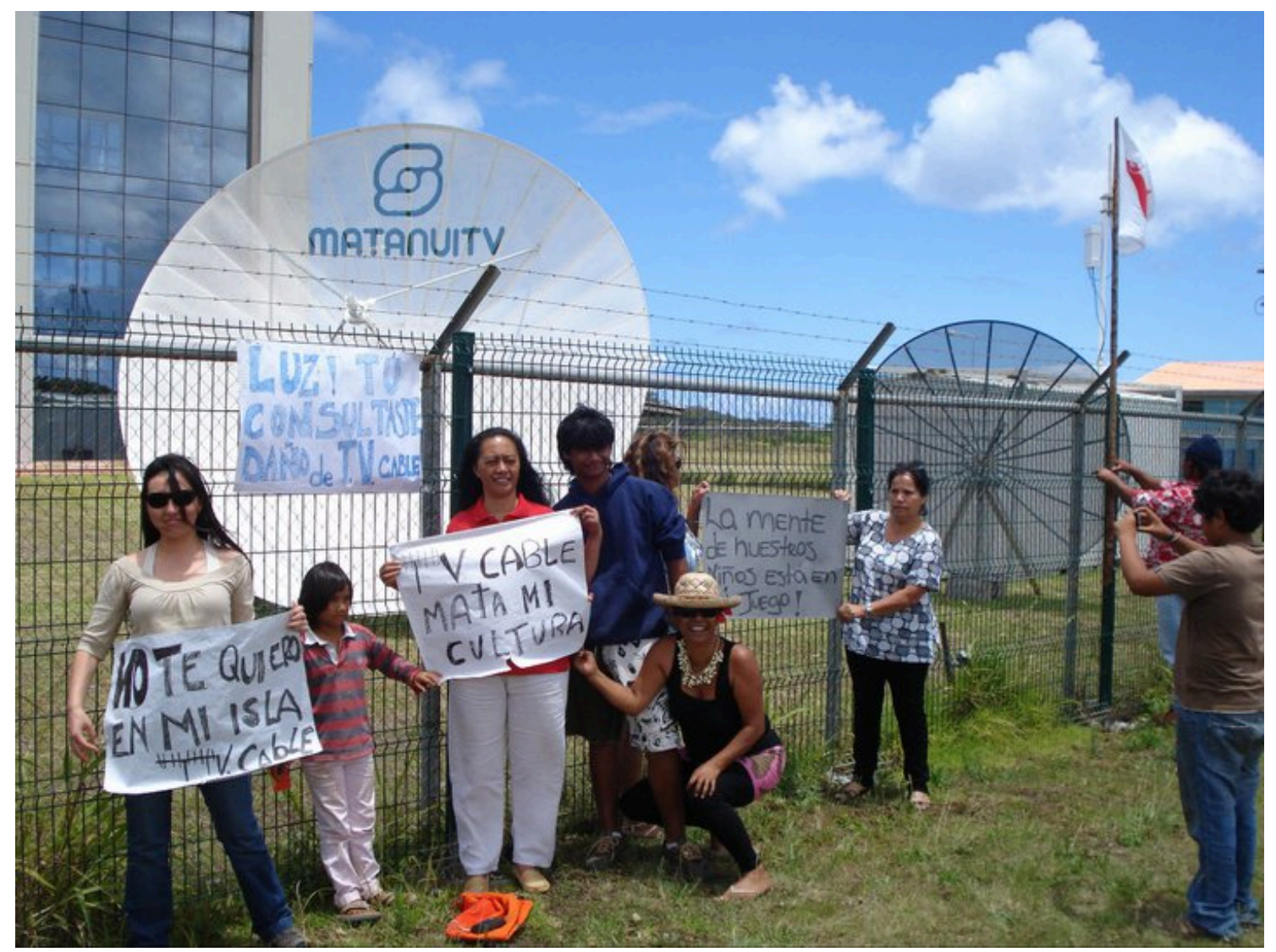

Figure 14: "Cable TV kills my culture"

(Source: Makenu Re'o Rapa Nui)

They also protested against the removal of one of the moai from the island and were successful. It was also mentioned that Makenu played an important role in forcing more of the proceeds from the national park to stay on the island rather than being sent back to Chile.

While these are more of the tangible successes Makenu have had, I suggest Makenu's greatest success lies in their ability as a group to stay cohesive, to keep focused, to work together towards their common goals and to involve the community in their initiatives. Like any group of people working together, and on 
issues as sensitive and important as these, they have their problems and they are confronted with issues within the group that they must deal with. However, they strive to keep the group together and not create divisions in an already divided society, recognising the long journey in front of them and the necessary unity that is required for successful outcomes.

Their commitment to educating the population and raising awareness in the community is one of their greatest contributions to the decolonisation struggle. Makenu women are community educators, striving to build capacity amongst the population so that they have the information they need to make informed decisions and to work together in order to achieve their shared aspirations. I was frequently impressed by the women in this group and the passion they brought to their struggles. Their commitment to this is a success, as they show dedication and unwavering love for their families, their people and their island.

\section{Further research}

Contemporary issues in Rapa Nui are hugely under-researched, particularly when compared to the archaeological outputs of research projects occurring on the island. Therefore research possibilities are abundant. Understandings of social aspects of Rapanui life post-1966 are sparse, and research could turn its attention to a variety of issues including: health and well-being; alcoholism; the impacts of the Catholic Church on Rapanui lives as well as on gender relations and dynamics; domestic violence; sexuality and gender roles more generally; tourism and sustainable development; migration flows and Rapanui diaspora; globalisation and Rapa Nui's political economy - to list but a few.

Within the context of this thesis, and bearing in mind what participants deem as important for their island and their community, future research could also involve such projects as: investigating how development projects have been implemented on the island, including those recently instituted since the signing of ILO convention 169, and the relationship between Chile and Rapa Nui regarding development policy; investigating gender relations and roles on the island during the pre-contact period or at the time of missionaries, in order to acquire a better understanding of how gender roles may have changed; examining the environmental impacts of immigration on the island; exploring on a broader scale 
the different ways that women engage on the island within decolonisation struggles, and what development goals they seek, paying attention to how different generations are involved, what skills and assets they bring, and what priorities they put forth; exploring how ethnicity and gender interlock in Rapa Nui to structure women's experiences and perspectives of development.

Whatever research is taken up by researchers in the future, it is important to recall the assertions made regarding research processes with indigenous peoples. These included that the work done will have meaning and will contribute to the lives of the participants (Louis, 2007; Tuhiwai Smith, 1999), that it will not just be knowledge for knowledge's sake (Crazy Bull, 1997) and that it will be done ethically, respectfully, sympathetically, and from an indigenous perspective (Louis, 2007; Tuhiwai Smith, 1999). Hopefully this will resonate in the ears of any researcher conducting research in Rapa Nui in the future.

\section{Final reflections on my time with Makenu}

The voices presented in this thesis are those of the women in Makenu. However it is through my interpretations and understandings of these issues that these chapters have been formulated and the themes arising from them have been discussed. In constructing the second part of this thesis, I became acutely aware of the power I wield as a researcher. I decided what to write about and what not to write about, what is important and what is less so, and how everything fits within a larger framework that I too have constructed. In line with feminist and indigenous epistemologies, through my methodological approach I have tried to balance some of these power dynamics. However, in writing this section of the thesis, it has become clear that this work is my own and while I hope I have represented these women appropriately, I acknowledge that the ultimate responsibility belongs to me.

During my research with Makenu, I tried to be a contributing member of the group. I found that the women enjoyed having me around, even if I could not always understand everything that was going on and therefore could not always add to all conversations and interactions. While initially it was a bit difficult to navigate and to ensure that my presence was indeed wanted, by the end I started to really feel like I belonged and was a contributing member. I seemed to be recognised in the community as 'that girl' that was always with them, attending all community 
meetings, and upon leaving was even thanked at the airport by a security guard for "helping his community".

I also think Makenu enjoyed being asked about their lives. My presence and interest in their struggles, I believe, gave them even greater confidence in their work and their convictions and it made them proud that someone from 'outside' was paying attention to them, wanting to tell their story. While I still believe that my research will be of more benefit to me than anyone else, and for this I am eternally grateful to these women and the other research participants, I tried to contribute positively wherever I could. This included helping to make signs for protests, editing letters for government officials, translating documents and slogans into English, giving technical and administrative support, cooking for the group during long working hours, and lending a friendly ear when things got tough. By the end I felt like I was part of Makenu and my role as researcher and foreign visitor became a bit more blurred than when I had arrived.

\section{Contributions of this thesis}

This research represents a unique insight into the lives and experiences of some Rapanui women. It demonstrates the agency that women in Makenu have and the important role they play within decolonisation processes on the island. The engagement of women in Rapa Nui deconstructs the normative idea of decolonisation being a 'masculine space' while showing the multitude of concerns that women identify and work to change. This thesis makes clear that women in Makenu are passionate and committed to their work and struggles, and that they fight on multiple fronts to have their voices heard.

This thesis sought to recognise and appreciate Makenu's contributions to the decolonisation struggle on Rapa Nui, to challenge the silences in mainstream research, and to demonstrate that to understand the complexities of decolonisation, it is imperative to acknowledge women's presence and significance within anti-colonial struggles. In doing so, it has highlighted Makenu's aims in these efforts, drawing attention to their critiques of development, while demonstrating how their struggles for decolonisation are articulated through their development aspirations. 
It is my hope that this work will bring further awareness to the challenges the Rapanui people face and to the struggles they are engaged in to regain control over their territory and over their lives. I also hope that this thesis has demonstrated the importance of paying attention to women within these struggles, and ensuring that their voices and perspective are heard.

Indigenous women have largely been excluded from development - from both mainstream development theories and feminist perspectives. Different experiences need to be taken into account in order to adequately have their voices represented in development as their position is impacted by gender and their indigeneity, meaning that their development goals are centred on a position of decolonisation. Development Studies rarely turns its attention to the Fourth World even though indigenous peoples are working towards development goals. While Development Studies has occasionally paid attention to Fourth World contexts (Andolina, et al., 2009; Laurie \& Calla, 2004; Radcliffe, 2007; Radcliffe \& Laurie, 2006; Radcliffe \& Pequeño, 2010), this work has largely been left to indigenous scholars, anthropologists, those who engage in decolonisation debates, and others, not Development Studies. When development has been addressed in the Fourth World, it has frequently left gender out of its realm of analysis (Peredo Betrán, 2004).

Development is happening. People in the Fourth World are thinking about development - they are striving for it. This thesis, by exploring how women in Makenu are engaged in decolonisation has shown what these women want from development and how they are working towards it. They are working hard to achieve their development aspirations and they are using whatever means required in order to accomplish them. This is something that development needs to reckon with. Listening more closely to the concerns of indigenous peoples and their development perspectives, it is essential that Development Studies not only acknowledges the calls for decolonisation that are intimately intertwined, but also that women are central within these processes. This is imperative in order to create informed policy and programmes that speak to indigenous problems of development, and are appropriate, meaningful and support "good change" in peoples' lives. Indigenous women have agency and they struggle to have their voices heard. We need to Hakarongo Mai - Listen. 


\section{References}

Academia de la Lengua Rapa Nui. (2010). Retrieved 5 April, 2012, from http://academialenguarapanui.cl/index.htm

Agarwal, B. (1994). A field of one's own. Cambridge: Cambridge University Press.

Alexander, J., \& Mohanty, C. (1997). Feminist genealogies, colonial legacies, democratic futures. New York: Routledge.

Amin, S., Arrighi, G., Frank, A. G., \& Wallerstein, I. (1982). Dynamics of global crisis. New York: Monthly Review Press.

Amos, V., \& Parmar, P. (1984). Challenging imperial feminism. Feminist Review, 17.

Andolina, R., Laurie, N., \& Radcliffe, S. (2009). Indigenous development in the Andes: Culture, power and transnationalism. London: Duke University Press.

Andueza, P. (2000). Hacia el reconocimiento de los derechos politicos de los pueblos originarios: El modelo de cogestion en Isla de Pascua. Estudios Atacameños, 19, 113-120.

Andzaldúa, G. (1987). Borderlands - la frontera: The new mestiza. San Francisco: Aunt Lute Books.

Apentiik, C., \& Parpart, J. (2006). Working in different cultures: Issues of race, ethnicity and identity. In V. Desai \& R. Potter (Eds.), Doing Development Research. London: Sage Publishers.

ArcGISOnline (Cartographer). (2012). World Topograhical Map.

Arredondo, A. M. (2000a). The view of woman in Rapa Nui society part 1: Women in myths and legends. The Rapa Nui Journal, 14(2), 42-46.

Arredondo, A. M. (2000b). The view of woman in Rapanui society part 2: Rapanui women as seen through the eyes of Seafarers, Missionaries and Scientists in the 18th century. Rapanui Journal, 14(3), 80-84.

Ashcroft, B., \& Ahluwalia, P. (1999). Edward Said. London: Routledge. 
Ashcroft, B., Griffiths, G., \& Tiffin, H. (Eds.). (2006). The postcolonial studies reader (2nd ed.). Oxford: Taylor and Francis Group.

Aspin, C., \& Hutchings, J. (2007). Reclaiming the past to inform the future: Contemporary views of Māori sexuality. Culture, Health \& Sexuality, 9(4), 415427.

Bahn, J. \& Flenley, P. (1992). Easter Island, earth island. London: Thames and Hudson.

Barker, J. (2006). Gender, sovereignty, and the discourse of rights in native women's activism. Meridians: Feminism, Race, and Transnationalism, 7(1), 127-161.

Barker, J. (2008). Gender, sovereignty, rights: Native women's activism against social inequality and violence in Canada. American Quarterly, 60(2), 259-266.

Barton, J. R., \& Murray, W. (2002). The end of transition? Chile 1990-2000. Bulletin of Latin American Research, 21(3), 329-338.

Battiste, M. (2000). Reclaiming indigenous voice and vision. Vancouver: UVC Press.

Beetham, G., \& Demetriades, J. (2007). Feminist research methodologies and development: overview and practical application. Gender and Development, 15(2), 199-216.

Beneria, L., \& Sen, G. (1981). Accumulation, reproduction, and "Women's Role in Economic Development": Boserup Revisited. Signs, 7(2), 279-298.

Bhabha, H. (1983). The Other question. Screen, 24(6), 18-36.

Bhabha, H. (1994). The location of culture. Oxon: Routledge Classics.

Bhavnani, K.-K., Foran, J., \& Kurian, P. (Eds.). (2003). Feminist futures: Re-imaging women, culture and development. New York: Zed Books.

Bishop, R. (1997). Maori peoples concerns about research into their lives. History of Education Review, 26, 25-41.

Bishop, R., \& Glynn, T. (2003). Culture counts: Changing power relations in education. London: Zed Books. 
Bolabola, C. (Ed.). (1986). Land rights of Pacific women. Suva: University of the South Pacific.

Boserup, E. (1970). Women's role in economic development. Towbridge: Cromwell Press.

Braidotti, R., Charkiewicz, E., Häusler, S., \& Wieringa, S. (1994). Women, the environment, and sustainable development: Towards a theorectical synthesis. London: Zed Books.

Bujra, J. (2006). Lost in translation? The use of interpretors in fieldwork. In V. Desai \& R. Potter (Eds.), Doing Development Research. London: Sage Publishers.

Butalia, U. (2000). The Other side of silence. Voices from the partition of India. Durham, NC: Duke University Press.

Butalia, U. (2004). Legacies of departure: Decolonization, nation-making, and gender. In P. Levine (Ed.), Gender and empire (pp. 203-219). Oxford: Oxford University Press.

Butler, J. (1990). Gender trouble: Feminism and the subversion of identity. New York: Routledge.

Cameron, J., \& Gibson, K. (2005). Participatory action research in a poststructuralist vein. Geoforum, 36(3), 315-331.

Cannella, G., \& Manuelito, K. (2008). Feminism from unthought locations: Indigenous worldviews, maginalized feminisms, and revisioning an anticolonial social science. In N. Denzin, Y. Lincoln \& L. Tuhiwai Smith (Eds.), Handbook of critical indigenous methodologies. Thousand Oaks: Sage Publications Inc.

Castro, N. (2006). El Diablo, Dios y la Profetisa: Evangelización y Milenarismo en Rapa Nui, 1864-1914: MAPSE.

Censo 2002, Chile. Retrieved 30 April, 2012, from http://www.ine.cl/

Chambers, R. (1983). Rural development: Putting the last first. Essex: Pearson Education Limited. 
Chambers, R. (1997). Whose reality counts? Putting the last first. London: Intermediate Technology Publications.

Chapman, P. (2007, 20-25 August). Why are we living in the past? Paper presented at the migration, identity and cultural heritage: Selected papers from the VII international conference on Easter Island and the Pacific, Gotland University, Sweden.

Chatterjee, P. (1993). The nation and its fragments: Colonial and postcolonial histories. Princeton: Princeton University Press.

Chilean government mum on Rapa Nui conflict. (2010, 19 August). Radio New Zealand International.

Christ, K. (10 July, 2011). Reflective diary.

Christ, K. (20 July 2011). Reflective diary.

Christ, K. (29 June 2011). Reflective diary.

Christ, K. (2011). Research proposal.

Chu, C. (2007). Developing Pacific leaders within a tertiary education setting through appreciative inquiry: A personal perspective.

Clea Hoskins, T. K. (2000). In the interests of Māori women? Discourses of reclamation. In A. Jones, P. Herda \& T. M. Suaalii (Eds.), Bitter sweet: Indigenous women in the Pacific. Dunedin: University of Otago Press.

Consejo de Jefes de Rapanui, \& Hotus, A. (1988). Te Mau Hatu 'o Rapa Nui: Los soberanos de Rapa Nui; Pasado, presente y futuro: Editorial Emision Centro de Estudios Politicos Latinoamericanos Simon Bolivar.

Conte Oliveros, J. (1994). Isla de Pascua. Horizontes sombrios y huminosos. Santiago: Centro de investigacion de la imagen.

Cook, I. (1997). Participant observation. In R. Flowerdew \& D. Martin (Eds.), Methods in human geography. Essex: Pearson Education Limited. 
Cooperrider, D. L., Whitney, D., \& Stavros, J. M. (2003). Appreciative inquiry handbook. Bedford Heights: Lakeshore Publishers.

Corbridge, S. (1998). "Beneath the pavement only soil": The poverty of postdevelopment. Journal of Development Studies, 34(6), 138-148.

Cornwall, A. (2003). Whose voices? Whose choices? Reflections on gender and participatory development. World Development, 31(8), 1325-1342.

Cowen, M. P., \& Shenton, R. W. (2003). Doctrines of development. London: Routledge.

Crazy Bull, C. (1997). Advice for the non-native researcher. Tribal College: Journal of American Higher Education 9(1), 24.

Cristino, C., et al. (1984). Isla de Pascua: Proceso, alcances y efectos de la aculturacion. Santiago de Chile: Universidad de Chile.

Cristino, C., \& Fuentes, M. (Eds.). (2010). La Compania Explotadora de Isla de Pascua: Patrimonio, memoria e identidad en Rapa Nui. Santiago: Consejo Nacional de la Cultura y las Artes.

Crocombe, R. (Ed.). (1987). Land tenure in the Pacific. Suva University of the South Pacific.

Crook, T. (2007). Anthropological knowledge, secrecy and Bolivip, Papua New Guinea: exchanging skin: Oxford University Press.

Crush, J. (1995). Power of development. London: Routledge.

Dandavati, A. (2005). Engendering democracy in Chile. New York: Peter Lang Publishing. Darwin, J. (2011). Decolonization - a history of failure? Paper presented at the National History Center's Sixth International Seminar on Decolonization.

de Estrella, B. (1920). Los misterios de la Isla de Pascua. Santiago: Cervantes.

de Ishtar, Z. (1994). Daughters of the Pacific. Melbourne: Spinifex Press.

Deere, C. D. (1985). "Rural women and state policy" The Latin American agrarian reform experience. World Development, 13(9), 1037-1053. 
Deere, C. D., \& Leon, M. (1998). Women, land rights and counter-reforms in Latin America. [article]. Debate Agrario (Lima)(27), 129-153.

Delsing, R. (2004). Colonialism and resistance in Rapa Nui. Rapa Nui Journal, 18(1), 2430.

Delsing, R. (2009). Articulating Rapa Nui: Polynesian cultural politics in a Latin American nation-state. University of California Santa Cruz, Santa Cruz.

Delsing, R. (2010). Articulating Rapa Nui: Polynesian cultural politics in a Latin American nation-state. Paper presented at the Congress of the Latin American Studies Association.

Delsing, R., Largo, E., \& Arredondo, A. M. (1998). Relaciones de genero en Isla de Pascua una sociedad multicultural en cambio. Unpublished Report Proyecto FONDECYT No 1960146

Denzin, N., K., \& Lincoln, Y., S. (2005). Introduction: The discipline and practice of qualitative research. In N. Denzin, K. \& Y. Lincoln, S. (Eds.), The sage handbook of qualitative research (3rd ed.). Thousand Oaks: Sage Publications.

Denzin, N., \& Lincoln, Y. (1994). Handbook of qualitative research. London: Sage Publishers.

Denzin, N., Lincoln, Y., \& Tuhiwai Smith, L. (Eds.). (2008). Critical and indigenous methodologies. Thousand Oaks: Sage Publications.

Desai, V., \& Potter, R. (Eds.). (2002). The companion to development studies. New York: Oxford University Press.

Devereux, S. (1992). 'Observers are worried': Learning the language and counting the people in northeast Ghana. In S. Devereux \& J. Hoddinott (Eds.), Fieldwork in Developing Countries (pp. 3-24). New York: Harverster Wheatsheaf.

Diamond, J. (2005). Collapse: How societies choose to fail or survive. New York: Viking Books. 
Diaz, V. (2010). Repositioning the missionary: Rewriting the histories of colonialism, Native Catholicism, and indigeneity in Guam Honolulu: University of Hawaii Press.

Dodds, K. (2002). The Third World, developing countries, the South, poor countries. In V. Desai \& R. Potter (Eds.), The Companion to Development Studies. London: Arnold Publishers.

Durie, M. (1998). Te mana te kawanatanga: The politics of Maori self determintation. Oxford: Oxford University Press.

Durie, M. (2003). Launching Maori future. Wellington Huia Publishers.

Durie, M. (2005). Indigenous knowledge within a global knowledge system. Higher Education Policy, 18, 301-312.

Emberson-Bain, A. (Ed.). (1994). Sustainable development or malignant growth: Perspectives of Pacific Island women. Suva: Marama Publications.

England, K. (1994). Getting personal: Reflexivity, positionality, and feminist research. The Professional Geographer, 46(1), 80-89.

Englert, S. (1970). Island at the center of the world; new light on Easter Island. New York: Charles Scribner's and Sons.

Englert, S. (2004 [1948]). La Tierra de Hotu Matu'a: historia y ethnologia de la isla de Pascua. Santiago: Editorial Universitaria.

Enloe, C. (1989). Bananas, beaches and bases: making feminist sense of international politics. Berkeley: University of California Press.

Enloe, C. (2004). The curious feminist: Searching for women in a new age of empire. Berkely and Los Angeles: University of California Press.

Escobar, A. (1995). Encountering development: The making and unmaking of the third world. Princeton: Princeton University Press.

Esteva, G., \& Prakash, M. S. (1998). Grassroots post-modernism: Remaking the soil of cultures. London: Zed Books. 
Estimaciones de poblacion. (2007). Santiago: Ministry of Housing and Urban Development.

Fairbairn-Dunlop, P. (1998). Tamaitai Samoa: Their stories. Suva: University of the South Pacific.

Fanon, F. (1961). The wretched of the Earth. New York: Grove Press.

Fischer, S. R. (1993). Rapanui or Rapa Nui? The Rapa Nui Journal, 7(4), 73-75.

Fischer, S. R. (2005). Island at the end of the world: The turbulent history of Easter Island. London: Reaktion.

Fiske, J.-A. (1996). The womb is to the nation as the heart is to the body: Ethnopolitical discourses of the Canadian indigenous women's movement. Studies in Political Economy, 51.

Flenley, J., \& Bahn, P. (2003). The enigmas of Easter Island: Island on the edge. Oxford: Oxford University Press.

Foucault, M. (1980). Power/Knowledge. Selected interviews and other writings 19721977. New York: Pantheon Books.

Frank, A. G. (1967a). Capitalism and underdevelopment in Latin America: Historical studies of Chile and Brazil. New York: Monthly Review Press.

Frank, A. G. (1967b). Crisis in the Third World. New York: Holmes and Meier.

Frank, A. G. (1969). Latin America: Underdevelopment or revolution. New York: Monthly Review Press.

Freire, P. (1970). Pedagogy of the oppressed. New York: The Continuum Publishing Company.

Gegeo, D. (1998). Indigenous knowledge and empowerment: Rural development examined from within. Contemporary Pacific, 10(2), 289-315.

Gegeo, D., \& Watson-Gegeo, K. A. (2001). "How we know": Kwara'ae rural villagers doing indigenous epistemology. The Contemporary Pacific, 13(1), 55-88. 
Gibson-Graham, J.-K. (1984). Stuffed if I know! Reflections on post-modern feminist social research. Gender, Place, and Culture, 1, 205-224.

Gomez, R. (2004). Informe final sobre Catastro de tenencia, dominio y transferencias de inmuebles en Isla de Pascua. Bienes Nacionales.

Gomez, R. (2009). Rapanui and Chile, a debate on self-determination: A notional and legal basis for the political decolonisation of Easter Island. Unpublished thesis. Victoria University of Wellington.

Green, J. (2007). Taking account of indigenous feminism. In J. Green (Ed.), Making space for indigenous feminism. Winnipeg: Fernwood Publishing.

Green, J. (2009). The complexity of indigenous identity formation and politics in Canada: Self determination and decolonisation. International Journal of Critical Indigenous Studies, 2(2), 36-47.

Griffen, V. (2006). Gender relations in Pacific cultures and their impact on the growth and development of children. Paper presented at the seminar on Children's Rights and Culture in the Pacific

Grifferos, A. (2000a). Construcción cultural de genero y sexualidad en Rapa Nui. Paper presented at the Pacific 2000: Proceedings of the Fifth International Conference on Easter Island and the Pacific, Kamuela, Hawai'i.

Grifferos, A. (2000b). We are merely asking for respect. The reformulations of ethnicity in Rapa Nui (Easter Island 1966). Paper presented at the Proceedings of the Fifth International Conference on Easter Island and the Pacific, Kamuela, Hawai'i.

Griggs, R. (1992). An Excerpt From CWIS Occasional Paper \#18, The Meaning of "Nation" and "State" in the Fourth World. Retrieved 24 June 2012, from http://cwis.org/GML/background/FourthWorld/

Guijt, I., \& Shah, M. K. (Eds.). (1999). The Myth of Community: Gender issues in participatory development. Exeter: Intermediate Technology Publications Ltd. 
Hall Kahaleole, L. (2008). Strategies of Erasure: U.S. Colonialism and Native Hawaiian Feminism. American Quarterly, 60(2), 273-280.

Hammers, C., \& Brown, A. (2004). Towards a feminist-queer alliance: A paradigmatic shift in the research process. Social Epistemology, 18(1), 85-101.

Haraway, D. (1988). Situated knowledges: The science question in feminism and the privileges of partial perspective. Feminist Studies, 14, 575-599.

Haussman, M., Sawer, M., \& Vickers, J. (2010). Federalism, feminism and multilevel governance. Surrey: Asgate Publishing Ltd.

Hay, I. (2010). Qualitative research methods in human geography. Oxford: Oxford University Press.

Hereniko, V. (2000). Indigenous knowledge and academic imperialism. Paper presented at the Rememberance of Pacific Pasts: An Invitation to Remake History.

Hettne, B. (2002). Current trends and future options in development studies. In V. Desai \& R. Potter (Eds.), The companion to development studies (pp. 7-11). New York: Oxford University Press.

Hickey, S., \& Mohan, G. (2004). Towards participation as transformation: Critical themes and challenges. In S. Hickey \& G. Mohan (Eds.), Participation: From tyranny to transformation? (pp. 3-24). London: Zed Books.

Hill Collins, P. (2000). Black feminist thought: Knowledge, conciousness, and the politics of empowerment. New York: Routledge.

Hito, S. (2004). Vaai Hanga Kainga ghiving care to the motherland: Conflicting narratives of Rapanui. Journal of Intercultural Studies, 25(1), 21-34.

Hodge, P., \& Lester, J. (2006). Indigenous research: Whose priority? Journeys and possibilities of cross-cultural research in geography. Geographical Research, 44(1), 41-51.

hooks, b. (1986). Sisterhood: Political solidarity between women. Feminist Review, $125-138,125-138$. 
hooks, b. (1989). Talking back: Thinking feminist, thinking black. Boston: South End Press.

Howe, K. (1977). The fate of the savage in Pacific historiography. New Zealand Journal of History, 11(2), 137-154.

Huffer, E. (Ed.). (2008). Land and women: The matrilineal factor: The cases of the Republic of the Marshall Islands, Solomon Islands and Vanuatu: Pacific Islands Forum Secretariat.

Hunt, T. (2006). Rethinking the fall of Easter Island: New evidence points to an alternative explanation for a civilization's collapse. American Scientist, 94, 412419.

Hunt, T., \& Lipo, C. (2009). Revisiting Rapa Nui (Easter Island) "Ecocide". Pacific Science, 63(4), 601-616.

Hutchings, J. (2002). Decolonisation and Aotearoa - a pathway to right livelihood. Swaraj. Retrieved from http://www.swaraj.org/shikshantar/ls3_jessica.htm

lati lati. (2010). Reconsidering land reform in the Pacific: Research paper for the Council for International Development.

Ife, J. (2010). Human rights from below: Achieving rights through community development. Melbourne: Cambridge University Press.

Independence of Colonized Peoples: Progress of Decolonization. (2007-2012). Encyclopedia of the Nations Retrieved 27 March 2012, from http://www.nationsencyclopedia.com/United-Nations/Independence-ofColonial-Peoples-PROGRESS-OF-DECOLONIZATION.html

Jaimes Guerrero, M. A. (1998). Savage hegemony: Feminist and indigenous women's alliances. In E. Shohat (Ed.), Talking visions: Multicultural feminism in transnational age. Cambridge: MIT Press.

Jaimes, M. A. (1992). The state of Native America: Genocide, colonization, and resistance. Boston: South End Press. 
Jaimes, M. A., \& Halsey, T. (1992). American Indian Women: At the center of indigenous resistance in North America. Boston: South End Press.

Jones, A., Herda, P., \& Suaalii, T. M. (Eds.). (2000). Bitter sweet: Indigenous women in the Pacific. Dunedin: University of Otago Press.

Kabeer, N. (1994). Reversed realities: Gender hierarchies in development thought. London: Verso.

Kahaleole Hall, L. (2008). Strategies of erasure: U.S. colonialism and Native Hawaiian feminism. American Quarterly, 60(2), 273-280.

Kauanui, K. (2008). Native Hawaiian decolonization and the politics of gender. American Quarterly, 60(2), 281-287.

Kearns, R. (2005). Knowing seeing? Undertaking observational research. In I. Hay (Ed.), Qualitative research methods in human geography (pp. 192-206). Melbourne: Oxford University Press.

Kennedy, V. (2000). Edward Said: A critical introduction. Malden: Blackwell Publishers Ltd.

Kincheloe, J., \& McLauren, P. (1994). Rethinking critical theory and qualitative research. In N. Denzin \& Y. Lincoln (Eds.), The sage handbook of qualitative research. London: Sage

Kindon, S. (1998). Of mothers and men: Questioning gender and community. In I. Guijit \& M. Kaul Shah (Eds.), The myth of community: Gender issues in participatory development (pp. 131-140). London: Intermediate Technology Publications.

Kindon, S., Pain, R., \& Kesby, M. (2007). Origins, approaches and methods. In S. Kindon, R. Pain \& M. Kesby (Eds.), Participatory action research approaches and methods: Connecting people, participation and place (pp. 9-18). London Routledge.

Kirch, P. V. (1984). The evolution of the Polynesian chiefdoms. Cambridge: Cambridge University Press. 
Ladner, K. (2009). Gendering decolonization, decolonizing gender. Australian Indigenous Law Review, 13(1), 62-77.

Laurie, N., \& Calla, P. (2004). Development, postcolonialism, and feminist political geography. In L. Staeheli, E. Kofman \& L. Peake (Eds.), Mapping women, making politics: Feminist perspectives on political geography. New York: Routledge.

Lazreg, M. (1994). The eloquence of silence. New York: Routledge.

Leal, C. (2011). Cuatro hombres y una mujer son elegidos para conformar mesa de desarrollo en Rapa Nui hasta 2015. BioBio Chile

Lee, A. (2010, 4 August). Rapanui, Chilean officials seek resolution to land conflict. Santiago Times.

Letherby, G. (2003). Feminist research in theory and practice. Buckingham: Open University Press.

Levine, P. (2010a). Gendering decolonisation. Histoire@Politique, 2(11), 9-9. Retrieved from www.histoire-politique.fr. doi:10.3917/hp.011.0009

Levine, P. (2010b). Independence and decolonization. Retrieved 17 March 2012, from http://www.utexas.edu/cola/depts/history/features/_features/independencedecolonization10.php

Ley Indigena (1993).

Linnekin, J. (1990). Sacred queens and women of consequence: Rank, gender, and colonialism in the Hawaiian Islands. Ann Arbor: University of Michigan.

Loomba, A. (1998). Colonialism/postcolonialism. London: Routledge.

Louai, H. (2012). Retracing the concept of the subaltern from Gramsci to Spivak: Historical development and new applications. African Journal of History and Culture, 4(1), 4-8.

Louis, R. (2007). Can you hear us now? Voices from the margin: Using indigenous methodologies in geographic research. Geographical Research, 45(2), 130-139. 
Lugones, M. (2007). Heterosexualism and the colonial/modern gender system. Hypatia, 22(1), 186-209.

Lugones, M. (2008). The coloniality of gender. Worlds and Knowledge Otherwise(Spring), 1-17.

Maese-Cohen, M. (2010). Introduction toward planetary decolonial feminism. Qui Parle: Critical Humanities and Social Sciences, 18(2, Spring and Summer), 3-27.

Māhina, O., \& Nabobo-Baba, U. (2004). The issue of Pacific past and future: A challenge for Pacific students and academics in the present. In T. Baba, O. Mahina, N. Williams \& U. Nabobo-Baba (Eds.), Researching the Pacific and indigenous peoples: Issues and perspectives. Auckland: University of Auckland.

Makihara, M. (2005a). Being Rapa Nui, speaking Spanish: Children's voices on Easter Island. Anthropological Theory, 5(2), 117-134.

Makihara, M. (2005b). Rapa Nui ways of speaking Spanish: Language shift and socialization on Easter Island. Language in Society, 34(5), 727-762.

Manuel, G., \& Posluns, M. (1974). The Fourth World: An Indian reality. New York: The Free Press.

Marchand, M., \& Parpart, J. (Eds.). (1995). Feminism/postmodernism/development. London: Routledge.

McCall, G. (1976). Reaction to disaster: Continuity and change in Rapa Nui social organisation. Unpublished thesis. Australian National University.

McCall, G. (1988). Chile's bitter Pacific legacy. Pacific Island Monthly, 59(11), 43-46.

McCall, G. (1992). Thirty-seven days that shook the (Rapanui) world: Angata's cult on Easter Island. Paper presented at the Pacific History: Papers from the 8th Pacific History Association Conference, Mangilao, Guam.

McCall, G. (1994). Rapanui: Tradition and survival on Easter Island (2nd ed.). St Leonards, N.S.W: Allen \& Unwin.

McCall, G. (1995). Rapanui. Pacific Islands Year Book - 17th Edition. 
McCall, G. (2000). The Pacific: Rapa Nui - our own place. Race \& Class, 41(3), 84-90.

McClintock, A. (1995). Imperial leather: Race, gender, and sexuality in the colonial conquest. New York: Routledge.

McClintock, A., Mufti, A., \& Shohat, E. (Eds.). (1997). Dangerous liasons: Gender, nation and postcolonial perspectives. Minneapolis: University of Minnesota.

Memmi, A. (1974). The colonizer and the colonized. Boston: Beacon Press.

Menon, R., \& Bhasin, K. (1998). Borders and boundaries. Women in India's partition. New Brunswick, NJ: Rutgers University Press.

Menzies, C. (2001). Reflections on research with, for, and among indigenous peoples. Canadian Journal of Native Education, 25(1), 19-36.

Merry, S. (2000). Colonizing Hawai'i: The cultural power of law. Princeton: Princeton University Press.

Metraux, A. (1940). Ethnology of Easter Island. Honolulu: Edward Enterprises, Inc.

Mihesuah, D. A. (2003). Indigenous American women: Decolonization, empowerment, activism. Lincoln: University of Nebraska Press.

Mohanty, C. (1993). Under western eyes: Feminist scholarship and colonial discourses. In P. Williams \& L. Chrisman (Eds.), Colonial discourse and post-colonial theory: A reader (pp. 196-220). New York and London: Havester Wheatsheaf.

Monture-Angus, P., \& Turpel, M. E. (1995). Thunder in my soul: A Mohawk woman speaks. Halifax, Nova Scotia: Fernwood Publishing.

Morton, S. (2004). Gayatri Chakravorty Spivak. New York: Routledge.

Moser, C. (1993). Gender planning and development: Theory, practice and training. London: Routledge.

Mosse, J. (1993). Half the world, half the chance. Oxford: Oxfam. 
Mow, J. (2006). The native islanders of San Andres, Old Providence and Santa Catalina: Dreaming between two worlds. Providence Foundation, 1-17. Retrieved from http://www.unesco.org/csi/smis/siv/inter-reg/comvision-panel-June2.pdf

Murray, W. (2002). From dependency to reform and back again: The Chilean peasantry during the twentieth century. The Journal of Peasant Studies, 29(3-4), 190-227.

Murray, W. (2006). Neo-feudalism in Latin America? Globalisation, agribusiness, and land re-concentration in Chile. Journal of Peasant Studies, 33(4), 646-677.

Mutua, K., \& Swadener, B. B. (Eds.). (2004). Decolonizing research in cross-cultural contexts: Critical personal narratives. Albany: SUNY Press.

National Geophysical Data Center. (2012). Shoreline/coastline resources. Retrieved 3 July 2012: http://www.ngdc.noaa.gov/mgg/shorelines/

Nelson, C., Treichler, P. A., \& Grossberg, L. (1992). Cultural studies. In L. Grossberg, C. Nelson \& P. A. Treichler (Eds.), Cultural studies. New York: Routledge.

Nueva sangre para viejos problemas. (2011, July). Correo del Moai.

Occre: modelo internacional. (2010). Retrieved 29 July, 2012, from http://xn--elisleo9za.com/index.php?option=com_content\&view=article\&id=797:occre-modelointernacional\&catid=39:cultura\&ltemid=82

Ocupantes de terrenos exigen al gobierno 4 medidas para terminar movilizaciones. (2010, 4 August). El Mercurio.

Otsuka, S. (2006). Talanoa research: Culturally appropriate research design in Fiji. Paper presented at the International Education Research Conference: Creative Dissent-Constructive Solutions, Melbourne, Australia.

Overton, J. (1999). Sustainable development and the Pacific Islands. In J. Overton \& R. Scheyvens (Eds.), Strategies for sustainable development: Experiences from the Pacific. London: Zed Books.

Oyewumi, O. (1997). The invention of women: Making an African sense of western gender discourses. Minneapolis: University of Minnesota Press. 
Parpart, J., Connelly, P., \& Barriteau, E. (Eds.). (2000). Theoretical perspectives on gender and development. Ottawa: International Development Research Centre.

Parry, B. (1995). Problems in current theories of colonial discourse. In B. Ashcroft, G. Griffiths \& H. Tiffin (Eds.), The post-colonial studies reader. London: Routledge.

Peredo Betrán, E. (2004). Una aproximación a la problemática de genero y ethnicidad en América Latina. Santiago: UN-CEPAL Unidad Mujer y Desarrollo.

Pihama, L. (2001). Tihei Mauri Ora: Honouring our voices. Mana Wahine as a Kaupapa Maori theoretical framework. Unpublished PhD thesis. University of Auckland.

Porteous, D. (1981). The modernization of Easter Island. Victoria, B.C: University of Victoria.

Porteous, D., \& Shepard-Toomey, T. (2005). Resistance and land control on Rapa Nui. The Rapa Nui Journal, 19(1), 10-12.

Potter, R., Binns, T., Elliott, J., \& Smith, D. (Eds.). (2008). Geographies of development: An introduction to development studies (3rd ed.). Essex: Pearson Education Limited.

Prebisch, R. (1950). The economic development of Latin America and its principal problems. New York: United Nations.

Prieto, M., Cuminao, Flores, A., Maldonado, G., \& Pequeno, A. (2005). Las mujeres indigenas y la busqueda del respeto. In M. Prieto (Ed.), Mujeres ecuatorianas: entre las crisis y las oportunidades 1990-2004. Quito: CONAMU-FLACSOUNFPA-UNIFEM.

Propuestas para Ley Orgánica Constitucional de Migración al Territorio Especial Rapa Nui. (2010). Unpublished Draft Law Proposal. Makenu Re'o Rapa Nui.

¿Proyecto de Ley para restringir acceso a Isla de Pascua? (2009). Retrieved 27 April 2012, from Biblioteca del Congreso Nacional de Chile - BCN Blog Legal:

Radcliffe, S. (2007). Latin American indigenous geographies of fear: Living in the shadow of racism, lack of development and anti-terror measures. Annals of the Association of American Geographers, 97(2), 385-397. 
Radcliffe, S., \& Laurie, N. (2006). Culture and development: Taking indigenous culture seriously in the Andes. Environment and Planning D: Society and Space, 24(2), 231-248.

Radcliffe, S., \& Pequeño, A. (2010). Ethnicity, development and gender: Tsáchila indigenous women in Ecuador. Development and Change, 41(6), 983-1016.

Rahnema, M., \& Bawtree, V. (Eds.). (1997). The post development reader. Dhaka: The University Press Ltd.

Ramirez, R. (2007). Race, tribal nation, and gender: A native feminist approach to belonging. Meridians: Feminism, Race, and Transnationalism, 7(2), 22-40.

Rathgeber, E. (1990). WID, WAD, GAD: Trends in research and practice. The Journal of Developing Areas, 24(4), 489-502.

Razavi, S. (2003). Introduction: Agrarian change, gender and land rights. Special Issue of Agrarian Change, 3, 2-32.

Razavi, S. (2007). Liberalisation and the debates on women's access to land. Third World Quarterly, 28(8), 1479-1500.

Razavi, S., \& Miller, C. (1995). From WID to GAD: Conceptual shifts in the women and development discourse: United Nations Research Institute for Social Development, United Nations Development Programme

Reed, J. (2007). Appreciative inquiry Available from http://srmo.sagepub.com/view/appreciative-inquiry/n1.xml

Reeves, H., \& Baden, S. (2000). Gender and development: Concepts and definitions. 140. Retrieved from http://www.bridge.ids.ac.uk/reports/re55.pdf

Reid, E. (2004). Transformational development and the wellbeing of women. Development Bulletin, 64, 16-20.

Riley, J. (2004). Some reflections on gender mainstreaming and intersectionality. Development Bulletin, 64, 82-86.

Rist, G. (2002). The history of development: From western origins to global faith. 
Rochona-Ramirez, S. (1993). La propiedad de la tierra en la Isla de Pascua. Santiago: La Corporacion Nacional de Desarrollo Indigena

Rose, G. (1997). Situating knowledges: Positionality, reflexivities and other tactics. Progress in Human Geography, 21, 305-320.

Rostow, W. (1956). The take-off into self-sustained growth. Economic Journal, 66, 2548.

Routledge, K. (1919). The mystery of Easter Island: The story of an expedition. London: Hazel, Watson and Viney.

Sachs, W. (1992). The development dictionary: A guide to knowledge as power. London: Zed Books Ltd.

Said, E. (1978). Orientalism. London: Penguin.

Said, E. (1989). Representing the colonized: Anthropology's interlocutors. Critical Inquiry, 15(2), 205-225.

Said, E. (1993). Culture and imperialism. London: Vintage.

Saunders, K. (2002). Feminist post-development thought: Rethinking modernity, postcolonialism and representation. London: Zed Books.

Saunders, R. (2006). Decolonizing the body: Gender, nation, and narration in Tahar Ben Jelloun's L'enfant de sable. Research in African Literatures, 37(4).

Scheyvens, R. (1998). Subtle strategies for women's empowerment: Planning for effective grassroots development. Third World Planning Review, 235-253.

Schiwy, F. (2007). Decolonization and the question of subjectivity. Cultural Studies, 21(2-3), 271-294.

Sen, G., \& Grown, C. (1987). Development, Crisis, and Alternative Development. New York: Monthly Review Press.

Settee, P. (2007). Pimatisiwin: indigenous knowledge systems, our time has come. Saskatoon: University of Saskatchewan. 
Sharp, J. (2004). Doing feminist political geographies. In L. Staeheli, E. Kofman \& L. Peake (Eds.), Mapping women, making politics: Feminist perspectives on political geography. New York Routledge.

Shepard-Toomey, T. (2001). The development of Rapa Nui (Easter Island) Chile 19672001. Rapa Nui Journal, 15(2), 110-113.

Shikina, R. (2010, 13 August). Unrest increases on Rapa Nui. Honolulu Star-Advertiser.

Simmonds, N. (2011). Mana wahine: Decolonising politics. Women's Studies Journal, 25 (2), 11-25.

Sinha, M. (2004). Nations in an imperial crucible. In P. Levine (Ed.), Gender and empire. Oxford: Oxford University Press.

Smith, A. (2003). Not an Indian tradition: The sexual colonization of native peoples. Hypatia, 18(2).

Smith, A. (2005). American feminism, sovereignty, and social change. Feminist Studies, 31(1), 116-132.

Smith, A. (2006). Indigenous feminism without apology. New Socialist, 16(16).

Smith, A., \& Kauanui, K. (2008). Native feminisms engage American studies. American Quarterly, 60(2), 241-249.

Spivak, G. (1984). The Rani of Sirmur. In F. Barker, et al (Ed.), Europe and Its Others (Vol. 1, pp. 128-151). Colchester: University of Essex.

Spivak, G. (1988). Can the subaltern speak? In C. Nelson \& L. Grossberg (Eds.), Marxism and the interpretation of culture (pp. 271-313). Chicago: University of Illinois Press.

St Denis, V. (2007). Feminism is for everybody: Aboriginal women, feminism and diversity. In J. Green (Ed.), Making space for indigenous feminisms. Winnipeg: Fernwood Publishing.

Stanley, L., \& Wise, S. (1993). Breaking out again: Feminist ontology and epistemology. London: Routledge. 
Sunseri, L. (2000). Moving beyond the feminism versus the nationalism dichotomy: An anti-colonial feminist perspective on Aboriginal liberation struggles. Canadian Woman Studies, 20(2).

Sunseri, L. (2007). Indigenous voice matters: Claiming our space through decolonising research. Junctures, 9, 93-106.

Sunseri, L. (2008). Sky woman lives on: Contemporay examples of mothering the nation. Canadian Woman Studies, 26(3,4), 21-25.

Teaiwa, T. (1992). Microwomen: U.S. colonialism and Micronesian women activists. Paper presented at the Pacific History: Papers from the 8th Pacific History Association Conference, Mangilao, Guam.

Teaiwa, T. (1994). bikinis and other s/pacific n/oceans. The Contemporary Pacific, 6(1), 87-110.

Teaiwa, T. (1999). Resisting writing and writing resistance. Tok Blong Pasifik, September, 35-40.

Temple, B., \& Young, A. (2004). Qualitative research and translation dilemmas. Qualitative Research, 4(2), 161-178.

Thomas, A. (2000). Meanings and views of development In T. Allen \& A. Thomas (Eds.), Poverty and development into the 21st century. London: Oxford University Press.

Thomas, A. (2004). The study of development. Paper presented at the DSA Annual Conference.

Tinker, I. (1990). Persistent inequalities: Women and world development. Oxford: Oxford University Press.

Tongamoa, T. (1998). Pacific women: Roles and status of women in Pacific societies. Suva: Institute of Pacific Studies of the University of the South Pacific.

Torre, M., \& Fine, M. (2006). Participatory action research (PAR) by youth. In L. Sherrod, C. Flanagan, R. Kassimir \& A. Bertelsen (Eds.), Youth activism: An international encyclopedia (pp. 456-462). Westport: Greenwood Publishing Group. 
Trask, H.-K. (1984). Fighting the battle of double colonization: The view of a Hawaiian feminist. East Lansing: Office of Women in International Development.

Trask, H.-K. (1993). From a native daughter: Colonialism and sovereignty in Hawai'i. Honolulu: University of Hawai'i Press.

Trask, H.-K. (1996). Feminism and indigenous Hawaiian nationalism. Signs, 21(4, Feminist Theory and Practice), 906-916.

Trask, H.-K. (2000). Problems in paradise: Sovereignty in the Pacific. Cultural Survival Quarterly 24(1). Retrieved from http://www.culturalsurvival.org/ourpublications/csq/article/tourism-and-theprostitution-of-hawaiian-culture

Tuhiwai Smith, L. (1999). Decolonizing methodologies: Research and indigenous peoples. London: Zed Books Ltd.

Tuhiwai Smith, L. (2008). Research through imperial eyes. In A. Jaggar (Ed.), Just methods: An interdisciplinary feminist reader. Boulder: Paradigm Publishers.

Turpel, M. E. (1989). Aboriginal peoples and the Canadian Charter: Interpretive monopolies, cultural differences. Canadian Human Rights Yearbook: Annuaire Canadien des Droits de la Personne, 6, 3-45.

Turpel, M. E. (1993). Patriarchy and paternalism: The legacy of the Canadian state for First Nations women. Canadian Journal of Women and Law, 174, 174-192. Retrieved from heinonline.org

Vaioleti, T. M. (2006). Talanoa research methodology: A developing position on Pacific research. Waikato Journal of Education, 12, 21-34.

Valencia, P. (2011). Multicultural recognition at the Archipelago de San Andrés, Providencia, and Santa Catalina: Between ethnic enclosure and social conflict. Revista Colombiana Antropologia, 47(2), 69-95.

Valentine, G. (1997). Tell me about...:using interviews as a research methodology. In R. Flowerdew \& D. Martin (Eds.), Methods in human geography. 
Van Tilburg, J. A. (1994). Easter Island: Archaelology, ecology, and culture. Washington D.C.: Smithsonian Press.

Vergara, V. (1939). Isla de Pascua, dominacion y dominio. Santiago: Publicaciones de la Academia Chilena de la Historia.

Visvanathan, N., Duggan, L., \& Wiegersma, N. (Eds.). (1997). The women, gender and development reader. London: Zed Books Ltd.

Wallerstein, I. (1976). The modern world-system: Capitalist agriculture and the origins of the European world econony in the sixteenth century. New York: Academic Press.

Watkins, J., Mohr, B., \& Kelly, R. (2011). Appreciative inquiry: Change at the speed of imagination. San Francisco: Pfeiffer.

Young, F. W. (2011). Unwriting Easter Island: Listening to Rapanui. Unpublished thesis. University of Hawai'i at Manoa.

Young, K. (2002). WID, GAD, and WAD. In V. Desai \& R. Potter (Eds.), The Companion to Development Studies. New York: Oxford University Press.

Zanotta, L. (1994). Indigenous communitarianism as a critique of modernity and its juridical implications. In W. Assies \& A. J. Hoekema (Eds.), Indigenous peoples' experiences with self-government. Amsterdam: IWGIA Document No 76.

Zierott, N. (2005). Aboriginal women's narratives: Reclaiming identities. Munster: Lit Verlag 


\section{Appendix One: Spanish quotes}

1. Pienso que tu tema con las mujeres y la tierra es el mejor. Siento que la lucha por el territorio de nuestros hijos es un tema que hoy nos preocupa demasiado, por la tremenda inmigración que hay en estos momentos en Rapa Nui, y cada vez nos hacemos menos en número, situación que al Estado le favorece, son menos los que tienen que silenciar y gastar (Ana).

2. Sí, me ha pasado a mí que... yo... he hecho un comentario, ehhh... que... ehhh... después para mí no era bueno. ¿Ya? Y... o sea, no era que no está la verdad, pero no me gustaba las expresiones. ¿Ya? Esto y... Sí, me parece bien si lo hacemos así como tú dices (Ana).

3. The original quote was in English (Maria).

4. Si paso el congreso pero no la que pedimos sino la que el presidente Piñiera quiso no para sirve de nada (Ximena).

5. No pasó nada. Año tras año, si son 140 años de lo mismo. Mandan a otro político, mandan a otro político. Nada. Puras promesas, puras promesas. Y la gente está cansada. Llegaba un político por acá, "Sí, vamos a ver su problema”. Nosotros decimos que en el trayecto que hay en el avión hacia Chile, hay una nube que te borra la memoria. Todos los gobiernos, hasta este gobierno - Este gobierno dijo "el cambio, voten por nosotros. El cambio, el cambio". Ya, votamos el cambio. Lo primero que llegó, fueron a dispararnos. Ese fue el cambio. Los otros nos mentían, los otros gobiernos nos mentían. Esto nos llegó con... con armamento. Nos dispararon (Hitorangi family member).

6. [Hubo] una toma en el aeropuerto con el Parlamento, que es un otro grupo que tenemos en la comunidad... Bueno, de ellos fue la iniciativa. Y nosotros sin ser del Parlamento, nosotros pensamos que era, una buena protesta, que haya apoyando y estuvimos allí en al aeropuerto. Era para el tema de la inmigración, o sea, de una vez por todo que parara... llegan la gente a quedarse a quedarse... que significa, el trabajo, y al futuro, el kaina. Y eh, esa día, hubo mucho, hubo 
conferencia con el estado, y, bueno, la cabeza de la Parlamento, llegaron un acuerdo con, con gente del estado, de que viajarían para resolverlos - los problemas, allá. En Santiago de Chile.

Es que nada pasado. Tres anos. Y nosotros las mujeres decimos que no. Porque siempre los problemas de acá de nosotros, partiendo por el kaija no sean resuelto en muchos años, y siempre ha sido hay que ir allá, hay que ir allá, hay que ir allá. Esta vez, queremos que vengan aquí. Y así, nos quedamos dos noches en el aeropuerto... y al final... nos sacaron (Ana).

7. El trato más que nada...El trato indigno. $\mathrm{Y}$ a veces que te griten que estás loca que ándate a hacer algo en tu casa. La misma gente... siempre, la misma gente. Ándate a tu casa hacer algo - algo mejor (Ana).

8. Lo más importante es que somos luchadoras sin miedo y la determinación que te da la maternidad... mirar al futuro y ver qué quieres dejar para tus hijos (Ana).

9. Ojo, no se pierdan su esencia de mujeres, de madres. Y la esencia de mujeres madres es autodominar todo lo que es entorno. La tierra, sus hijos, lo que... lo que lo más sencillo... manejen, no se dejen debilitarse por... (Ana).

10. Tenemos que decir tal cual. No hay que engañar a la gente. Hay que decir la verdad. Y aquí hay muchos abusos, abusos de poder y abusos de... como en todos lugares... el Makenu tiene mucho peso. ¿Por qué? Porque se ha... Ha mostrado las cosas que le han hecho. El Parlamento muchas cosas lo esconde, en vez de mostrar. A ellos no le hace bien esconder las cosas. Más vale mostrar todo. La única manera pa que conquista la gente... Es ser transparente (Alicia).

11. Para los pueblos originarios, la tierra es el útero de una cultura y la descendencia y conservación de ella en el tiempo (Lili). 
12. Bueno, pensar en que, la tierra es vida, y sentirse agradecida, porque es parte, es parte de la tierra, por que volvemos hacer parte de ella... también. 0 sea, uno tiene un origen con el kaina, y tiene un final con el también... de nacer y volver a, a, meterte al dentro... y te vuelve a coger. Mira, que hermoso... porque, porque tú tienes tú bebe en tu útero... tan calentito... y después... tú vuelves y te acógela... el kaina de otra forma, o sea, un otro memento (Consuelo).

13. Tierra... henua es la superficie. Pero eso tiene que ver con la definición... occidental. 0 sea, tierra, superficie... lo que está por encima... y kaina lo que está por debajo... o sea, territorio. Неnua - si uno lo piensa, henua se pone sobre el kaija materno. La placenta es henua. Y esta placenta posa, se afirma sobre el kaija, sobre el territorio. En nuestra... en nuestro organismo materno. Porque lo que está por encima se alimenta de lo que hay por debajo. Y ocurre exactamente lo mismo dentro de nuestro kaija materno y henua, la placenta, que envuelve el bebé (Ana).

14. ¿Tú te acuerdas que yo expliqué algo como esto en el seminario? Cuando hablé yo dije que... Ah, pero cómo vas a entender... Yo lo hice en RN. Perdón. [risas] Sí. Fue para... fue para reincorporar este concepto en la gente nuestra. Y por eso yo pregunté “ ¿es así?” Y la gente dijo “sí, es así” (Ana).

15. [Es] súper complicado. La tierra es lo que ahora nos está dividiendo a nosotros. Es increíble, pero ya ha producido, ya está empezando a producir los quiebres. Está empezando a producir quiebres sociales súper fuertes. Porque algunas personas piensan que la tierra es de uno, propiedad individual, y mientras más tierra yo tenga, más poderosa soy... (Consuelo).

16. La gente empezo a recibir el papel, del parte del estado y sea seguron... Y tambien hay se produce un cambio significativo en la, en cuanto, el significado esta kaina con respeto a la perso, ¿Ya? La gente empieza como apoderarse de este kaina, como que, como es un bien material, ¿Ya? No es en kaina donde yo me desarollo, como individo como persona - que yo lo necessito para desarrollarme... Sino que ya como un bien material más (Ana). 
17. La peor de las luchas es contra los míos. ¿Sabes por qué te digo? Porque hoy día la estabilidad que tienen ellos mismos con ellos mismos, no captar que esto es lindo, paraíso, lindo, su propia isla. Es un... es linda. Tonce ellos lo tienen que enfocar en que... en apreciarlo. Amar y querer a su gente. Entonces quieren... palpar lo que el ojo ve. Quieren tener lo mismo. Para tener lo mismo tiene que vender a su madre. Poco menos, poh. ¿Me entendís? Ese es mi lucha contra mi gente. Porque si vendís tu pedazo de tierra es como estái vendiendo a la madre (Alicia).

18. Ana: Si hay de alguna manera que nosotros, nosotros como pueblo, podamos pedir protección territorial y humana, o sea, todo el patrimonio para que ellos no sigan determinando sobre cómo... qué hacer con la isla, qué hacer con el patrimonio y que espere, o sea que nosotros tenemos que ir participando, ¿Ya?, Siendo consultados para llegar a una determinación. 0 sea... porque aquí hay un tema de consciencia con nuestro pueblo. ¿Ya? De consciencia con el pueblo. Y un tema de que lo que queda de gente RN, no somos muchos. Si esta migración que nos ha llegado ha sido como que se nos cayó un cerro de gente encima. ¿Ya? Y obviamente que el Estado, el Estado tiene que buscar de qué manera ellos legislar sobre este territorio para que se beneficien también esos inmigrantes, que son chilenos, también. ¿Ya? Inmigración es urgente, urgente. Porque en realidad están llegando aviones diarios trayendo familiares de la gente que vive acá.

Ximena: Y con malas costumbres más encima.

Ana: Y a mí me da un asco ir al aeropuerto.

Marisol: O sea, la política de Estado yo creo que va a empezar, va a empezar a ver cómo proteger también... con esta gran cantidad de gente que están llegando.

Ximena: Esto es como Haití. Esto es como Haití. Tiran toda la basura de Chile, el patio de atrás de Chile. Todo lo tiran p’acá. 
Marisol: Todos los instituciones fiscal. Aeronáutica, digamos, carabineros. Todo... Claro. Todo viene toda la semana con 15 a 20 personas que son familiares, que el cuñado, que el vecino y todo. Y todos los trae a la casa donde ellos están... Casa gratis, y indagan nuestra isla, ensucian, bota... Es terrible. Terrible.

Ana: Es urgente, una cuestión urgente. Control de inmigración.

19. Bueno, allí se producen un momento, se produjo un momento... cuando, yo creo que - cuando llega así, en cantidad, llega gente, llega otra idea, llegan otra forma de vivir (Ana).

20. The original quote was in English (Alejandra).

21. O sea, para mí, ellos están utilizando, están aprovechando de kaina nuestro para su beneficio, sacarlo... sacarlo de aquí hace al fuera. No están trabajando un nuestra territorio para que esta comunidad se desarrolle. ¿No, me entiendes? Ellos sacan todo beneficio y se los llevan. Entero, pero dejar la caca aquí, poh. Y, no, no pagan impuestos. Y por eso, creo que ellos han encontrado la mine de oro aquí - ¡no pagan impuestos! Entonces, son gente que tienen, que tienen poder económico, y, y se enriquecen y más... a costa nuestra. ¿Que nuestra rigueza es nuestra kaina, Ya? Y esto lo que molesta... (Ana).

22. Entonces, vemos, como de alguna manera nos amenaza la llegada de mucha gente a Rapa Nui. Y cada vez, este territorio esta kaina es, va en disminución. Va en disminución. Y, emm, eso implica emmm, de como nosotros a reducir nuestra kaina. Entonces en esta momento, el grupo de la mujeres está enfocado a ver a... bueno, a protestar de controle la cantidad de inmigrantes que llega acá, a Rapa Nui y quedarse. Tenemos cada vez menos para poder 'ser'. Hoy en día toda vía, de plantar, y cosechar para compartir. Compartir con nuestra familia, con la gente que nos proteja. Ya, por un situación que yo creo es casi lógica o si, mientras, si tú tienes en útero varios bebe, lo bebes competen por el alimentación que les llega de su madre. Y yo comparo eso con este hogar de que existe determinado recurso para alimentarnos - biológicamente y espiritualmente. Entonces, si sigue 
alimentando como se ha venido produciendo ya casi una década de gente es que nosotros vamos a colapsar en un momento dado (Ana).

23. Es porque nosotros... para nosotros... Cuando paramos el avión, era inmigración. ¿Por qué inmigración? Porque la tierra no necesita de tanto eso. La tierra es la básica. Sabemos. Es la lucha - la tierra (Alicia).

24. Creo que desarrollo, destruir algo... es destruir, lo propio para optar por algo que tiene, que tiene un estatus... económico - peligroso, poh (Ana).

25. Lo que hubiera decirse desde punta de vista de esta generación de mis hijas que si eso es desarrollo que si eso es calidad de vida, o sea hay consumismo si eso es desarrollo que si eso es calidad de vida, o sea hay consumismo está incorporado el tema de calidad de vida, están pensando en el consumo. Están pensando en chucha, no se poh, un scooter nuevo, un forma de salir de aquí. De otra cosas allá y en un trabajo que les rápido... rápidamente un estatus económico mejor que la de uno y... y nosotros una generación mas, mas, más apegado a kaina. Más apegado a compartir, que yo comparto me, me, me me quedo contenta... yo me, me, satisfago en el compartir, en el compartir con el otro. Y no, en acumular para mí (Ana).

26. 0 sea, esos son dinero que, que nosotros no se queda acá, no, que sale de aquí a, a sea, Chile. Y tal vez, y yo creo, que si la plata de CONAF no mas, del turismo, quedar acá. La isla pudiera desarrollarse en caminos, en obras, mucho más que, lo que hoy en día su sede. Mira - los recursos de nuestra escuela - Tu has visto nuestra escuela. No tenemos suficiente mobiliario, y, en la municipalidad que tiene que ver con la escuela. $Y$, y la municipalidad dice que tiene un presupuesto bajo, como para tratar a resolver todos los problemas en educación, en salud, en caminos, en obras sociales. Dice que si no hay impuestos tampoco podemos... ellos pueden tener plata para arreglar el camino, o para reglar nuestra escuela, en fin. 0 sea, es un círculo vicioso (Ana). 
27. No tiene consciencia suficiente de que la tierra no es para venderla poh. No puede vender la tierra. Y con gente joven... ¡Bastante! Muchas gentes jóvenes venden su tierra. Y lo empresario compran, compran, compran. Compran terreno. Y obviamente que en un momento dado, acá, va a ver gente que va a tener mucho terreno - y otros que no, poh... Y un problema también (Ana).

28. Porque, es casi absurdo, es casi ridículo que gente, jóvenes de la isla, tiene que pagar arriendo. 0 sea, el arriendo, no es un concepto nuestro, para vivir. Porque se supone que había suficiente para todos (Alicia).

29. Si sigue... como se ha venido, produciendo ya casi una década de gente es que nosotros vamos a colapsar en un momento dado (Ana).

30. The original quote was in English (Alejandra).

31. Yo no niego que la isla tiene que tener un desarrollo. Me, ojo. Un desarrollo tiene que haber estudios del agua, estudios del impacto ambiental, estudios de las tierras... dedicar a informar a la gente. Tú no puedes llegar y hacer un desarrollo según tú pinta - no, poh! ...Entonces estoy totalmente de acuerdo que el desarrollo... que progreso. ¡Ta bien! Tiene que ten... tomar en cuenta de estos estudios y tiene que ser equitativo (Alicia).

32. Mira, si empezamos a que el mar, que la selva, o sea, nosotros no somos muchos. Nos estamos desgastando (Ana).

33. Karly: ¿Entonces, ellos no están em, ensenando los niños en la lengua Rapanui?: Ensenan en, hacen, en folclor. Creo que es básica, en la básica lo da pero, son como horas de, son como la hora de ingles, de idioma extranjero. ¿Ya? No es que trabajen todo la aprendizaje, de los subsectores, de las áreas de enseñanza en Rapanui. Y, em, y es importante, ahh, de de validar nuestra lengua también en educación. Para poder mantenerlo, po. Si se valida en el sentido de que ellos se sienten, con propiedad, de uno, de uno forma de comunicarse, de una lengua propia, y que tiene raíces propias (Ana). 
34. A nosotros a las mujeres nos afecta, es a gran influencia de gente de afuera de nuestro territorio, que lleguen de una otra forma a Rapa Nui, ayy, y nos vemos... amenazada (Ana). 


\section{Appendix Two: Participant information sheet (Spanish)}

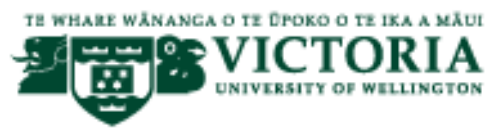

\section{Maihe Koe? Kihe Koe? Las mujeres de Rapanui, la tenencia de la tierra y la lucha para la soberanía}

Investigadora: Karly Christ: Escuela de Geografía, Medio Ambiente y Geología, Universidad de Victoria, Wellington, Nueva Zelanda

Soy candidata del Magisterio de Estudios del Desarrollo Comunitario de la Universidad Victoria en Wellington. Como una parte de la carrera, estoy haciendo un proyecto de investigación que culminará en una tesis. Estoy explorando el papel de las mujeres en el movimiento social sobre la tenencia de la tierra en Rapanui. La universidad Victoria me ha dado aprobación ética para este proyecto.

Este proyecto alcanza a explorar el papel de cómo es la participación de las mujeres en la lucha por la tenencia de la tierra en Rapanui, y cuáles son sus aspiraciones en este movimiento.

Esta investigación incluya las mujeres quien son participantes en el movimiento. A usted le han preguntado a participar por esta razón. También, entrevistaré a intelectuales especializados, miembros de grupos ONG, y miembros del gobierno, en relación al movimiento en Rapanui, con el fin de ayudarme a contextualizar este proyecto. Me gustaría tener la oportunidad de reunirnos pocas veces (con un mínimo de 2 veces), para hablar sobre la tierra y el movimiento en Rapanui y su papel correspondiente a este tema. Las entrevistas serán grabadas. Cada entrevista demorará una hora más o menos. Es mi intención que usted tendrá una oportunidad de examinar los transcritos después de cada entrevista para asegurarse que su voz está representada apropiadamente lo que usted quiere decir. Espero también poder consultar con usted, especialmente acerca de los asuntos de representación, durante el periodo de análisis y escritura, si es que quisiera ser involucrada en esto. Sin embargo, si siente que no quiere participar toda vía en 
cualquier forma en este proyecto, puede retirarse sin explicación hasta dos semanas después de la entrevista.

A no ser que quiera que su identidad sea revelada en este proyecto, detalles personales e identificaciones estará conocimiento solamente por mí y mis supervisores - Dr. Teresia Teaiwa y Profesor Warwick Murray. Las transcripciones y grabaciones estarán guardaras en una carpeta con contraseña, y devueltas a usted cuando termine el proyecto, o destruidos si no las quieras guardar. Adicionalmente, tendrá la opción de recibir un resumen ejecutivo de la tesis cuando esté terminada.

La tesis será sometida a la Escuela of Geografía, Medio Ambiente y Geología y estará depositada en la biblioteca de la universidad. Mis supervisores y yo esperamos escribir uno o dos artículos para publicación con referencia a este proyecto.

Si tiene preguntas o quiere más información sobre este proyecto, por favor no dude en contactarme a mi o mis supervisores.

Muchas gracias

Karly Christ

Firma:

karly.christ@gmail.com

+6421 1130260 (mobile)

+6449711522 (home)

Teresia Teaiwa - teresia.teaiwa@vuw.ac.nz - +64 44635110

Warwick Murray - warwick.murray@vuw.ac.nz - +64 44635029 


\title{
Appendix Three: Participant information sheet (English)
}

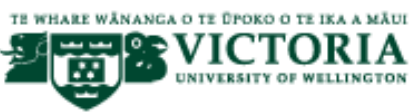

\author{
Maihe Koe? Kihe Koe? Rapa Nui women, land and the struggle for sovereignty \\ Researcher: Karly Christ: School of Geography, Environment and Earth Sciences, \\ University of Victoria, Wellington, NZ
}

I am a Masters student in Development Studies at Victoria University of Wellington. As part of this degree I am undertaking a research project that will lead to a thesis. I am exploring the role of women in the land movement in Rapa Nui. The University of Victoria Ethics Committee has granted ethical approval for this project.

This study aims to explore what role women are playing in the land sovereignty movement, how they are involved in the current land struggles on Rapa Nui and what their aspirations are.

This research includes women who are participants in the movement. You have been asked to participate for this reason. Also, I will interview academics, members of NGOs and members of the governments, about the movement on Rapa Nui to help me contextualise this work. I would like to have the opportunity to meet with you on a number of occasions (with a minimum of 2 times), to talk about the land movement in Rapa Nui and your role within it. The interviews will be audio-recorded but you can turn this off at any point without having to give any reasons. Each interview should take approximately an hour. It is also my intention that you will have the opportunity to review the transcripts after each interview to ensure that your voice is represented appropriately. I also hope to consult with you during the analysis period and write-up period of this research if you are happy to be involved. However, if you feel that you no longer can participate in any way in this project, you can withdraw yourself without any explanation up to two weeks after the interview. 
Unless you would like to have your identity revealed in this research, personal identifying details will be known only to me and my supervisor, Dr Teresia Teaiwa and Professor Warwick Murray. The transcripts and recordings will be kept in a password-protected file and returned to you when the research is complete, or destroyed if you do not wish to keep them. Additionally, you will have the option to receive an executive summary of the thesis when the project is complete.

The thesis will be submitted for marking to the School of Geography, Environment and Earth Science and deposited in the University Library. With my supervisors, we aim to write one or two articles for publication based on this work.

We will seek to present and publish findings from the research at conferences and in other academic arenas, including journals. We will supply copies of any such publications on request to any participants in the study. Additionally, if desired, a summary of the research will also be sent to participants.

If you have any more questions, or would like additional information about this project please don't hesitate to contact me or my supervisors.

Thank you for taking the time to read this information sheet.

Karly Christ Signed:

karly.christ@gmail.com

+6421 1130260 (mobile)

+6449711522 (home)

Teresia Teaiwa - teresia.teaiwa@vuw.ac.nz - +64 44635110

Warwick Murray - warwick.murray@vuw.ac.nz - +64 44635029 


\title{
Appendix Four: Agreement of confidentiality
}

\author{
TE WHARE WANANGA O TZ LPOKO O TE TKA A MAUU \\ H: \\ UNIVERSITY OF WELLINGTON \\ VICTORIA UNIVERSITY OF WELLINGTON - \\ AGREEMENT OF CONFIDENTIALITY \\ Researcher: Karly Christ
}

Title of project: Maihe koe? Kihe koe? Rapa Nui women, land and the struggle for autonomy

I have been asked by the researcher to transcribe interviews for the purposes of the above stated research project and I have agreed to participate.

As part of the understanding between the researcher and myself I:

$\square$ Recognise that the information on these recordings is sensitive and personal and I will not share this information with anyone other than the researcher

Agree to transcribe and document the information as accurately as I can

Agree to not share names of the interviewees whose interviews I am transcribing with anyone

Signed:

Name of participant

(please print clearly)

Date: 


\title{
Appendix Five: Makenu's Migration Law Proposal
}

\author{
ORGANIZACIÓN AUTÓNOMA RAPA NUI MAKENU RE'O RAPA NUI117
}

\section{Propuestas para Ley Orgánica Constitucional de Migración al Territorio Especial Rapa Nui}

1. Deben limitarse y regularse los derechos de ingreso y permanencia de las personas en el Territorio Especial Rapa Nui.

2. Toda persona perteneciente al pueblo Rapa Nui deberá tener la calidad de "residente permanente Rapa Nui" del Territorio Especial Rapa Nui. La calidad de residente permanente Rapa Nui no se perderá por causa alguna.

3. Podrá adquirir la calidad de "residente permanente no Rapa Nui" la persona chilena no perteneciente al Pueblo Rapa Nui o extranjera que cumpla con las normas generales de extranjería y que:

a) Haya contraído matrimonio con un miembro del Pueblo Rapa Nui y cuyo domicilio sea el Territorio Especial Rapa Nui y mientras esté vigente el matrimonio.

b) Tenga la posesión notoria del estado civil de cónyuge de una persona perteneciente al Pueblo Rapa Nui, siempre que hayan fijado domicilio común por más de 6 años continuos con inmediata anterioridad a la entrada en vigencia de la ley en el Territorio Especial Rapa Nui, y mientras exista tal posesión notoria.

c) Teniendo la posesión notoria del estado civil de cónyuge de una persona perteneciente al Pueblo Rapa Nui, siempre que hayan fijado domicilio común por más de 6 años continuos en el Territorio Especial Rapa Nui, y mientras exista tal posesión notoria, y que a la fecha de la solicitud tenga la calidad de residente temporal.

d) Tenga domicilio comprobable en el Territorio Especial Rapa Nui por más de 50 años continuos con anterioridad inmediata a la dictación de la ley.

\footnotetext{
${ }^{117}$ This was included in this thesis with permission from Makenu.
} 
4. Una persona residente permanente no Rapa Nui perderá tal calidad si incurre en alguna de las siguientes causales:

a) Ha fijado domicilio fuera del Territorio Especial Rapa Nui por un período continuo superior a 2,5 años;

b) Ha violado las medidas de control de circulación y residencia establecidas en la ley;

c) Ha violado las disposiciones sobre conservación de recursos naturales, ambientales y patrimoniales del Territorio Especial Rapa Nui.

d) Ha violado las normas de extranjería.

e) Ha perdido la posesión notoria del estado civil de cónyuge de una persona perteneciente al Pueblo Rapa Nui.

f) Ha dejado de ser cónyuge de una persona perteneciente al Pueblo Rapa Nui, excepto en el caso de viudez, en que será opcional conservar la calidad de residente permanente.

5. Podrá adquirir la calidad de "residente temporal" en el Territorio Especial Rapa Nui la persona chilena o extranjera que cumpla con las normas generales de extranjería y que:

a) Deba realizar actividades académicas, religiosas, deportivas, científicas, profesionales, culturales o similares por un tiempo determinado;

b) Deba realizar actividades laborales por un tiempo determinado que consten de un contrato de trabajo;

c) Deba realizar una función pública que conste de una resolución administrativa o lo que corresponda; o

d) Tenga la posesión notoria del estado civil de cónyuge de una persona perteneciente al Pueblo Rapa Nui, siempre que hayan fijado domicilio común en el Territorio Especial Rapa Nui, y mientras exista tal posesión notoria, y que a la fecha de la solicitud tenga la calidad de "turista".

6. La calidad de residente permanente no Rapa Nui y de residente temporal la otorgará la Oficina de Control de Ingreso y Permanencia en el Territorio Rapa Nui, OCIP.

El interesado en obtener la residencia temporal deberá:

a) Demostrar que tiene capacidad económica suficiente para su sostenimiento en el Territorio Especial Rapa Nui por el tiempo solicitado: para letras a, b y d del número 5 anterior;

b) Disponer de un contrato de trabajo otorgado ante notario público y visado por la Dirección del Trabajo o la Inspección del Trabajo: para letra b del número 5 anterior; 
c) Disponer de un proyecto o similar debidamente autorizado, dependiendo del tema se deberá contar con la visación de la OCIP: para letra a del número 5 anterior;

d) Disponer de la resolución, decreto o similar correspondiente a la entidad administradora o ejecutora y autorizada por la OCIP: para letra c del número 5 anterior;

e) Disponer de un tutor durante su permanencia temporal y que deberá tener la calidad de residente permanente Rapa Nui y mayor de edad: para letras a, b y d del número 5 anterior.

7. Para el otorgamiento de la calidad de residente temporal se tendrá en cuenta el cumplimiento de los requisitos de la ley, la densidad poblacional en el Territorio Especial Rapa Nui, la suficiencia de sus servicios públicos y las condiciones personales del solicitante.

8. Se podrá extender la calidad de residente temporal, si así se solicita, en las mismas circunstancias y por el mismo lapso, al cónyuge o pareja, y a sus hijos.

Los hijos de quien ha obtenido la calidad de residente temporal podrán continuar sus estudios en los establecimientos educativos en el Territorio Especial Rapa Nui, durante el tiempo que les sea permitido permanecer allí.

9. El residente temporal sólo podrá realizar la actividad y permanecer el tiempo en el Territorio Especial Rapa Nui que se le ha autorizado.

10. La calidad de residente temporal se pierde por:

a) Haber fijado domicilio fuera del Territorio Especial Rapa Nui por un período continuo de 1 año durante su residencia temporal.

b) Realizar dentro del Territorio Especial Rapa Nui una actividad económica no autorizada;

c) Haber violado las medidas de control de ingreso y permanencia contemplados en la ley.

d) Haber violado las disposiciones sobre la conservación de los recursos naturales, ambientales y patrimoniales del Territorio Especial Rapa Nui.

e) Haber perdido la posesión notoria del estado civil de cónyuge de una persona perteneciente al Pueblo Rapa Nui. 
11. La calidad de residente temporal expira por cumplimiento del plazo por la que se otorgó.

12. Para la contratación de trabajadores no residentes en el Territorio Especial Rapa Nui, deberá el empleador residente, permanente o temporal, cumplir con los siguientes requisitos:

a) Demostrar la idoneidad laboral de quien pretende contratar;

b) Pagar una suma de dinero, por una sóla vez, de diez UTM, por cada persona no residente que emplee, suma que será destinada a la creación de un Fondo Especial que será administrado por la OCIP para el desarrollo del Territorio Especial Rapa Nui.

c) Gestionar la obtención de la residencia temporal del trabajador, y su familia, si corresponde, por el tiempo de duración del contrato y de conformidad con lo señalado en la ley.

13. Los empleadores que dieren empleo a personas no residentes sin el cumplimiento de los requisitos aquí señalados serán sancionados con multas sucesivas de 10 a 100 UTM. Será obligación de las policías y de todo funcionario público denunciar estos hechos a los organismos competentes cuando tomen conocimiento de ellos.

14. Los que deseen visitar el Territorio Especial Rapa Nui en calidad de turistas, deberán:

a) Obtener la autorización de "turista", mediante procedimientos expeditos, a través de las oficinas de turismo, agencias de viajes, despachos de las líneas aéreas u oficinas de transporte marítimo de pasajeros;

b) Presentar a los funcionarios competentes, al momento del ingreso al Territorio Especial Rapa Nui, la autorización respectiva.

15. Las oficinas de turismo, agencias de viajes, líneas aéreas o empresas de transporte marítimo, expedirán la autorización de turista a quien cumpla con los requisitos siguientes:

a) Adquiera el tíquet de viaje, personal e intransferible, de ida y regreso a su lugar de origen.

b) No se encuentre dentro de la relación de las personas que no pueden ingresar al Territorio Especial Rapa Nui, de acuerdo con la información suministrada por la OCIP. 
16. Las personas que se desplacen al Territorio Especial Rapa Nui utilizando un medio de transporte privado, deberán acreditar tal situación mediante certificación de la autoridad aeronáutica o portuaria correspondiente. De esta manera suplirán el cumplimiento del requisito contemplado en la letra a) del número anterior, para la obtención de su respectiva autorización de turista.

17. Las personas que viajen en calidad de turistas al Territorio Especial Rapa Nui sólo podrán permanecer por un lapso no mayor de 30 días continuos o discontinuos al año. Excepcionalmente la OCIP podrá autorizar la permanencia por más de 30 días y hasta por 60 días, a aquel turista que justifique la necesidad de prolongar su permanencia y demuestre capacidad económica suficiente para tal prolongación y la factibilidad de obtener el tíquet de viaje de regreso a su lugar de origen en la nueva fecha.

18. Se encuentran en situación irregular las personas que:

a) Ingresen al Territorio Especial Rapa Nui sin la respectiva autorización;

b) Permanezcan dentro del Territorio Especial Rapa Nui por fuera del término que les ha sido autorizado;

c) Violen las disposiciones sobre conservación de los recursos ambientales, naturales y patrimoniales del Territorio Especial Rapa Nui.

d) Realicen actividades laborales o comerciales dentro del Territorio Especial Rapa Nui sin estar autorizados para ello.

19. Las personas que se encuentren en situación irregular serán devueltas a Chile continental y deberán pagar una multa de hasta 100 UTM, la que será destinada a la creación del Fondo Especial estipulado en la letra b) del número 12.

20. La OCIP abrirá un registro alfabético y cronológico de turistas y residentes temporales en el que indicará su nombre, su cédula de identidad o pasaporte, la fecha de llegada y de partida y el total de tiempo que ha permanecido durante ese año dentro del Territorio Especial Rapa Nui.

El registro deberá ser publicado y distribuido entre los organismos encargados de fiscalizar el sistema. Un boletín que contendrá la información detallada de las personas que no pueden ingresar al Territorio Especial Rapa Nui también será publicado, distribuido y mensualmente actualizado, incluyendo las entidades del numeral 15.

Asímismo, trimestralmente se emitirá un informe, en las mismas condiciones, de aquellas personas que no pueden permanecer en el Territorio Especial Rapa Nui por los próximos tres meses por expirar el término de permanencia que les es permitido. Las policías serán las encargadas de notificar a los turistas y residentes 
temporales la fecha de expiración de su autorización con una antelación de a lo menos 2 días.

21. Créase la Oficina de Control de Ingreso y Permanencia, OCIP, del Territorio Especial Rapa Nui, servicio público autónomo, para la realización y cumplimiento de las disposiciones de la ley.

La OCIP estará integrada por un Director, una Junta Directiva y el personal técnico y administrativo.

El Director y la Junta Directiva de la OCIP serán elegidos en votación popular por los miembros del Pueblo Rapa Nui por un período de 3 años y podrán ser reelegidos por igual período y por una única vez.

22. El Director de OCIP cumplirá las siguientes funciones:

a) Expedir las autorizaciones de residente permanente no Rapa Nui y residente temporal, con la aprobación mayoritaria de la Junta Directiva, conforme lo dispone la ley;

b) Proponer a la Junta Directiva el diseño de planes y programas de control de ingreso y permanencia;

c) Coordinar técnica y administrativamente, de manera permanente, la OCIP;

d) Convocar a reuniones extraordinarias a los miembros de la Junta Directiva de la OCIP, cuando a su juicio, sea necesario para el desarrollo de las disposiciones de la ley y la gestión de OCIP;

e) Adoptar y poner en marcha medidas de emergencia, tendientes a la solución de eventualidades que pongan en peligro el control de la densidad demográfica en el Territorio Especial Rapa Nui;

f) Denunciar ante los tribunales competentes todas las infracciones a la ley de las que tome conocimiento.

g) Contratar y administrar el personal técnico y administrativo.

23. La Junta Directiva estará integrada por cinco representantes del pueblo Rapa Nui elegidos mediante votación popular, de conformidad con los registros de CONADI o el que le reemplace.

24. La Junta Directiva sesionará ordinariamente una vez cada mes, y extraordinariamente cuando así lo considere la mayoría de sus miembros. 
Serán sus funciones:

a) Colaborar, de conformidad con las normas constitucionales y legales vigentes, en la formulación de la política de control de la densidad poblacional del Territorio Especial Rapa Nui.

b) Aprobar o rechazar los planes y programas de control de ingreso y permanencia, sometidos a su consideración por el Director de la OCIP, e implementarlos, cuando proceda.

c) Gestionar con las autoridades competentes el desarrollo de planes y programas para la preservación, defensa y rescate de los recursos naturales y patrimoniales del Territorio Especial Rapa Nui;

d) Fijar los procedimientos para la expedición de las autorizaciones de que trata la ley;

e) Declarar la pérdida o caducidad de la autorización de residencia temporal o residencia permanente no Rapa Nui en el Territorio Especial Rapa Nui, cuando se cumplan los presupuestos contemplados en la ley;

f) Participar en la coordinación de censos poblacionales que deberán realizarse cada 2 años en el Territorio Especial Rapa Nui;

g) Proponer y colaborar en la coordinación de la implementación de mecanismos y programas para lograr la salida definitiva de personas del Territorio Especial Rapa Nui, con el fin de reducir la densidad poblacional;

h) Elaborar los reglamentos que la ley requiere, en consulta con el Pueblo Rapa Nui, según señala el Convenio 169 de la OIT.

25. El incumplimiento de las disposiciones respectivas por algún miembro de la Junta Directiva o del Director de la OCIP será causal de destitución inmediata, sin perjuicio de las acciones disciplinarias y legales a que hubiere lugar.

26. Las agencias de viajes o de turismo que incumplan las disposiciones de la ley deberán pagar multas sucesivas hasta el valor de 550 UTM.

27. Las compañías transportadoras nacionales o extranjeras que incumplan las disposiciones de la ley serán obligadas a transportar de regreso al turista al lugar de origen, y deberán pagar multas sucesivas de hasta el valor de 550 UTM. 
28. Los hoteles o establecimientos de alojamiento del Territorio Especial Rapa Nui deberán exigir a las personas, antes de su registro como huéspedes, la correspondiente autorización.

El incumplimiento de esta disposición acarreará la imposición de multas sucesivas de hasta por el valor de 150 UTM.

29. Todas las infracciones a la ley deberán ser denunciadas al Tribunal competente, el que conocerá a través de un procedimiento breve y sumario que se establecerá mediante un auto acordado que dictará la Corte de Apelaciones competente. En contra de la sentencia que dicte el Juzgado señalado no procederá recurso alguno.

Todas las multas a que se refiere la ley irán en beneficio de la OCIP, y serán destinadas al Fondo Especial estipulado en la letra b) del número 12.

30. La Junta Directiva determinará el costo de la expedición de cada una de las autorizaciones a que se refiere la ley, y cuyos montos serán destinados al Fondo Especial estipulado en la letra b) del número 12.

31. Las medidas tendientes a lograr el control demográfico y la protección del medio ambiente serán difundidas ampliamente dentro del Territorio Especial Rapa Nui y en general en todo el país, de tal manera que se logre la concientización de todos, sobre la necesaria intervención de todos, en la protección de la identidad cultural del Pueblo Rapa Nui y la preservación del medioambiente y los recursos naturales y patrimoniales del Territorio Especial Rapa Nui.

32. A partir de la vigencia de la ley, el Gobernador Insular del Territorio Especial Rapa Nui, o quien lo reemplace, tendrá un plazo de tres meses para poner en funcionamiento la Oficina de Control de Ingreso y Permanencia del Territorio Especial Rapa Nui, OCIP.

33. Una vez electo y en funciones el Gobernador Insular del Territorio Especial Rapa Nui deberá incluir la OCIP dentro de la nueva institucionalidad que se genere para el Territorio Especial Rapa Nui.

34. Al momento de entrada en vigencia de la ley se deberá realizar un censo de población en el Territorio Especial Rapa Nui que permita identificar la población de personas residentes permanentes Rapa Nui y la potencial población de personas residentes permanentes no Rapa Nui y residentes temporales. 


\section{Appendix Six: Women in the public sphere}

With the integration of Rapanui into the Chilean nation-state in 1966, approximately 25 Chilean institution and organisations were on Rapanui (Delsing, 2010). Below is a table highlighting the current heads of the public institutions on the island.

\begin{tabular}{|c|c|c|c|}
\hline Position & Name & $\begin{array}{l}\text { RapaNui/ } \\
\text { Chilean }\end{array}$ & $M / F$ \\
\hline Head of the Mataveri Airport & Miguel Morales Novillo & Chilean & Male \\
\hline $\begin{array}{l}\text { Director of the Hanga Roa } \\
\text { Hospital }\end{array}$ & Ivan Sepulveda Cid & Chilean & Male \\
\hline $\begin{array}{l}\text { Head of the Provincial } \\
\text { Agriculture and Livestock } \\
\text { Service (S.A.G). }\end{array}$ & Eric Guital Alarcón & Chilean & Male \\
\hline $\begin{array}{l}\text { Head of the Provincial } \\
\text { National Forest Corporation } \\
\text { (CONAF) }\end{array}$ & Ninoska Cuadros Hucke & Rapanui & Female \\
\hline $\begin{array}{l}\text { Director of the Regional } \\
\text { Public Works Ministry }\end{array}$ & Patricio Silva Galvez & Chilean & Male \\
\hline $\begin{array}{l}\text { Head of the Provincial } \\
\text { National Assets Ministry }\end{array}$ & Luis G. Alvarez Guzman & Chilean & Male \\
\hline $\begin{array}{l}\text { Head of the regional Chilean } \\
\text { Indigenous Development } \\
\text { Corporation (CONADI) }\end{array}$ & Elizabeth Velasquez Hotus & Rapanui & Female \\
\hline $\begin{array}{l}\text { Director of the Sebastian } \\
\text { Englert Museum }\end{array}$ & Francisco Torres Hochstetter & Chilean & Male \\
\hline $\begin{array}{l}\text { Head of the Provincial level } \\
\text { National Oil Company } \\
\text { (ENAP) Refinery S.A. }\end{array}$ & Alejandro Maure Tuki & Rapanui & Male \\
\hline $\begin{array}{l}\text { Director of the } \\
\text { Education Village } \\
\text { (Liceo Aldea Educativa) }\end{array}$ & Lorena Zúñiga Leon & Chilean & Female \\
\hline $\begin{array}{l}\text { Director of the Lorenzo } \\
\text { Baeza Vega School }\end{array}$ & Jacqueline Rapu Tuki & Rapanui & Female \\
\hline $\begin{array}{l}\text { General Manager of } \\
\text { Agriculture and Services } \\
\text { on Easter Island (SASIPA) } \\
\text { (subsidiary of CORFO) }\end{array}$ & Pedro Hey Icka & Rapanui & Male \\
\hline
\end{tabular}




\begin{tabular}{|c|c|c|c|}
\hline Position & Name & $\begin{array}{l}\text { RapaNui/ } \\
\text { Chilean }\end{array}$ & $M / F$ \\
\hline $\begin{array}{l}\text { State Bank Officer } \\
\text { (Bancoestado) }\end{array}$ & Rodrigo Herrera & Chilean & Female \\
\hline $\begin{array}{l}\text { Zonal Director of the Supply } \\
\text { Company for Isolated Areas } \\
\text { (EMAZA) }\end{array}$ & Paola Gonzalez Reyes & Chilean & Female \\
\hline Head of Postal Services & Carolina Tepano Hotu & Rapanui & Female \\
\hline $\begin{array}{l}\text { Technical Authority of } \\
\text { National Fishing Service } \\
\text { (SERNAPESCA) }\end{array}$ & Marcela Hey Aravena & Rapanui & Female \\
\hline In charge of the I.P.S. Office & Gloria Contreras Passeron & Chilean & Female \\
\hline $\begin{array}{l}\text { Official assistant of the } \\
\text { regional civil and } \\
\text { identification office }\end{array}$ & Mahina Pakomio Riquelme & Rapanui & Female \\
\hline $\begin{array}{l}\text { Director of the Kindergarten } \\
\text { Hare Nga Poki }\end{array}$ & Blanca Tuki Tepano & Rapanui & Female \\
\hline $\begin{array}{l}\text { Person in charge of technical } \\
\text { matters SERNATUR }\end{array}$ & Angie Pont Chamorro & Rapanui & Female \\
\hline $\begin{array}{l}\text { Legal Office head of Easter } \\
\text { Island }\end{array}$ & Paul Diaz Jara & Chilean & Male \\
\hline $\begin{array}{l}\text { Head of the Public Library } \\
N^{\circ} 5\end{array}$ & Fatima Hotus Hey & Rapanui & Female \\
\hline Chief Health Authority & Dr. Ximena Goya Aldana & Chilean & Female \\
\hline $\begin{array}{l}\text { Office of the Coordinator } \\
\text { of Liason C.N.C.A. }\end{array}$ & Macarena Oñate & Chilean & Female \\
\hline
\end{tabular}

(up-to-date as of April 2012) 
There are 24 departments listed here. Nine of these institutions have a Rapanui woman as its head; two have a Rapanui male; seven have Chilean males and six are Chilean females. This list does not include the Governor, Carmen Cardinali or the Mayor Luz Sasso, both of whom are Rapanui women. While this table does not show the full picture of Rapanui women's involvement within Chilean politics, it is interesting to note how women are predominately the leaders of these services and organisations.

The Rapanui women in the public sector, with whom I spoke, were part of a number of these institutions. These included: CONADI, (Corporación Nacional de Desarrollo Indígena), which is a part of the Ministry for Social Development and the only government agency in Chile that specifically focuses on addressing indigenous issues. SERNAM (Servicio Nacional de la Mujer) is the "National Women's Service" which is a government agency that promotes gender equality in Chile and seeks to make policies in Chile more gender sensitive (Dandavati, 2005). PRODEMU (Asociación Promoción y Desarrollo de la Mujer) is the "Promotion and Development of Women." This organisation assists women mainly by providing workshops that help them to develop practical and personal skills to help improve their lives (Dandavati, 2005). SERNAM works primarily at a national level, while PRODEMU functions more at the local level. 


\section{Appendix Seven: Informe Technico - Aplicacion instrumento de consulta al Pueblo Rapanui}

This two-part document can be found on the attached CD. ${ }^{118}$ If reading this electronically, please click here to view Part I and Part II.

${ }^{118}$ This was included in this thesis with permission from Makenu. 